\title{
MESTRADO ACADÊMICO EM BIOENGENHARIA EESC 1980 A 2012: AVALIAÇÃO DOS EGRESSOS
}

Tese de doutorado apresentada ao Programa de PósGraduação Interunidades Bioengenharia de São Carlos/ Faculdade de Medicina de Ribeirão Preto/Instituo de Química de São Carlos da Universidade de São Paulo como parte dos requisitos para a obtenção do título de doutor em Ciências.

Área de Concentração:

Bioengenharia

Orientador: Prof. Dr. João Manuel Domingos de Almeida Rollo

Co-orientadora: Profa.Dra. Dilma de Mello Silva

\section{VERSÃO CORRIGIDA}


AUTORIZO A REPRODUÇÃO TOTAL OU PARCIAL DESTE TRABALHO, POR QUALQUER MEIO CONVENCIONAL OU ELETRÔNICO, PARA FINS DE ESTUDO E PESQUISA, DESDE QUE CITADA A FONTE.

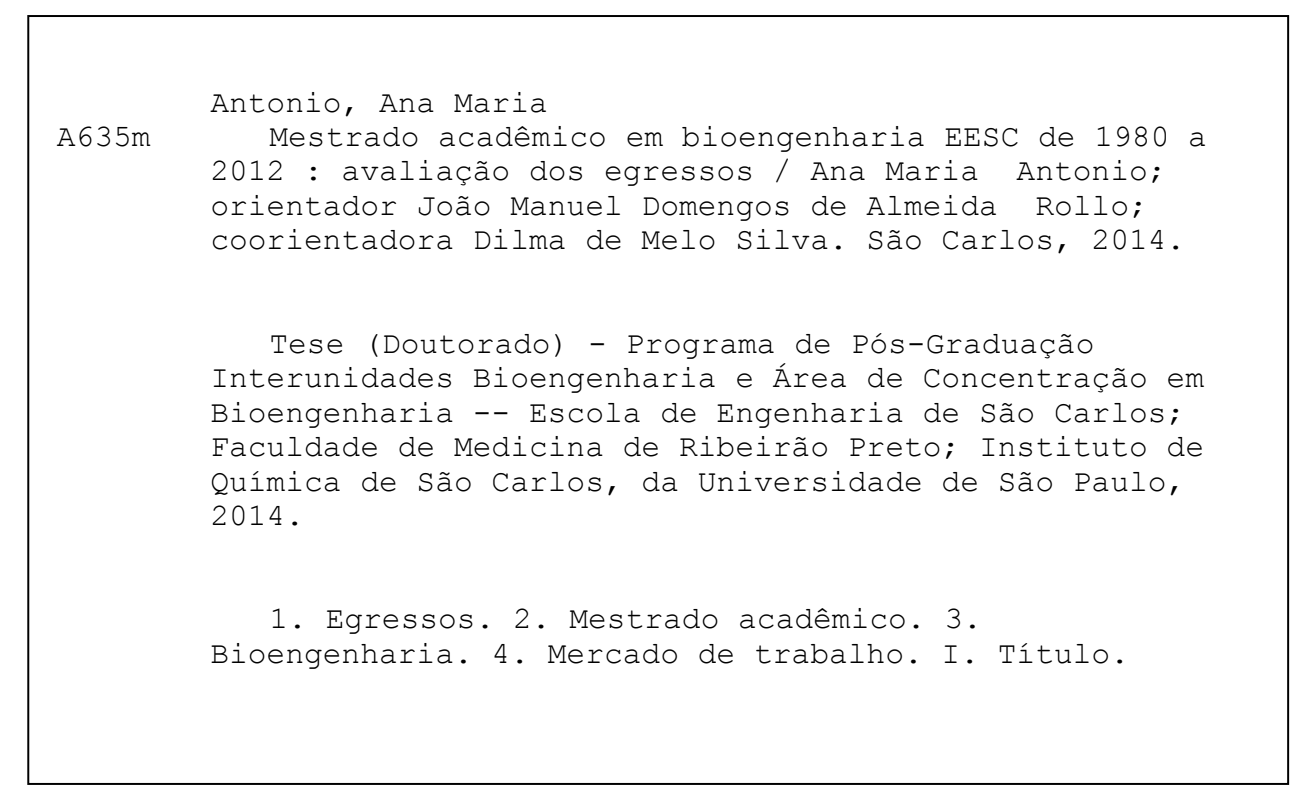


Programa de Pós-Graduação Interunidades em Bicengentaria EESC / FMFP/IQSC

Ana Maria Antorio

Thulo: "Avalaçăo da irserçào no mercado de trabalho dos egressos do mestrajo académico em Bibengenhaia".

TESE APFESENTAOS AO PROGRAMA DE POS-GRADUACEOO IVTERUNIDADES BOENBENHARIA - EESCIFNRPIOSC DA IVTERUNIDADES BOENSENHARIA
UNIVERSIDADE DE SHO PAULO PARA OETENÇAO DO TITULO DE DOUTORA IM CIENCAS NA AREA DE BIOENGENHAVIA.

Aprovado em $25,06,2014$

Prof. Dr. Joas Manjel Damingos de Almeda Rollo (Crientadar)

Resulade: APrS VA D H

Prafa. Dra. Elana Cristina da Silva Rigo

Resultado

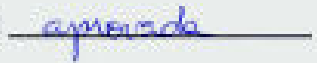

Profa. Dra. Luza Sgol Fernandes Costa

Fiesullatos.

Profa. Dra. Sofia Cistone lest Pavarni

Resultado: Iyoudada

Pnota. Dra. Ana Maria Mnarelli Gasjar

Resultado:

AProver 4
Unversidade de Sao Paito - USP

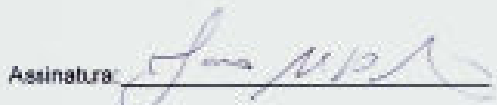

Unwersicada ce Sap Pauo - USP

Assinatura

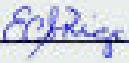

Unwersidade Foderal de Sá Carlas - UFSCar

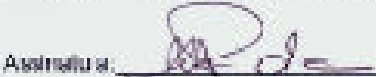

Unwersidade Federal de Sâ Carlos - UFSCar

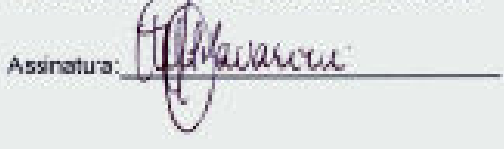

Unversidade Estadual Paulista "Jôtio de Mescult: Filhc' - UNESP

Assinatura:

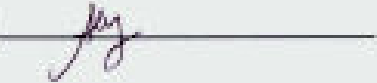

Honciogado en: 
Dedico este trabalho ao Professor Titular Luiz Romariz Duarte (in memoriam) pela criação do Programa Pós-Graduação Interunidades Bioengenharia Escola de Engenharia de São Carlos- Faculdade de Medicina de Ribeirão Preto-Instituto de Química de São Carlos da Universidade de São Paulo 


\section{AGRADECIMENTOS}

Primeiramente a Maria Santíssima, que sempre me mostra o melhor caminho a ser percorrido, além de me dar saúde e forças, para enfrentar todas as dificuldades.

À minha família, meu pai Waldomiro Antonio (in memoriam), minha mãe Maria Aparecida Bergamasco e meus irmãos Rita de Cássia, Waldomiro Antonio Filho, Angela Maria e Ana Paula Camargo que sempre me ensinaram a ser uma pessoa melhor, além de sempre me darem muita alegria e amor. Eu amo a cada um.

Para a minha amada filha Tatiana sempre ao meu lado demonstrando seu amor e carinho comigo.

Ao meu orientador Prof. Dr. João Manuel Domingos de Almeida Rollo e coorientadora Dra Dilma de Melo Silva, pela disponibilidade durante a realização desta pesquisa.

Aos queridos (in memoriam) Maria Carmem Bargas Bergamasco, Silvio Bergamasco e Mauro Jose Mattiazzi, por terem feito parte da caminhada comigo.

Aos meus sobrinhos, Wellington Fernando, Wallisson Luís, Emilly Maria, Raul Antonio, Raquel, Luiza e Murilo, pela alegria que vocês dão a minha vida.

Aos homens Rodrigo Luiz da Silva, Marcos Antonio dos Santos, Cícero da Silva e Adriano Cordeiro, pelo incentivo que vocês me transmitem.

Aos serviços de secretaria do Programa de Pós-Graduação Interunidades em Bioengenharia, na pessoa de Janete Ferreira Rodrigues dos Santos, pela disponibilidade sempre.

A todos os alunos egressos e profissionais que responderam a minha solicitação e contribuíram direta ou indiretamente com esta pesquisa. 
Sinceros agradecimentos a todos e aos outros não citados aqui, mas que contribuíram direta ou indiretamente para que este trabalho se concretizasse. 


\section{RESUMO}

ANTONIO, A. M. Mestrado Acadêmico em Bioengenharia EESC-IQSC-FMRP-USP 1980 a 2012: Avaliação dos egressos. 2014. 154f. tese (doutorado). Programa de Pós-Graduação Interunidades Bioengenharia - Escola de Engenharia de São Carlos, Faculdade de Medicina de Ribeirão Preto, Instituto de Química de São Carlos. Universidade de São Paulo, São Carlos, 2014

O objetivo desta pesquisa foi avaliar a inserção no mercado de trabalho dos egressos do mestrado acadêmico do curso de Pós-Graduação Interunidades Bioengenharia EESC-FMRP-IQSC-USP. Foi utilizado o sistema customizado em linguagem de programação especial "Hypertext Preprocessor" PHP com banco de dados MySQL para avaliar os dados. Foram avaliados 276 egressos do mestrado acadêmico em bioengenharia da USP formados no período de 1980 a 2012 . Para avaliar o perfil dos egressos foram identificadas: a formação acadêmica, atividades profissionais, produção cientifica, opinião dos egressos sobre o curso e mercado de trabalho. Os resultados das variáveis de desfecho: ensino médio, graduação, formação geral, avaliação do curso pelo egresso, formação acadêmica, adequação da pesquisa, adequação da orientação, contribuição para a formação profissional, avaliação pelo egresso, mercado de trabalho. Os resultados mostram que $46 \%$ dos egressos são do sexo masculino e $54 \%$ do sexo feminino; $44 \%$ cursaram o ensino médio em escola pública; $76 \%$ graduação em período integral; $35 \%$ desenvolveram atividades culturais no país; $54,3 \%$ participaram de projeto de iniciação cientifica durante a graduação; $80 \%$ consideram positivamente o PPGIB para sua formação profissional, $44 \%$ apresentaram artigos em eventos científicos; $59 \%$ publicaram durante a permanência no PPGIB; $86 \%$ utilizaram sistema informatizado de bibliotecas; 25\% consideram a pesquisa do PPGIB inovadora; $55 \%$ trabalham em IES na área do programa; $14 \%$ atuam em área diferente a do Programa; $12 \%$ exercem posições de liderança e estão trabalhando em IES; $14 \%$ estão insatisfeitos com salário oferecido. Conclui-se que o PPGIB oferece boas condições aos egressos para competirem profissionalmente.

Palavras-chave: Egressos, Mestrado Acadêmico, Bioengenharia, Mercado de Trabalho. 


\begin{abstract}
ANTONIO, A.M. Master Scholar in Bioengineering EESC-IQSC-FMRP-USP 19802012: Evaluation of graduates. 2014. 154f.thesis (doctoral). Programa de PósGraduação Interunidades Bioengenharia - Escola de Engenharia de São Carlos, Faculdade de Medicina de Ribeirão Preto, Instituto de Química de São Carlos. Universidade de São Paulo, São Carlos, 2014

The objective of this research was to evaluate the integration in the labor market for graduates of the academic Master Course Graduate Bioengineering Interunits EESCUSP-FMRP-IQSC. The custom system in special programming language "Hypertext Preprocessor" PHP with MySQL database was used to evaluate the data. 276 graduates of the academic master in bioengineering at USP graduated from 1980 to 2012 were analyzed. In order to evaluate the profile of the graduates education, professional activities, scientific production, opinion over the course of the graduates and the labor market were identified. The results of the outcome variables: high school, undergraduate, general education course evaluation by the enrolled student, academic training, adequacy of research, adequacy of guidance, contribution to training, evaluation by the enrolled student, the labor market. The results show that $46 \%$ of graduates are male and $54 \%$ female; $44 \%$ attended high school in a public school; $76 \%$ full-time undergraduate; $35 \%$ developed cultural activities in the country; $54.3 \%$ participated in undergraduate research project for graduation; $80 \%$ think positively PPGIB for their training, $44 \%$ had articles in scientific events; $59 \%$ published during the permanence in PPGIB; $86 \%$ used computerized library system; $25 \%$ consider the research of innovative PPGIB; $55 \%$ work in HEls in the program area; $14 \%$ work in a different area of the program; $12 \%$ are in leadership positions and are working in HEls; $14 \%$ are dissatisfied with the salary offered. We conclude that the PPGIB offers good conditions for graduates to compete professionally.
\end{abstract}

Keywords: Graduates, Academic Master, Bioengineering, Labor Market. 


\section{LISTA DE FIGURAS}

Figura 1- Localização de Sao Carlos no Estado de São Paulo 44 Fonte: http://www.wikipedia.org

Figura 2- Edifício construído no Bloco E-1 da EESC-USP 46 Fonte: http://www.eesc.usp.br/60anos

Figura 3- Professor Titular Luiz Romariz Duarte 50 Fonte: http://www.bioeng.eesc.usp.br/ 


\section{LISTA DE GRÁFICOS}

Gráfico 1- Total de dissertações ao longo do período pesquisado 52

Gráfico 2- Ano de nascimento dos egressos 66

Gráfico 3- $\quad$ Formação dos egressos na graduação 67

Gráfico 4- Porcentagem dos egressos segundo o tipo de escola que 68 cursou o ensino médio.

Gráfico 5- $\quad$ Porcentagem dos egressos segundo o tipo de ensino 69 médio que concluiu.

Gráfico 6- Porcentagem dos egressos segundo o período que 69 freqüentou o ensino médio.

Gráfico 7- Porcentagem dos egressos segundo o tipo de organização 72 acadêmica que freqüentou no curso de graduação.

Gráfico 8- Porcentagem dos egressos segundo o tipo de categoria 74 administrativa da instituição em que freqüentou o curso graduação.

Gráfico 9- Porcentagem dos egressos segundo o período de estudo do curso de graduação que freqüentou.

Gráfico 10- Porcentagem dos egressos segundo as atividades que 77 participou durante a graduação.

Gráfico 11- Porcentagem dos egressos segundo o conhecimento de 78 língua inglesa no inicio da pós-graduação.

Gráfico 12- Avaliação em porcentagem dos egressos oriundos do 80 curso de graduação quanto ao preparo para a realização da pós-graduação

Gráfico 13- Porcentagem dos egressos segundo tipo de organização acadêmica que freqüentou o curso de graduação. Fator que contribuiu positivamente para seu desempenho na pós-graduação.

Gráfico 14- Porcentagem dos egressos segundo categoria 82 administrativa que freqüentou a graduação. Fator que contribuiu positivamente para o desempenho na pós- 
graduação.

Gráfico 15- Porcentagem dos egressos segundo o período em que 83 freqüentou a graduação. Fator que contribuiu positivamente para o desempenho na pós-graduação.

Gráfico 16- Porcentagem dos egressos segundo o grau de satisfação 83 do seu desempenho na pós-graduação (nota de 01 a 10).

Gráfico 17- Porcentagem dos egressos segundo razões que 84 influenciaram na decisão ao ingressar no PPGIB.

Gráfico 18- Porcentagem dos egressos segundo o intervalo entre a 86 conclusão da graduação e inicio da pós-graduação.

Gráfico 19- Porcentagem dos egressos segundo sua participação em 86 projeto de iniciação cientifica antes da pós-graduação.

Gráfico 20- Porcentagem de egressos segundo característica que 88 melhor descreve o PPGIB.

Gráfico 21- Porcentagem dos egressos segundo os aspectos relativos 89 ao PPGIB que considera plenamente satisfatório.

Gráfico 22- Porcentagem dos egressos segundo considera ser a 91 principal contribuição do PPGIB.

Gráfico 23- Porcentagem dos egressos segundo o que define sua 93 orientação no PPGIB

Gráfico 24- Porcentagem dos egressos segundo a continuidade da 94 parceria com seu orientador em outros projetos após a conclusão do PPGIB

Gráfico 25- Porcentagem dos egressos segundo sua parceria com seu 95 orientador no PPGIB

Gráfico 26- Porcentagem dos egressos segundo seu relacionamento 96 com seu orientador no PPGIB considerado satisfatório

Gráfico 27- Porcentagem dos egressos segundo contribuições 97 positivas do PPGIB para sua formação profissional

Gráfico 28- Porcentagem dos egressos segundo a contribuição para 98 sua formação que considera ser atribuída ao PPGIB

Gráfico 29- Porcentagem dos egressos segundo os artigos 99 apresentados durante sua permanência no PPGIB 
Gráfico 30- Porcentagem dos egressos segundo o tipo de encontro e o 100 número de artigos apresentados

Gráfico 31- Porcentagem dos egressos segundo publicação incluindo 101 as já aceitas para serem publicadas

Gráfico 32- Porcentagem dos egressos segundo o número de :

Gráfico 33- Porcentagem dos egressos segundo suas publicações no 103 PPGIB incluindo também as serem publicadas

Gráfico 34- Porcentagem dos egressos segundo a decisão de 104 participar PPGIB ocorreu no momento apropriado

Gráfico 35- Porcentagem dos egressos segundo o PPGIB atender 105 totalmente as expectativas

Gráfico 36- Porcentagem dos egressos segundo as instalações físicas 106 do PPGIB serem perfeitamente adequadas às necessidades

Gráfico 37- Porcentagem dos egressos segundo a disposição do 107 sistema informatizado das bibliotecas disponíveis para o PPGIB serem compatíveis com as necessidades

Gráfico 38- Porcentagem dos egressos segundo o acervo de livros das 108 bibliotecas serem adequados em face das necessidades da pesquisa

Gráfico 39 Porcentagem dos egressos segundo a participação no 109 PPGIB ser decisiva na definição da vida profissional

Gráfico 40- Porcentagem dos egressos segundo a participação no 110 PPGIB ter contribuído para sua formação

Gráfico 41- Porcentagem dos egressos segundo os aspectos mais 111 positivos do PPGIB.

Gráfico 42- Porcentagem dos egressos sobre os aspectos mais 112 negativos do PPGIB

Gráfico 43- Porcentagem dos egressos segundo sua dissertação ter 113 sido publicada

Gráfico 44- Porcentagem dos egressos segundo nota atribuída de zero 114 a dez, referente ao grau de satisfação com o PPGIB

Gráfico 45- Porcentagem dos egressos segundo o objetivo imediato 116 
após o PPGIB

Gráfico 46- Porcentagem dos egressos segundo a atual ocupação no 117 mercado de trabalho

Gráfico 47- Porcentagem dos egressos segundo o ingresso em seu 118 emprego atual

Gráfico 48- Porcentagem dos egressos segundo após a conclusão do 119 mestrado ter mudado diversas vezes de emprego

Gráfico 49- Porcentagem dos egressos segundo salário 120

Gráfico 50- Porcentagem dos egressos segundo abono/incentivos- 121 outras vantagens

Gráfico 51- Porcentagem dos egressos segundo condições de 121 trabalho

Grafico52- Porcentagem dos egressos segundo prestígio onde 122 trabalha

Gráfico 53- Porcentagem dos egressos segundo a variedade de 123 atividade que desempenha

Gráfico 54- Porcentagem dos egressos segundo estabilidade no 124 emprego

Gráfico 55- Porcentagem dos egressos segundo após conclusão do 125 PPGIB estar aptos a concorrer com outros profissionais na área, formados por outras instituições, para ingresso em curso de PG nível doutorado ou mercado de trabalho 


\section{LISTA DE ABREVIATURAS}

$\begin{array}{ll}\text { BSCS } & \text { Biological Sciences Curriculum Study } \\ \text { CAPES } & \text { Coordenação de Aperfeiçoamento de Pessoal de Nível Superior } \\ \text { CACEX } & \text { Carteira do Comercio Exterior } \\ \text { CNES } & \text { Cadastro Nacional de Estabelecimentos de Saúde } \\ \text { CONEAU } & \text { Comission Nacional de Evaluación y Acreditación Universitária } \\ \text { CONFEA } & \text { Conselho Federal de Engenharia e Agronomia } \\ \text { COPPE } & \text { Instituto Alberto Luiz Coimbra de Pós-Graduação e Pesquisa em } \\ & \text { Engenharia } \\ \text { EACH } & \text { Escola de Artes, Ciências e Humanidades } \\ \text { EESC } & \text { Escola de Engenharia de São Carlos } \\ \text { ESCP } & \text { Escola Superior de Comércio (Ecole Supérieure de Commerce) } \\ \text { EUA } & \text { Estados Unidos da América } \\ \text { FAPESP } & \text { Fundação de Amparo à Pesquisa do Estado de São Paulo } \\ \text { FAMEB } & \text { Faculdade de Medicina da Bahia } \\ \text { FEI } & \text { Faculdade de Engenharia Industrial } \\ \text { FMRP } & \text { Faculdade de Medicina de Ribeirão Preto } \\ \text { IBECC } & \text { Instituto Brasileiro de Educação, Ciência e Cultura } \\ \text { ICMC } & \text { Instituto Ciências Matemáticas e de Computação } \\ \text { ICMSC } & \text { Instituto de Ciências Matemáticas São Carlos } \\ \text { IFSC } & \text { Instituto de Física São Carlos } \\ \text { IFQSC } & \text { Instituto de Física e Química de São Carlos } \\ \text { IQSC } & \text { Instituto de Química de São Carlos } \\ \text { IPS } & \text { Instituto Politécnico Superior } \\ \text { ITA } & \text { Instituto Tecnológico de Aeronáutica } \\ \text { LDB } & \text { Lei de Diretrizes e Bases } \\ \text { MEC } & \text { Ministério da Educação } \\ \text { PEB } & \text { Programa Engenharia Biomédica } \\ \text { PPGIB } & \text { Programa de Pós-Graduação Interunidades em Bioengenharia } \\ \text { PSSC } & \text { Physical Science Study Curriculum } \\ \text { PUC } & \text { Pontifícia Universidade Católica } \\ \text { RBEB } & \text { Revista Brasileira de Engenharia Biomédica } \\ \text { SBEB } & \text { Sociedade Brasileira de Engenharia Biomédica } \\ & \end{array}$




$\begin{array}{ll}\text { SEI } & \text { Serviço Exportação Internacional } \\ \text { SMSG } & \text { School Mathematics Study Group } \\ \text { UNESCO } & \begin{array}{l}\text { Organização das Nações Unidas para a Educação à Ciência e a } \\ \text { Cultura }\end{array} \\ \text { UNIVAP } & \text { Universidade do Vale do Paraíba } \\ \text { UFBA } & \text { Universidade Federal da Bahia } \\ \text { USP } & \text { Universidade de São Paulo } \\ \text { UFPE } & \text { Universidade Federal de Pernambuco } \\ \text { UFPB } & \text { Universidade Federal da Paraíba } \\ \text { UFRJ } & \text { Universidade Federal do Rio de Janeiro }\end{array}$




\section{SUMÁRIO}

1. INTRODUÇÃO

2. JUSTIFICATIVA 19

3. OBJETIVO 21

3.1. Objetivos específicos 21

4. REVISÃO BILIOGRÁFICA 22

4.1. SAÚDE NO BRASIL COLÔNIA 24

4.2. INÍCIO DA ENGENHARIA BIOMÉDICA NO BRASIL 26

4.3. ENGENHARIA DE REABILITAÇÃO 28

4.4. INFORMÁTICA MÉDICA 29

4.5. ENGENHARIA CLÍNICA OU HOSPITALAR 30

4.6. BIOENGENHARIA 31

5. INICÍO DA ENGENHARIA BIOMÉDICA E BIOENGENHARIA NO BRASIL 33

6. EDUCAÇÃO EM ENGENHARIA BIOMÉDICA 40

6.1.MERCADO DE TRABALHO DO PROFISSIONAL CURSO 42 BIOENGENHARIA

6.2. MERCADO DE TRABALHO DO BIOENGENHEIRO 42

7. CRIAÇÃO DA ESCOLA DE ENGENHARIA DE SÃO CARLOS 44

7.1. A HISTÓRIA DA BIOENGENHARIA NA ESCOLA DE 48 ENGENHERIA DE SÃO CARLOS

7.2. LINHA DE PESQUISA DO PPGIB: Período inicial 50

7.3. LINHA DE PESQUISA DO PPGIB: Período atual 51

7.4. DISSERTAÇÕES DO PPGIB 1980 A 2012

8. PÓS-GRADUAÇÃO NO BRASIL 52

9. PRODUÇÃO E APLICAÇÃO DA ENGENHARIA 53

BIOMÉDICA E BIOENGENHARIA NO BRASIL

9.1. MAPEAMENTO DA ENGENHARIA BIOMÉDICA E BIOENGENHARIA NO BRASIL

10. MÉTODO

10.1. Aspectos Éticos 62

10.2. Participantes 63

10.3. Procedimentos para coleta dos dados 63

10.4. Instrumentos para coleta de dados 64 
10.5. Perfil dos Egressos

10.6. Perfil do Mestre em Ciência: área Bioengenharia 65

10.7. Perfil Ocupacional 65

10.8. Mercado de Trabalho 65

11. RESULTADOS E DISCUSSÃO 66

11.1. O Perfil dos Egressos 68

11.2. Características do curso de graduação 71

11.3. A pós-graduação em Bioengenharia 80

11.4. O mercado de trabalho 115

12. CONCLUSÃO 126

REFERÊNCIAS 131

$\begin{array}{ll}\text { Apêndice A } & 136\end{array}$

$\begin{array}{ll}\text { Apêndice B } & 138\end{array}$

$\begin{array}{ll}\text { Apêndice C } & 139\end{array}$ 


\section{INTRODUÇÃO}

O ensino de Pós-Graduação na Universidade de São Paulo-USP teve início a partir de 1969, na cidade de São Paulo, através da Resolução CoPGr № 4678 e assim estruturado: pós-graduação Stricto Sensu e pós-graduação Lato Sensu. Os cursos Stricto Sensu são oferecidos em nível de mestrado e doutorado, sempre com o objetivo de formar recursos humanos altamente qualificados, com vistas ao ensino, pesquisa e ao desenvolvimento científico e tecnológico. Já os cursos Lato Sensu são direcionados ao treinamento profissional ou científico e conferem certificado de Especialista. A educação continuada por meio dos cursos de especialização, mestrado e doutorado, permite formar um profissional que atende às necessidades acadêmicas e profissionalizantes do mercado, sempre buscando o aperfeiçoamento especializado do conhecimento (USP, 2013).

No campus da USP de São Carlos, a Pós-Graduação Interunidades em Bioengenharia teve seu funcionamento autorizado pela Câmara de Pós-Graduação do Conselho de Ensino, Pesquisa e Extensão de Serviços à Comunidade (na pessoa do Professor Titular Paschoal Ernesto Américo Senise), após o exame do processo 16965/77 e usando das atribuições que the conferiam o artigo $4^{\circ}$ da Portaria GR-1538, de 19 de julho de 1971. O programa de Pós-Graduação Interunidades em Bioengenharia, então autorizado, contemplava a Escola de Engenharia de São Carlos-EESC, a Faculdade de Medicina de Ribeirão PretoFMRP, o Instituto de Ciências Matemáticas de São Carlos-ICMSC e o Instituto de Física e Química de São Carlos- IFQSC, com o curso de Pós-Graduação na área Interunidades "Bioengenharia", em nível de Mestrado, os quais deveriam reger-se

pelas normas baixadas pela Resolução nº 1283, de 4.11.1977 (DIÁRIO OFICIAL, 18/11/1977). 
A graduação em engenharia biomédica iniciou no Brasil no ano de 2005 na Universidade do Vale do Paraíba- UNIVAP. O Engenheiro Biomédico deve ser um profissional multidisciplinar voltado às ciências da saúde. Dentro deste leque dinâmico, a formação de profissionais com: conhecimento das mais novas tecnologias de diagnósticos e tratamentos; aplicação da informática e computação na área biomédica, na administração e na arquitetura de ambientes de saúde, aplicando conhecimentos matemáticos para modelagem e execução; conhecimento de biomateriais e sistemas biomecânicos; aplicados à medicina e biomedicina; habilidades de gestão e espírito de liderança com consciência de grupo, empreendedorismo, atualização constante e automotivação; projetos e fabricação de dispositivos eletrônicos para diagnósticos e tratamento, facilitando o trabalho médico, o suporte a vida, com habilidades para estimular a comunicação entre o setor produtivo e médico-hospitalar.

A pós-graduação em engenharia biomédica no Brasil foi introduzida pelo programa de engenharia biomédica da Coppe - Universidade Federal do Rio de Janeiro pioneiro em 1971, com a ambição de formar profissionais num campo então desconhecido no Brasil e contribuir para melhorar a qualidade da medicina e dos programas de assistência à saúde, praticados no país, pela união das praticas dos saberes da medicina e da engenharia. Trazia a marca inovadora que, desde o inicio caracterizou a Coppe, professores e alunos com dedicação integral e forte ênfase na combinação de ensino e pesquisa, comunicação entre o setor produtivo e médicohospitalar.

Assim o aluno que cursa a Pós-Graduação em nível de mestrado em engenharia biomédica, está apto no final do curso a ser um profissional de alto nível para o exercício da docência e para pesquisa e inovação tecnológica, capazes de 
aplicar conceitos das áreas de engenharia, ciências exatas e biológicas para solução de problemas relativos à área da saúde e para o desenvolvimento da ciência e da tecnologia nacional.

A Pós-Graduação em nível de doutorado em engenharia biomédica visa formar recursos humanos que atuem, ou pretendem atuar, em universidades, institutos de pesquisas, hospitais e empresas de base tecnológica e de inovação na área de saúde, visando à utilização e a aplicação dos conceitos recebidos no desenvolvimento de novas técnicas de diagnósticos não-invasivos, uso de novas metodologias de tratamento, assim como, o domínio no desenvolvimento e preparação de novos biomateriais. O Doutorado Direto é uma excelente opção para alunos que terminaram sua graduação e que buscam novos desafios. Os candidatos que tiveram a oportunidade de participar de pesquisa científica durante seu curso de graduação e que já possuem artigos indexados publicados poderão ingressar diretamente nesta modalidade. $\mathrm{O}$ profissional formado terá toda a capacidade de exercer as atividades profissionais de ensino, pesquisa e desenvolvimento em engenharia biomédica, atendendo as exigências de qualificação e expansão no mercado de trabalho.

Quando se pesquisa o mercado de trabalho, algumas dúvidas surgem quanto a sua definição. Para Toledo e Milione (1983) "refere-se às oportunidades qualitativas e quantitativas de emprego em determinada região". Pires (2009) define mercado de trabalho, como "o conjunto das ofertas de trabalho oferecidas pelas empresas, em certa época e em determinado lugar". Para esses autores citados como exemplos, mercado de trabalho restringe-se às ofertas de trabalho (vagas) pelas empresas e à procura de trabalho. 
O mercado de trabalho brasileiro, referente aos profissionais da Bioengenharia, apresenta crescimento da oferta de mão-de-obra e estrutura profissional própria. Assim, o profissional habilitado pode atuar em atividades de projeto, produção, gestão e controle de qualidade de dispositivos biomédicos em organizações de saúde publica e privada. Também desempenha atividades de pesquisa e desenvolvimento de processos e dispositivos biomédicos para uso em prevenção e diagnóstico de doenças; terapia e monitoração de sinais vitais, além de dispositivos biomédicos para reabilitação e tecnologia assistida (JIMENEZ VIVAS, 2005)

Segundo Menezez Filho et al. (2004), a profissão de bioengenheiro evidencia que o conhecimento cientifico é um só e não está compartimentado pela divisão das profissões. Ainda segundo esse pesquisador, o bioengenheiro atua com mais freqüência em hospitais, não sendo descartada sua atuação em laboratórios de análises clínicas e na indústria de instrumentação hospitalar, biológica e de engenharia biológica.

Desta maneira, independente do setor, no qual o bioengenheiro esteja atuando, ele só se sentirá estimulado a exercer sua profissão, caso esteja satisfeito com seu trabalho. Uma profissão em sua prática, não deve ser considerada somente o resultado de aptidões e habilidades de quem as executa. Há que se levar em conta também, os fatores psicológicos e sociais, cuja grande influência no comportamento do trabalhador diante de seu exercício profissional pode condicionar a sua compatibilização com o trabalho. É esta compatibilização que leva a chamada satisfação profissional, a qual pode ser definida como o estado emocional positivo resultante do prazer que se têm com as experiências do trabalho (LOPES, 2005). 


\section{JUSTIFICATIVA}

A escolha de estudar os egressos do curso de pós-graduação Interunidades em Bioengenharia em nível de mestrado ocorreu por não existir até o ano de 2005 nenhum curso de graduação na área de engenharia biomédica, somente mestrado/ doutorado em engenharia biomédica. O Programa de Pós-Graduação Interunidades em Bioengenharia EESC-IQSC-FMRP-USP é o único no Brasil a desenvolver pesquisas em bioengenharia.

As variações no comportamento do mercado de trabalho do bioengenheiro aliadas à formação constante de novos mestres em Bioengenharia, oriundos do curso de Pós-Graduação em Bioengenharia da USP levaram-me a pensar como se processa a inserção dos egressos no mercado de trabalho em bioengenharia.

Em razão destes fatos, e por se tratar de uma pesquisa ainda não concebida no curso de mestrado da Pós-Graduação Interunidades em Bioengenharia PPGIBEESC-FMRP-IQSC-USP, decidi fazê-la com os egressos do referido curso, na tentativa de descobrir sua inserção no mercado de trabalho, quais as principais dificuldades encontradas no exercício da profissão e o seu grau de satisfação com a mesma. Também realizei esta pesquisa com o objetivo de verificar se os egressos estão devidamente capacitados para se inserir no mercado de trabalho.

Atualmente, em decorrência das novas Diretrizes Curriculares Nacionais estabelecidas pelo Ministério da Educação e Cultura - MEC, mudanças nos currículos dos cursos de pós-graduação se fazem necessárias na tentativa de adequar a formação com a realidade social da população. Desta forma, se faz necessário conhecer a realidade profissional dos egressos, a fim de se avaliar a 
necessidade de possíveis mudanças nos cursos de Pós-Graduação e caso essas ocorram, guiá-las para uma melhor formulação. 


\section{OBJETIVO}

O objetivo desta pesquisa foi avaliar a inserção no mercado de trabalho dos egressos do Programa de Pós-Graduação Interunidades em Bioengenharia EESCIQSC-FMRP da Universidade de São Paulo, tendo como finalidade conhecer as atividades acadêmicas e profissionais verificando as mudanças ocorridas e descrever a percepção do curso pelos egressos titulados mestres em Ciências; área de concentração Bioengenharia no período de 1980 a 2012.

Procurei trabalhar as evidencias de modo a construir o perfil do curso realizado pelo egresso, o perfil ocupacional e o perfil de mercado de trabalho e construir esse mesmo perfil a partir de informações colhidas.

A expectativa que moveu esta pesquisa foi reafirmar a convicção de que a pesquisa cientifica sobre o mercado de trabalho constitui um instrumento objetivo e eficaz de diagnostico e de avaliação das relações de ensino superior com o sistema produtivo.

\subsection{Objetivos específicos}

Os objetivos específicos da pesquisa foram: 1) proceder à avaliação tanto do ensino como campo profissional a partir dos egressos e 2) apontar tendências e perspectivas em ambos os setores.

A pesquisa acumulou uma quantidade de dados, fruto da elaboração de uma serie de indicadores gerais, quantitativos e qualitativos (permanência na área, exigências ocupacionais, tendências setoriais, etc.), os quais foram registrados no curso de Interunidades em bioengenharia em nível de mestrado. 


\section{REVISÃO BIBLIOGRÁFICA}

A avaliação dos egressos dos programas de Pós-Graduação é um tema relevante, em pesquisas realizadas tanto no Brasil, quanto no exterior. (LOPES, 1998; HORTALE e KOIFMAN, 2007; PIRES, 2008; MENDES, 2010; MODESTO, 2012; SÃO LUIS, 2012; ORTIGOSA et al., 2012; PRIES, 2000).

Pelo relatado no estudo de Hortale e Koifman (2007), pode-se constatar que há semelhanças no processo de avaliação da Pós-Graduação da Argentina e do Brasil. Um ponto a destacar é a natureza dos órgãos que atuam na avaliação da Pós-Graduação, na Argentina é a Comission Nacional de Evaluación y Acreditación Universitária-CONEAU, e no Brasil é a Coordenação de Aperfeiçoamento de Pessoal de Nível Superior-CAPES. Segundo Spagnolo e Calhau (2002), o sistema de avaliação da CAPES está mais orientado para a pesquisa do que para a qualidade do ensino. No instrumento de avaliação utilizado não há indicadores próprios para se avaliar os métodos de ensino; a qualidade é inferida a partir da análise do número de publicações, da qualificação do corpo docente, das orientações realizadas e da carga horária docente no programa (PIMENTA e ANASTASIOU, 2002).

Em relação ao Brasil, parte do documento- CONTRIBUIÇÕES DA COMUNIDADE: PROPOSTA USP DE AVALIAÇÃO DA PÓS-GRADUAÇÃO-2012apresentado no Encontro Acadêmico de Gestão da Pós-Graduação USP- Avaliação como instrumento, realizado de 24 a 26 de setembro de 2012, na Escola de Artes, Ciências e Humanidades (EACH), Campus USP Leste, São Paulo-SP, veio reforçar a necessidade da realização do presente trabalho, cujo tema é a Avaliação da inserção no mercado de trabalho dos egressos do mestrado acadêmico em Bioengenharia. Neste documento, o propósito foi apresentar de forma sintética as 
contribuições recebidas pela Comunidade Acadêmica. Além das premissas gerais para o Sistema de Avaliação USP da Pós-Graduação, e de suas características quanto ao formato da Avaliação, foram identificadas diversas questões, compondo sete elementos principais do processo de avaliação, considerados pela comunidade presente no evento como contemplados apenas parcialmente pelo atual sistema de avaliação da CAPES, a saber, (1) Egressos; (2) Internacionalização (mobilidade, convênios e cooperação); (3) Qualidade de produto final; (4) Detalhamento da produção intelectual; (5) Captação de recursos; (6) Cooperação entre os Programas da própria USP; (7) Pesquisa, desenvolvimento e inovação.

Como se pode observar, o primeiro elemento refere-se ao foco deste trabalho, os egressos, que no documento se apresentam de forma geral e no presente trabalho, especificam-se como sendo os mestres do Programa de Pós-Graduação Interunidades em Bioengenharia. Os itens específicos sugeridos pelo documento Avaliação USP (USP, 2012) foram:

\section{-Egressos}

.-Diferenciação entre mestres e doutores;

--Considerar atuação acadêmica e não acadêmica;

.-Atuação dentro ou fora da área de formação;

-Compatibilidade do cargo com nível de formação;

--Liderança;

-Captação de recursos;

.-Distribuição geográfica;

-Nucleação;

.-Opinião dos egressos sobre o programa. 


\subsection{SAÚDE NO BRASIL COLÔNIA}

Durante o período do Brasil colônia, o Rio de Janeiro apresentou-se como um verdadeiro "campo experimental" para remédios, tal sua quantidade. Além, de serem imitados os de Portugal, havia também remédios da cultura indígena ou africana. $\mathrm{Na}$ Farmacopéia de Vigier, de 1766, encontram-se descritos alguns tipos de remédios e suas indicações, tais como carne de víbora em pó para a sífilis, açúcar rosado com leite de jumenta ou cabra para a tuberculose pulmonar ou "chaga de bofe", raspas de chifre de veado para a verminose, pomada de gordura humana retirada dos enforcados para a calvície, pescoço de galo torrado e pulverizado nas anginas, entre outros, comprovando a vasta gama de remédios e suas diferentes origens no Brasil colonial. Com a abertura dos portos do Brasil às nações amigas de Portugal, D. João VI assinou, em 18 de fevereiro de 1808, o documento que mandou criar a Escola de Cirurgia da Bahia (atual UFBA) e deu início ao ensino da medicina no país (FAMEB, 2013). A Faculdade de Medicina da Universidade Federal do Rio de Janeiro- UFRJ foi criada pelo príncipe regente D. João VI, por Carta Régia, assinada em 5 de novembro de 1808, com o nome de Escola de Anatomia, Medicina e Cirurgia e instalada no Hospital Militar do Morro do Castelo (UFRJ, 2013).

A interiorização do ensino da medicina iniciou-se em 1950 quando foi fundada a primeira faculdade de medicina no interior do Brasil, a Faculdade de Medicina de Sorocaba da Pontifícia Universidade Católica de São Paulo - PUC-SP (ESCOLAS MÉDICAS, 2013).

Em 13 de junho de 1954 o diretor do Instituto Brasileiro de História da Medicina plantou no Jardim Botânico do Rio uma muda vinda da árvore de Hipócrates, que ainda existe na ilha de Cós, na Grécia. 
A Medicina tem dois aspectos: um deles é o conhecimento (isto é, uma ciência) e o outro a aplicação desse conhecimento (as profissões médicas). A Medicina baseada em evidências é uma tentativa de ligar esses dois aspectos (ciência e prática) através do uso do método científico, buscando através de técnicas e pesquisas científicas o melhor tratamento para um determinado paciente.

Às vezes, pode ser difícil distinguir entre ciência médica e profissão em medicina. Os vários ramos especializados da medicina são estudados por ciências básicas especializadas e por correspondentes profissões médicas, igualmente especializadas, que lidam com órgãos, sistemas orgânicos e suas doenças. As ciências básicas da medicina freqüentemente são as mesmas de outras áreas da ciência da saúde ou ciência médica como a biologia, a física e a química. Existem várias áreas ligadas à ciência da saúde ou ciência médica: odontologia, serviço social, psicologia, enfermagem, farmácia, biomedicina, fonoaudiologia, educação física, fisioterapia, terapia ocupacional, nutrição, protética e bioengenharia (UFRJ, 2013).

O estudo do corpo humano, em algumas das suas formas e propósitos, constitui uma importante ligação entre a medicina e alguns campos da engenharia. A medicina tem como objetivo sustentar, aumentar e até substituir funções do corpo humano, se necessário, através do uso da tecnologia.

A moderna medicina pode substituir várias funções do corpo através do uso de órgãos artificiais e pode alterar significativamente várias dessas funções através de dispositivos como implantes cerebrais e marca-passos. A biônica é um campo específico que se dedica ao estudo dos implantes sintéticos em sistemas naturais (CNES, 2013). 
Reciprocamente, alguns campos da engenharia olham para o corpo humano como uma máquina biológica que merece ser estudada e dedicam-se a melhorar muitas das suas funções através da substituição da biologia pela tecnologia. Isto levou a novos campos de pesquisa, como a inteligência artificial, as redes neurais, a lógica difusa e a robótica. Existem também interações substanciais entre a engenharia e a medicina (ESCOLAS MÉDICAS, 2013; CNES, 2013).

\subsection{INÍCIO DA ENGENHARIA BIOMÉDICA NO BRASIL}

O perfil histórico da Engenharia Biomédica/ Bioengenharia no Brasil, além de uma análise contemporânea dos mais variados temas da especialidade, as opiniões que se seguem nos dão uma mostra de como a Engenharia Biomédica/Bioengenharia evoluiu no país e como ela vem se tornando um diferencial na qualidade da prestação de serviços de saúde para todo o mundo.

O que nos dias atuais se entende como Bioengenharia está muito ligado ao desenvolvimento da Instrumentação e, em particular, à instrumentação médica, cujo desenvolvimento é necessário a interação de médicos e engenheiros, nestes incluídos físicos, químicos, matemáticos e cientistas da computação. Surgem então

outros campos ligados à Bioengenharia, como Bioinformática, Genômica, etc. (INFANTOSI, 2001).

A medicina brasileira era principalmente clínica e sanitária até 1900 , com descentralização política, empréstimos culturais e urgências políticas que a ciência brasileira entraria no século XX. (ANTONIO, ROLLO, 2014)

O desenvolvimento científico no Brasil, caracterizado como sendo a vacina o tema predominante em ciências e tecnologia abordando os primórdios da 
bioengenharia no Brasil, sua continuação se dá na instrumentação que é considerada a continuidade da bioengenharia no Brasil.

A Engenharia Biomédica teve sua origem na engenharia, nascendo da evolução da indústria médico-hospitalar, odontológica e farmacêutica, é elevada à condição de especialidade pelo esforço de abnegados engenheiros que acreditaram na importância de sua atuação no setor, na formação de um mercado para os produtos de alta tecnologia, bem como, no potencial dos métodos da engenharia para a criação de soluções, tanto para a medicina como, numa visão mais ampla, para todas as biociências.

A solução dos problemas da biologia - ciência que estuda os seres vivos e suas relações, a fim de conhecer as leis peculiares à matéria viva - e medicina arte e ciência de curar e prevenir doenças - reside nos conhecimentos de engenharia, matemática, computação e física e, através desta multidisciplinaridade é possível definir a engenharia biomédica.

Esta multidisciplinaridade, incorporada recentemente, tem prestado substancial contribuição às ciências biomédicas e à tecnologia aplicada a problemas médicos. Na sua definição mais ampla, a engenharia biomédica tem pontos de tangência com outras áreas multidisciplinares do conhecimento, tais como fisiologia, biomatemática e informática médica.

Através dessa definição, percebe-se que a engenharia biomédica é uma área muito vasta e que hoje é impossível um único indivíduo cobrir toda a gama de conhecimentos desta ciência.

Pode-se dividir a Engenharia Biomédica em quatro subáreas: Engenharia de Reabilitação, Engenharia Médica, Engenharia Clínica ou Hospitalar e Bioengenharia. 


\subsection{ENGENHARIA DE REABILITAÇÃO}

Pode-se definir esta engenharia como a aplicação de métodos da engenharia - arte de aplicar os conhecimentos científicos à invenção, aperfeiçoamento ou utilização da técnica industrial em todas as suas determinações - e das ciências exatas - as que somente admitem princípios, conseqüências e fatos rigorosamente demonstráveis - no projeto e construção de sistemas, equipamentos e dispositivos para processamento de sinais biológicos, estimulação neuromuscular, sustentação, locomoção, fisioterapia e próteses artificiais utilizados para recuperação ou minimização dos efeitos de deficiências neurológicas e músculo-esquelético, estando contida no âmbito da engenharia biomédica como uma de suas subdivisões.

A Engenharia de Reabilitação é uma das mais recentes especialidades da engenharia biomédica e se concentra basicamente na pesquisa e produção de equipamentos e próteses, atuando na indústria ou, de forma multidisciplinar, junto à unidade de terapia e instituições de pesquisa. Os recentes avanços conquistados no campo do processamento de sinais biológicos e neurotransmissores constituem uma das áreas de maior desenvolvimento nesse setor e vem criando novas perspectivas para atuação da medicina na criação de terapias mais eficazes.

Em associação com novas gerações de materiais e novas concepções de fabricação, ampliaram-se as possibilidades para construção de próteses inteligentes comandadas por sinais mio-elétrico para as mais variadas finalidades, agora mais leves, mais confortáveis e com custo acessível.

O conhecimento preciso da biomecânica da estrutura esquelética e os efeitos causados pelos esforços sobre a estrutura alveolar dos ossos - adquiridos em simulações calculadas por métodos avançados como o de elementos finitos, por 
exemplo - inaugura novas gerações de próteses, tanto externas como implantáveis, muito mais resistentes, duráveis e seguras.

\subsection{INFORMÁTICA MÉDICA}

Refere-se à aplicação dos métodos da engenharia e das ciências exatas no projeto, construção, operação, e manutenção de equipamentos informatizados e programas especialmente desenvolvidos para as diversas áreas que compõem o setor da saúde.

Focaliza o estudo da informática e da informatização com o objetivo de pesquisar e desenvolver aplicações específicas nos campos da medicina, da odontologia, veterinária, farmácia, bioquímica e outras que compõe o setor da saúde.

A informática é aplicada na administração hospitalar, no diagnóstico não invasivo através de imagens, no controle e monitoramento de equipamentos cirúrgicos e de terapia, no controle de servo-mecanismo de próteses externas e implantáveis, na pesquisa, na educação virtual e na comunicação digital remota.

Como as atividades no ramo da informática são extensivas, compreendem desde a criação de software para administração de consultórios até o estudo de moléculas em microscópios digitais. Essas atividades podem ser altamente complexas quando envolvem, por exemplo, a simulação digital de redes neurais em supercomputadores ou sensoriamento remoto de guias de precisão em cirurgias cerebrais.

Sendo um dos ramos que mais tem se desenvolvido, apoiado fortemente tanto pela iniciativa privada como pelos órgãos governamentais em todo o mundo, o 
seu potencial de aplicação na área da saúde é incalculável, face ao próprio desenvolvimento acelerado do setor como um todo.

\subsection{ENGENHARIA CLIINICA OU HOSPITALAR}

A Engenharia Clinica ou Hospitalar tem como objetivo principal criar e manter a infra-estrutura necessária para a correta e ininterrupta operação de todos os sistemas implantados com a eficiente utilização dos insumos disponíveis. Esta ciência estabelece planos logísticos de suprimentos, rotinas de inserção, rotinas de manutenção preditiva e corretiva, políticas de racionalização e economia, métodos de treinamento de pessoal técnico, normas internas de segurança e higiene no trabalho, aferição da qualidade e produtividade, metas de produção, planejamento de custos e orçamento.

A esta engenharia compete, ainda, projetar e fiscalizar a construção de instalações prediais, mecânicas e elétricas; proceder à inspeção, avaliação e perícia das instalações clínicas e hospitalares de seus acessórios e equipamentos, quando, no âmbito da sua graduação específica, exercer a atividade profissional conforme estabelecido pelo Conselho Federal Engenharia, Arquitetura e AgronomiaCONFEA.

A crescente complexidade da tecnologia e das estruturas hospitalares para atendimento em larga escala, vem exigindo cada vez mais a presença de um corpo de engenharia no hospital. Além desse campo diretamente ligado à estrutura hospitalar, o engenheiro clínico poderá atuar em uma das muitas intersecções com outras áreas da engenharia e das biociências, como na pesquisa e desenvolvimento 
de equipamentos médicos, odontológicos, hospitalares, de próteses, de biomateriais, na certificação de qualidade de produtos, ou em consultoria, entre outros.

\subsection{BIOENGENHARIA}

Esta ciência refere-se à aplicação das técnicas e métodos da engenharia e das ciências exatas no desenvolvimento de órgãos internos artificiais e dispositivos auxiliares dos sistemas biológicos, estando contida no âmbito da engenharia biomédica como uma de suas subdivisões. Nascendo do esforço pioneiro dos médicos durante a fase inicial da era dos transplantes cardíacos que, médicos habituados a criar ferramentas e equipamentos para suas necessidades urgentes, encontraram as dificuldades técnicas inerentes ao gerenciamento de estruturas industriais produtivas, necessárias naquele momento, e também para o projeto de desenvolvimento de equipamentos de monitoração e de suporte da vida com alto nível de complexidade e de confiabilidade, competências que iam além dos domínios da Medicina.

A Bioengenharia focaliza o estudo do sistema orgânico à luz da matemática, física e bioquímica, entre outras, equacionando sua constituição e funcionamento sistêmico com o objetivo de criar ferramentas teóricas que permitam compreender e criar artificialmente órgãos internos, equipamentos extracorpóreos e próteses implantáveis. Um movimento de aproximação efetivo entre a medicina e engenharia, resulta na criação de centros de bioengenharia diretamente ligados às instituições hospitalares.

Apesar de já contar com mais de cinqüenta anos, a Bioengenharia apenas começa a se desenvolver, graças ao desafio constante de superar a extraordinária complexidade envolvida no funcionamento dos organismos vivos. Ela vem sendo 
trabalhada e utilizada em todo o mundo, em setores cujo desenvolvimento é considerado mais urgente e menos sujeito às limitações de ordem técnica ou material, como as áreas cardiorrespiratórias, a ortopedia de tecidos artificiais e de materiais biocompativéis.

Atuando em uma nova área do conhecimento, o profissional se verá, quase sempre, diante de situações inusitadas e absolutamente novas, que exigirão conhecimento profundo e técnico e uma grande capacidade criativa na solução de problemas. Essa característica faz da bioengenharia uma das mais excitantes carreiras técnicas, uma vez que o engenheiro pode exercer, de fato, todo o potencial para o qual foi treinado.

Constitui-se, assim, a bioengenharia, como um campo de atuação complexo, eminentemente multidisciplinar e que exige uma crescente colaboração entre especialistas das mais diversas áreas, cujo relacionamento nem sempre é fácil e, certamente, requer a renúncia às vaidades profissionais em benefício da ciência, além de total dedicação, sendo, pois, considerada, por muitos, um verdadeiro sacerdócio.

Diretamente envolvido com questões éticas e morais na aplicação de suas conquistas perante a sociedade, o bioengenheiro vive com o conflito, e na visão de alguns, não deve esperar reconhecimento por suas descobertas e criações. A história, infelizmente, nos mostra um passado de trabalho solitário e quase anônimo.

Suas atividades se estendem por uma série de especializações e uma vasta gama de pesquisas embrionárias desenvolvidas em centros especializados e empresas privadas espalhadas pelo mundo, entre as quais se destacam: bioengenharia cardiovascular, circulação extracorpórea assistida, estimulação 
interna artificial, órgãos artificiais, engenharia celular e tecido artificial, próteses biomecânicas e engenharia do sistema respiratório.

Estas atividades estão relacionadas a dois aspectos fundamentais, o primeiro com respeito à compreensão do relacionamento entre os sistemas que compõem os organismos vivos, que produzem substâncias transmissoras de informações e se comunicam quimicamente por mecanismos ainda não devidamente esclarecidos. $\mathrm{O}$ segundo com relação ao custo das pesquisas direcionadas, que exigem recursos humanos, materiais e financeiros, se impondo como um fator limitante ao avanço em determinadas áreas.

\section{O INÍCIO DA ENGENHARIA BIOMÉDICA E BIOENGENHARIA NO BRASIL.}

Na cidade do Rio de Janeiro no ano de 1963, o físico Alberto Luiz Coimbra, reuniu um grupo de pesquisa na Universidade Federal do Rio de Janeiro e deu inicio em pesquisas e desenvolvimentos ligados a física aplicada à medicina. Este grupo era independente da Universidade, e esta pesquisa desenvolvida com o passar dos anos foi agrupando outros departamentos da universidade (OLIVEIRA, 2003).

Essa evolução histórica criou um dos mais importantes núcleos de pesquisas aplicadas em bioengenharia para a medicina, sendo que em 1971 surge a COPPE Comissão de Pós-Graduação e Pesquisas em Engenharia, mantendo um departamento em separado da universidade. O que existia em termos de Engenharia biomédica/bioengenharia, tanto no Brasil quanto no resto do mundo, era fundamentalmente instrumentação biomédica e processamento de sinais biológicos, quase não se falava em imagem. No caso de processamento de sinais, estes em geral tinham como fonte o sistema cardiovascular e a instrumentação era também 
voltada para a cardiologia, tanto suportando as atividades clínicas quanto às cirúrgicas. Obviamente outros sinais de outros órgãos eram também processados, tais como o eletromiograma e eletro encefalograma (OLIVEIRA, 2003).

O programa de engenharia biomédica conscientizou-se que o "gargalo tecnológico" não estava no equipamento em si, mas no transdutor, ou seja, naquele elemento que se colocava em contato com a fonte geradora e que permitia que se captasse a informação sobre o órgão em questão. Aí se deu uma mudança significativa, no Brasil como um todo e também no exterior, em que o enfoque deixou de ser o equipamento em si para ser "o bloco do equipamento" que era a interface entre a eletrônica propriamente dita e o corpo humano. Isso no que se refere à instrumentação. No processamento, novas técnicas de análises foram desenvolvidas e a visão de sistema, e não somente o órgão, tornou-se cada vez mais relevante, em particular voltada para o controle biológico (OLIVEIRA, 2003).

Criado o primeiro curso de Pós-Graduação do país nesta área e somente voltado para a formação de mestres, do lançamento do primeiro congresso nacional da especialidade, em 1973 e 1974, a Sociedade Brasileira de Engenharia BiomédicaSBEB foi oficializada, tendo como fundadores um grupo ainda pequeno constituído pelos mestrados do Programa de Engenharia Biomédica- PEB - COPPE, e profissionais vinculados ao Instituto do Coração - USP, em 1975 (OLIVEIRA, 2003).

Desde então, a SBEB - Sociedade Brasileira de Engenharia Biomédica - tem participado da evolução da Engenharia Biomédica/Bioengenharia no país. Atualmente, a Sociedade tem buscado divulgar a área, facilitar a troca de experiências entre os especialistas, promovendo, assim, sua atualização científica e profissional. Para isso, além da realização de simpósios e do Congresso Brasileiro, a cada dois anos, edita a Revista Brasileira de Engenharia Biomédica - RBEB, que 
alcançou prestígio nacional e internacional com suas edições anuais. Hoje, a revista é distribuída para todas as sociedades científicas de Engenharia Biomédica/ Bioengenharia, dos países das Américas que apóiam à pesquisa e o ensino, tais como a CAPES e o CNPq (OLIVEIRA, 2003).

Ao longo dos anos, outros grupos se constituíram alguns vinculados à PósGraduação em Engenharia Elétrica, tais como a Universidade de CampinasUNICAMP, USP e a Universidade Federal de Santa Catarina- UFSC, e outros como programas de Engenharia Biomédica/Bioengenharia isoladamente como a Universidade Federal de Paraíba -. UFPB. O doutorado só surgiu na COPPE anos depois, na década de 80. Recentemente, cursos de mestrado em Engenharia Biomédica/Bioengenharia foram criados em universidades privadas, como em Mogi das Cruzes e São José dos Campos, ambas em São Paulo. Vale salientar que a graduação em Engenharia Biomédica/Bioengenharia é uma opção muito questionável, pois o profissional desta especialidade deve ter uma formação abrangente e multifacetada. Uma vez que a tecnologia cumpre papel fundamental na formação desse profissional e, enfatizando o fato de que, a tecnologia evolui com enorme rapidez, o conhecimento das ciências básicas é fundamental, ou então o profissional pode ficar desatualizado em curto espaço de tempo (OLIVEIRA, 2003).

O que, por um lado, historicamente, se justifica, hoje em dia, já não deveria mais acontecer, porque a Engenharia Biomédica/Bioengenharia não utiliza somente conceitos da Engenharia Elétrica. Utiliza-se também das outras engenharias, por exemplo, da Mecânica. Então, o que acontece, às vezes, até mesmo o fato de um grupo de Engenharia Biomédica/Bioengenharia estar inserido dentro do departamento sobre a inter e multidisciplinaridade da Engenharia Biomédica/Bioengenharia, pode ser um fator limitante. Isso pode acarretar uma 
inibição na criação de linhas de pesquisa com menor ênfase. Enfim, essa situação, às vezes, resulta na não criação de uma nova linha por se estar umbilicalmente ligada a um departamento de Engenharia Elétrica. Ou então, em uma mesma universidade trabalhando em separado, quando eles deveriam estar trabalhando em conjunto (OLIVEIRA, 2003).

Os equipamentos, em particular os digitais, foram cada vez mais incorporados à rotina das unidades de atendimento à saúde, em especial às hospitalares. $\mathrm{E}$ isso gerou, inicialmente, uma nova necessidade: o gerenciamento dos equipamentos. Até então, o gestor destas unidades era profissional da área médica. A incorporação da tecnologia cada vez mais sofisticada e em maior número se, por um lado, contribui para a melhoria da qualidade do atendimento à saúde, poderia aumentar, em contrapartida, os custos deste atendimento. Logo, tornou-se necessário formar equipes constituídas de especialistas na gestão desta tecnologia; surge, então, a Engenharia Clínica (OLIVEIRA, 2003).

No Brasil e demais países, o impacto das novas tecnologias hospitalares, bem como a revolução tecnológica da década de 80 , mostrou a importância de se formar, tais profissionais. Desta forma, a atuação do profissional da Engenharia Biomédica/Bioengenharia passa a se dar também dentro do sistema de saúde, no qual ele passa a ser consultado tanto sobre a aquisição do equipamento quanto em relação ao seu uso mais adequado. A Engenharia Clínica surge, por conseguinte, como uma conseqüência da incorporação da tecnologia no atendimento à saúde, e o profissional que exerce esta função é um engenheiro biomédico com atuação neste ramo (OLIVEIRA, 2003).

Hoje, a Engenharia Clínica e a avaliação tecnológica são do ponto de vista de diminuição de custos e também da melhoria da qualidade de serviço, uma 
necessidade. Assim, é possível ter um serviço de qualidade, a um custo menor, se a tecnologia for adequadamente incorporada e utilizada.

Como o atendimento à saúde no Brasil é parcialmente público e o sistema é, para a maioria da população, coberto pela previdência, o atendimento está deixando a desejar também, porque falta um melhor gerenciamento da tecnologia envolvida nesse processo. Tomar decisões com relação à aquisição de tecnologia, contratos de manutenção, metodologia de acompanhamento de equipamentos e uso adequado, exige que se tenha profissional preparado para tal. A Engenharia Clínica e a Avaliação de Tecnologia em Saúde são as áreas da Engenharia Biomédica/Bioengenharia que cumprem esse papel fundamental (OLIVEIRA, 2003).

Para Infantosi (2001), a graduação específica em Engenharia Biomédica/Bioengenharia apresentava alguns problemas. Vários foram os países que tentaram sua implementação e em boa parte deles, isso não foi em frente. Está certo que foi há uma década. Pode-se criar, mas para tomar esse tipo de decisão, as pessoas têm que estar muito cientes do perfil do profissional que querem formar. E, obviamente, ao mercado de trabalho que esse profissional vai ter que se adequar. Obviamente, os mestres, doutores e mesmo os especialistas que se formam em Engenharia Biomédica/Bioengenharia tem atuado na própria área. E, como esses profissionais têm uma formação bastante abrangente, podem atuar em outras áreas que não a Engenharia Biomédica/Bioengenharia. Para Infantosi "considero ser muito difícil formar um profissional deste tipo e com uma capacidade de visão crítica numa área tão extensa como a Engenharia Biomédica/Bioengenharia em termos de graduação".

Em relação às indústrias e à tecnologia computacional, não só o Brasil, como a maioria dos países em desenvolvimento, está, neste setor, muito aquém do 
desejado. O problema não é a capacidade, mas é ser economicamente viável. Para Infantosi "Alguém diria: olha seria fundamental que existisse eletrocardiógrafos em todos os postos de saúde do Brasil. Seria fundamental, sim. Mas quem vai comprar isso? É o Estado? Ele vai comprar um eletrocardiógrafo para cada posto de saúde? Não. Então a indústria vai fabricar para quem? Para exportar? (OLIVEIRA, 2003).

Sob o ponto de vista de Oliveira (2003): "Sendo o eletrocardiógrafo um dos equipamentos mais básicos, inclusive está completando 100 anos. Não estou falando de um equipamento de ultra-som obstétrico que também deveria ser acessível mesmo nos pontos mais remotos do país. A necessidade do equipamento existe. Só que quem tem que investir na aquisição de equipamentos é o Estado. Ou seja, a indústria teria que fabricar para o Estado que seria o principal consumidor e não as clinicas e os hospitais privados. Se o Estado não tem uma política voltada para isso, aquilo que a indústria produzir vai ser aquém da sua real capacidade e pode se tornar economicamente inviável."

O retorno se dá, talvez, de forma mais rápida, caso o custo baixe sensivelmente. O problema é que em tudo isso fica claro o seguinte: quando se quis fazer uma política voltada para a siderurgia, se criou a Siderbrás. Quando se quis uma política voltada para a produção de energia, criou-se a Eletrobrás, para o petróleo, a Petrobrás. Ou uma política voltada para a área nuclear, se criou a Nuclebrás. A população não tem a Saudebrás. Então não tem um esforço concentrado e voltado objetivamente para atender a saúde como um todo e de uma forma coerente, onde os diversos componentes deste sistema possam produzir de uma forma integrada com um único objetivo. Então, se a população não tem isso, também não se tem financiamento. E este é um dos problemas que a população enfrenta. Não é criar uma nova estatal, mas criar uma visão integrada. E essa visão 
integrada, infelizmente não existe, seja por parte das secretarias de saúde, estaduais e municipais, seja pelo Ministério da Saúde (Oliveira, 2003).

A predominância dos grupos de Engenharia Biomédica/Bioengenharia no país, historicamente, e em particular, está voltado à cardiologia, uma doença mais urbana. De acordo com Oliveira (2003) "Lógico que ela- cardiopatia- representa um enorme impacto social. Dados informam que na classificação de óbitos do Ministério da Saúde, as cardiopatias ocupam um lugar destacado. Mas este fato é uma questão histórica. Quando se iniciou a Engenharia Biomédica/Bioengenharia, esta era muito mais voltada para a área de cardiologia. Hoje, já se encontra um grande número de profissionais em linhas de pesquisa da bioengenharia: fisiologia pulmonar, neurologia, ginecologia, obstetrícia e até mesmo a parte mais clinica, mais laboratorial para a utilização de determinadas tecnologias, determinados métodos, que facilitem a obtenção de resultados de exames laboratoriais. Isso já está mais próximo da realidade, das necessidades da realidade" (OLIVEIRA, 2003).

Diversas pesquisas, e não apenas próteses e implantes, estão sendo realizadas. Apesar de ainda em etapa de testes, existem chips que auxiliarão na redução da dor e que serão eficazes para quem possui doenças hoje ainda sem cura.

Com a diversidade de temas de uma universidade, a qual contempla uma variedade de interesses, a pesquisa toma diferentes formas. A ciência é a pesquisa, cujo propósito imediato é gerar mais conhecimento. Ela abrange problemas de origem acadêmica ou prática. E o desenvolvimento é aonde a pesquisa quer chegar, rapidamente, seja a um produto ou processo de interesse comercial ou social (ANTONIO, ROLLO, 2013). 
A instrumentação é o trabalho investigativo destinado a produzir equipamento que, embora sem valor comercial, sejam necessários para apoio à própria pesquisa.

\section{EDUCAÇÃO EM ENGENHARIA BIOMÉDICA}

As ferramentas tradicionais de engenharia são a matemática, a física e a química, sendo estas as pernas do tripé que sustentam a engenharia. Para se adicionar a biologia como uma quarta ciência, faz-se necessário o corte de algo que já está sendo ensinado, ou o aumento do tempo extra para obtenção do diploma. No Canadá e nos EUA, ainda há debate sobre a melhor maneira de equilibrar a necessidade de material adicional, com o tempo para obter uma qualificação. Muitas universidades norte-americanas haviam cortado partes do programa de engenharia normal, a fim de se adicionar o lado biológico. Na opinião de Nigel Shrive (2012), apoiada por algum feedback da indústria, os alunos formados por esses programas não são tão bem versados em engenharia como os de programas regulares e também não estavam totalmente cientes dos aspectos biológicos que deveriam saber. A maioria das universidades no Canadá seguiu o exemplo da Universidade de Calgary, quanto à introdução de especializações em programas regulares, envolvendo perda mínima de engenharia para adicionar uma pequena quantidade de biologia. O programa tem um par de cursos extras comparado a um programa regular, e na realidade só expõem aos alunos as possibilidades da engenharia biomédica, em vez de fornecer qualquer profundidade.

Havia muito mais ênfase para estimular esses estudantes a fazer uma segunda graduação, do que para se tornarem proficientes. Assim, estes alunos levam mais tempo para se graduar, mas eram sólidos em suas capacidades de 
engenharia. Esta abordagem não foi totalmente aceita no Canadá com alguns colegas a seguir esse exemplo, porem outros pensando que o modelo dos EUA é bom, e tentando programar esse modelo em sua universidade (REVISTA AEASC, 2012). Além dos cursos de pós- graduação recentemente foram criados cursos de graduação em Engenharia Biomédica. Hoje são 11 cursos em nível de graduação localizados em: São José dos Campos EPM-UNIFESP, São José dos Campos, UNIVAP. São Paulo PUC/SP, ano de 2008. Santo André UFABC, ano de 2009. Belo Horizonte FUMEC/FEA, ano de 2010. Montes Claros FUNORTE, ano de 2007. Uberlândia UFU, ano de 2006. Recife UFPE, ano de 2002. Santa Maria UNIFRA, ano de 2010. Rio de Janeiro UFRJ. Ano de 2001 (ministra disciplinas na graduação em Física Médica). Faculdade Estácio de Sá, RJ. Esses cursos foram criados a partir do ano 2000.

Em função da necessidade crescente de um profissional que conheça e desenvolva tecnologia em saúde e suas aplicações (hospitais, indústrias, universidades, centros de pesquisas, governo, etc.)

No Brasil, existem 8200 hospitais, aproximadamente hospitais privados, hospitais públicos, hospitais universitários. Demanda imediata de engenheiros biomédicos (Feira Hospitalar 2009).

No Brasil existem atualmente 350.000 médicos em atividade, 1.200 .000 profissionais de enfermagem nos seus vários níveis, 5.000.000 de pessoas em cargos indiretos (direção, informática, técnicos, segurança, limpeza, alimentação, etc.) Neste cenário, no Brasil, existem poucos profissionais graduados em Engenharia Biomédica.

O engenheiro biomédico deve ter uma formação sólida em engenharia, deve compreender os sistemas biológicos, em especial, o corpo humano, deve possuir 
conhecimento sobre gestão, ser um profissional criativo, empreendedor e inovador, deve saber trabalhar em grupo, conhecer as tecnologias atuais ligadas à saúde e ser generalista na área da engenharia biomédica.

\subsection{MERCADO DE TRABALHO DO PROFISSIONAL CURSO BIOENGENHARIA}

A licenciatura em bioengenharia corresponde a uma formação abrangente e prática, dotando os alunos com competências específicas em diferentes vertentes da Bioengenharia, preparando-os não só para ingressar numa carreira profissional, como também para prosseguir formação científica em domínios especializados. Diferentes módulos opcionais são orientados para uma especialização (de acordo com cada universidade). É, assim, proporcionada uma multiplicidade de perfis aos alunos, podendo eles vir a atuar em diferentes sectores profissionais, como o setor agro - alimentar (indústrias agro-alimentares, hoteleira ou distribuição), ambiental (unidades de tratamento e valorização de águas ou resíduos, laboratórios de análises ambientais, etc.), ou da saúde (indústrias e serviços de instrumentação médica de diagnóstico e de terapia). Os licenciados podem integrar empresas industriais, bem como empresas de consultoria, empresas municipais ou outros organismos públicos, centros de investigação, universidades, etc. Além disso, a formação de base oferecida adéqua para ser prosseguida com uma formação mais avançada, através da realização de um mestrado em qualquer das áreas das Ciências de Engenharia ou das Ciências Biológicas.

\subsection{MERCADO DE TRABALHO DO BIOENGENHEIRO.}

O engenheiro biomédico deve aplicar princípios elétricos, mecânicos, químicos, ópticos e outros princípios de engenharia para: entender, modificar ou 
controlar sistemas biológicos; projetar e fabricar produtos que possam monitorar funções fisiológicas e auxiliar no diagnóstico e tratamento de pacientes.

O mercado de trabalho do bioengenherio no Brasil oferece ao profissional com formação interdisciplinar, aliada a base conceitual e habilidades para atuar no equacionamento, levantamento de dados e solução de problemas na área da saúde, um crescimento da oferta de mão-de-obra e estrutura própria. O trabalho deste profissional é desenvolver próteses, equipamentos cirúrgicos e de diagnóstico, podendo também atuar em atividades de projeto, produção, gestão e controle de qualidade de dispositivos biomédicos, em organizações de saúde pública e privada, além de atuar em atividades de pesquisa e desenvolvimento de processos e dispositivos biomédicos para uso, prevenção e diagnóstico de doenças, terapia e monitoração de sinais vitais, desenvolvimento de dispositivos biomédicos para reabilitação e tecnologia assistida. A profissão de bioengenheiro evidencia, que o conhecimento cientifico é um só, e não está compartimentado pela divisão das profissões, segundo Adolfo Leirner (1993), responsável pelo departamento de bioengenharia da Instituto do Coração, em São Paulo. Leirner formou-se engenheiro pelo Instituto Tecnológico da Aeronáutica, ITA, estudou medicina e hoje é doutor em cardiologia (REVISTA VEJA. 1993). 


\section{CRIAÇÃO DA ESCOLA DE ENGENHARIA DE SÃO CARLOS}

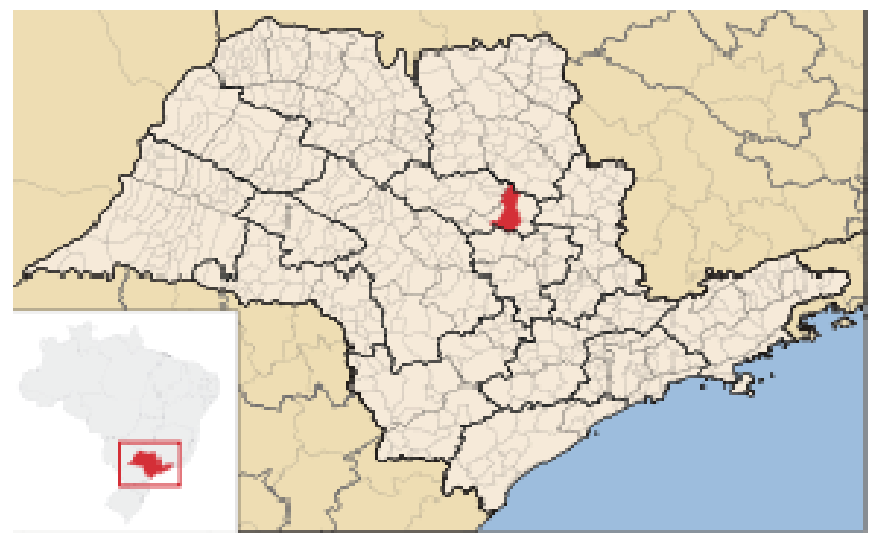

Figura 1. Localização de São Carlos no Estado de São Paulo.

Nos anos de 1940, as universidades eram privilégios das grandes capitais. Manifestações populares ocorridas em São Carlos refletiam articulações políticas: Miguel Petrilli, deputado estadual por São Carlos, era o principal articulador político da criação da EESC. Em contrapartida, o deputado Rubens do Amaral, considerava que as cidades maiores tinham mais direito à instalação da Universidade, colocando-se como oponente.

O então governador Adhemar de Barros, em sua campanha, prometera criar uma universidade no interior. Eleito, apresentou ao Conselho Administrativo do Estado o projeto de criação da futura Universidade do Interior e o deputado Miguel Petrilli logo apresentou à Assembléia Legislativa um projeto de lei para implantação da universidade em São Carlos.

Após várias discussões e alguns obstáculos, resolveu-se não criar uma nova universidade no interior do estado, mas Faculdades subordinadas à Universidade de São Paulo. Uma vez que, as grandes escolas de prestígio eram Medicina, Politécnica e Direito, Petrilli insistiu para que fosse criada em sua cidade a faculdade de Engenharia. Devido ao prestígio da Escola Normal- Escola "Dr. Álvaro Guião"-, o 
natural era que fosse criada a Faculdade de Ciências e Letras, porém, essa não possuía o prestígio das escolas acima citadas. Tal prestígio se devia à sensibilidade da sociedade em geral pela Tecnologia nos anos do pós-guerra, segundo a professora Yvonne Mascarenhas. Até então, as renomadas escolas de engenharia eram a Politécnica da Universidade de São Paulo, O Colégio Mackenzie e a Faculdade de Engenharia Industrial (FEI) (NOSELLA e BUFFA, 2000).

Criou-se então, em 1948, a Escola de Engenharia de São Carlos-EESC pela Lei Estadual n¹61, de 24/09/1948, como uma Faculdade da Universidade de São Paulo - USP. Enquanto eram construídas as instalações para o funcionamento da Faculdade, a Escola foi instalada provisoriamente na Casa D'Itália, da Sociedade Dante Alighieri. O curso iniciou-se em 1953, após os Concursos de Habilitação, hoje chamados de Exames Vestibulares. Os professores dos primeiros anos de funcionamento, alguns deles, estrangeiros vieram de importantes instituições da Itália, França, Alemanha, EUA, e eram respeitados e admirados. A USP tinha como prática convidar professores de fora do país para lecionar em seus cursos, e a EESC fez o mesmo. Os professores brasileiros criaram laboratórios de fama internacional. Todo esse corpo docente consolidou o prestígio da Escola.

O terreno para a construção da EESC foi doado pelo então Prefeito Municipal, Sr. Antonio Massei, uma grande área urbana, de propriedade da Prefeitura, na qual funcionava o Posto Zootécnico. O Campus de São Carlos passou a ocupar a área atual, de $321.457 \mathrm{~m}^{2}$ (NOSELLA e BUFFA, 2000). 


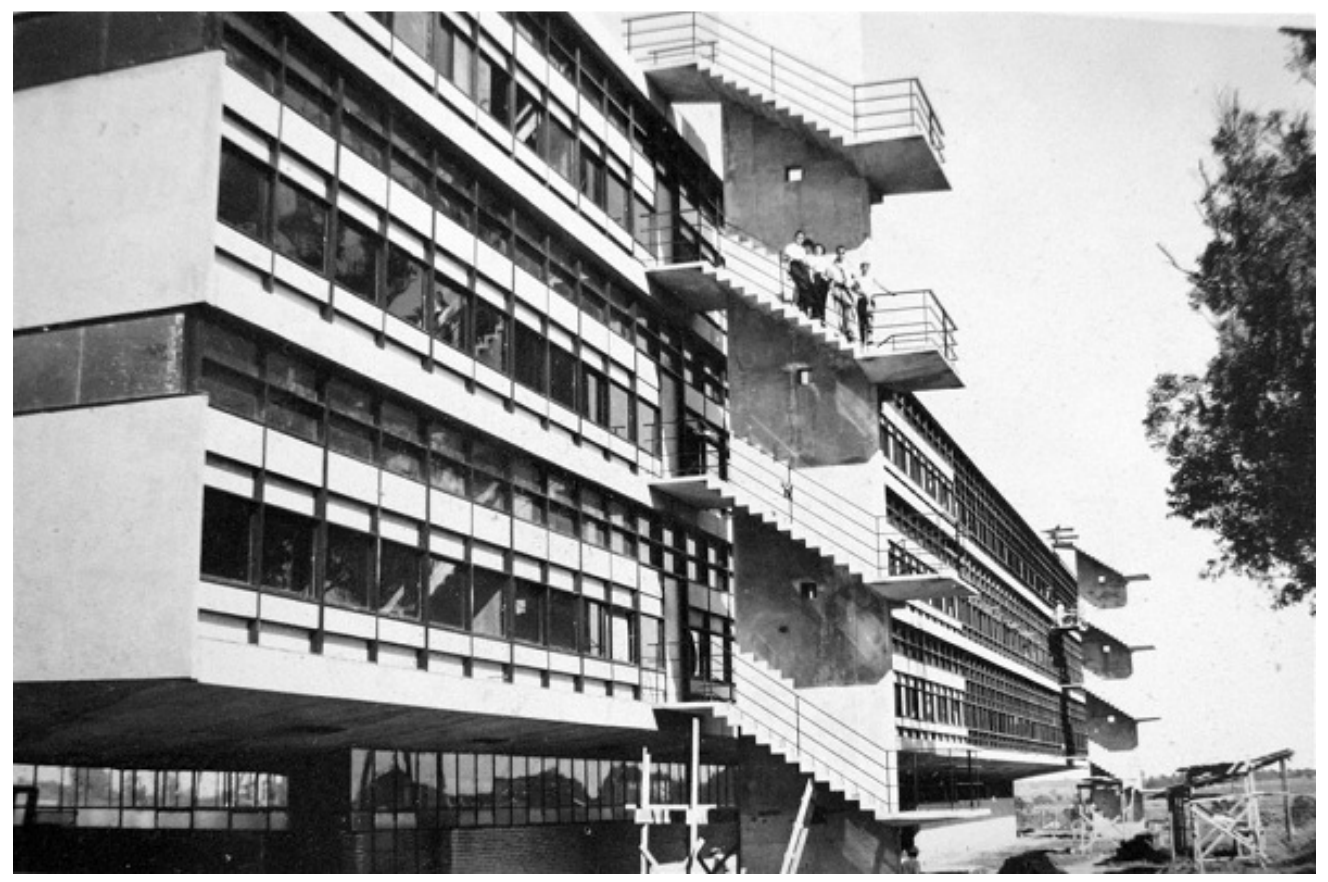

Figura 2. Primeiro Edifício Construído na EESC - E1.

A EESC viveu e discutiu as questões estudantis, políticas e sociais que marcaram o Brasil, inclusive o Golpe de Estado Militar que marcaram essa década. Citações dos jornais que noticiam as lutas dos estudantes, através inclusive das greves. As reivindicações, depois do Golpe, passam de acadêmicas para políticas. No final da década de 1960, as manifestações foram de caráter ideológico contra o chamado imperialismo norte-americano (FORESTI, 2003).

Na década de 1970, a diversificação e o crescimento das atividades da Escola de Engenharia se multiplicaram, resultando em um transbordamento da divisão de então. Isso levou à criação de novas unidades de ensino: o Instituto de Ciências Matemáticas e Computação de São Carlos - ICMSC e o Instituto de Física e Química de São Carlos - IFQSC. Mais tarde, em 1994, o IFQSC se divide, resultando na criação do Instituto de Física de São Carlos - IFSC e do Instituto de Química de São Carlos - IQSC. Já no ano de 1998, o ICMSC, muda de nome e 
passa a ser chamado de Instituto de Ciências Matemáticas e de Computação ICMC (ALTAFIM e SILVA, 2004).

Em 1985, foi implantado o Curso de Arquitetura, atual Curso de Arquitetura e Urbanismo e, no ano de 2002, teve início o Curso de Engenharia Aeronáutica. Em 2003 foram criados os Cursos de Engenharia Ambiental, Engenharia Mecatrônica, Engenharia de Computação e Engenharia Elétrica/Sistemas de Energia e Automação.

Compõe a Escola atualmente uma população de 8.023 pessoas entre alunos de graduação e Pós-Graduação, professores e funcionários. A cidade de São Carlos é conhecida como o berço dos doutores, possuindo a maior relação de doutores por $\mathrm{km}^{2}$ do país e a terceira maior do mundo. A cidade São Carlos é considerada uma ilha de excelência tecnológica no estado de São Paulo, envolta por dezenas de pequenas empresas que desenvolvem tecnologia de ponta, muitas delas com resultados pioneiros.

O Campus II, fundado em 2002, uma área com 102,4 hectares, apresentou-se como uma solução para o entrave que limitava o crescimento da Escola de Engenharia da USP em São Carlos. O objetivo se sua criação é nuclear nova iniciativa de ensino e pesquisa que representem não apenas um aumento no número de vagas de graduação, mas privilegiem carreiras e abordagens inovadoras, atendendo assim as demandas da sociedade para um mercado de trabalho novo e de alta tecnologia, prevendo inclusive uma maior aproximação com os setores industrial, médico-hospitalar e produtivo (ALTAFIM e SILVA, 2004). 


\subsection{HISTÓRIAS DA BIOENGENHARIA NA ESCOLA DE ENGENHARIA DE SÃO CARLOS.}

Aprovado em novembro de 1977, estava em funcionamento o curso de PósGraduação na área de concentração em Bioengenharia, cuja coordenação inicial se deu pela participação conjunta entre a Escola de Engenharia de São Carlos- EESC, Faculdade de Medicina de Ribeirão Preto- FMRP, e pelos Institutos de Física e Química- IFQSC e de Ciências Matemáticas- ICM, de São Carlos.

O referido curso de Pós-Graduação admitiu como candidatos os graduados em engenharia, ciências exatas, medicina e ciências biológicas. No primeiro semestre os candidatos inscritos deveriam cursar disciplinas de adaptação, sem direito a crédito, a fim de adquirirem linguagem unificada. Os engenheiros fizeram adaptação no campus de Ribeirão Preto, em disciplinas como Anatomia, Fisiologia, Histologia, Neurologia e Ortopedia e também no Campus de São Carlos. Os médicos fizeram adaptação em disciplinas como Mecânica, Cálculo, Eletricidade, Resistência e Propriedades dos Materiais. Após estes períodos de adaptação, foi exigida então, a aprovação em exame de seleção para a efetivação da matrícula no curso, que teve inicio em primeiro de agosto de 1978.

As matrículas nas várias disciplinas foram feitas de comum acordo com os orientadores, os quais tinham a responsabilidade direta de acompanhar os trabalhos dos discentes em seminários, participação nos laboratórios, andamento de pesquisas e elaboração das dissertações, atribuindo créditos a cada atividade, permitindo assim uma avaliação mais precisa no rendimento de cada aluno.

A linha de pesquisa da área do curso de Pós-Graduação em bioengenharia iniciou-se voltada para a ortopedia, com a colaboração constante do Hospital de 
Clinicas da Faculdade de Medicina de Ribeirão Preto e contou também com a participação semestral de professores visitantes.

A área já desenvolveu pesquisas no campo da ortopedia, realizadas pelo professor Dr. Luiz Romariz Duarte, do Departamento de Materiais da Escola de Engenharia de São Carlos, destacando-se: terapia de fraturas ósseas pelo ultrassom, osteotomia com bisturi ultra-sônico, fixação de próteses fêmurais no canal medular por meio de revestimento cerâmico em peças metálicas e a investigação de novas ligas metálicas resistentes a fadiga e a corrosão.

Desta forma, não poderíamos deixar de falar do nosso sincero agradecimento ao professor Titular Luiz Romariz Duarte, pessoa responsável pela coordenação do projeto de criação do curso Interunidades "Bioengenharia" no ano de 1977. Ele também foi coordenador do Programa até o ano 1998, tendo como principal linha de pesquisa a Estimulação de crescimento de tecidos com ultra-som de baixa intensidade. A criação desta linha de pesquisa possibilitou a união entre a Escola de Engenharia de São Carlos, o Instituto de Física e Química de São Carlos, o Instituto de Ciências Matemáticas de São Carlos e a Faculdade de Medicina de Ribeirão Preto. 


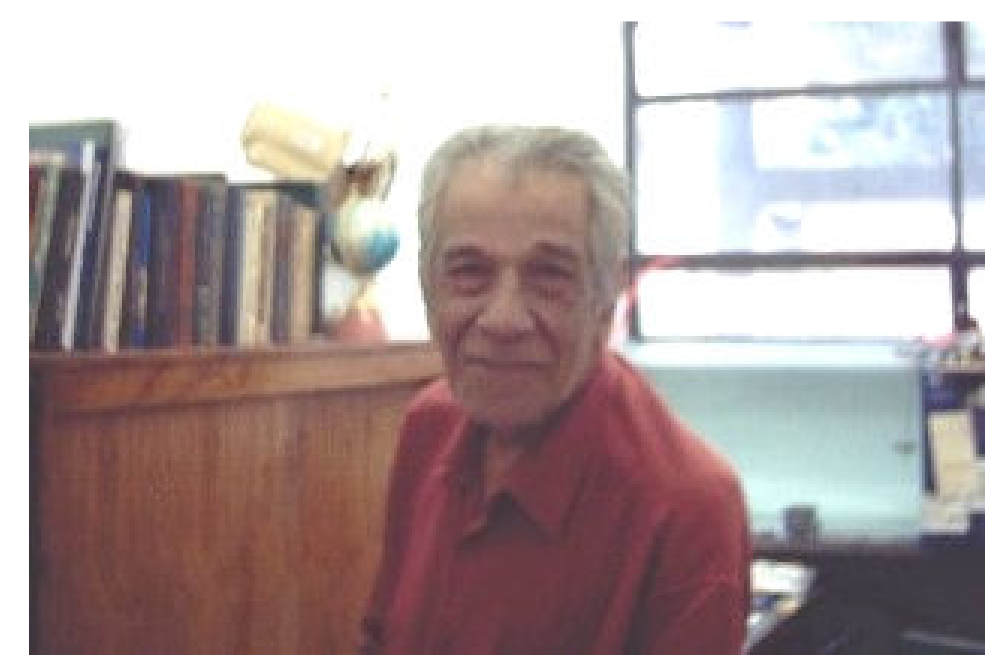

Figura 3. Professor Titular Luiz Romariz Duarte

(Fonte: PPGIB- EESC IQSC-FMRP-USP).

\subsection{LINHAS DE PESQUISA DO PROGRAMA DE PÓS-GRADUAÇÃO INTERUNIDADES BIOENGENHARIA: período inicial.}

A linha de pesquisa já consagradas em nosso meio em 1977, na área de concentração em Bioengenharia é a área da ortopedia. A Bioengenharia era um setor muito recente e, conseqüentemente, com pequena produção cientifica, em termos de trabalhos completos. No Estado de São Paulo, como no resto do País existiam poucos grupos desenvolvendo atividades em bioengenharia ou pesquisa nas Universidades Estaduais, limitando grandemente a formação de recursos humanos na área. Por esta razão, era freqüente a realização de trabalhos por iniciativas individuais, sem continuidade e profundidade desejada (Ciência e Tecnologia no Estado de São Paulo, 1981). 


\subsection{LINHAS DE PESQUISA DO PROGRAMA DE POS-GRADUAÇÃO INTERUNIDADES BIOENGENHARIA: período atual.}

Atualmente o programa de Pós-Graduação desenvolve pesquisas na área de concentração: Bioengenharia com as linhas de pesquisa que foram sendo ao longo dos anos sendo incluídas no programa: Biomecânica- estudo dos problemas com implicações de natureza mecânica relacionadas ao aparelho locomotor sejam eles intrínsecos ou resultantes da aplicação de sistemas auxiliares ou complementares à atividade física. Biomateriais- estudo de materiais biológicos como o osso ou materiais artificiais que se destinam à implantação no meio biológico para substituir as funções de um material biológico. Considera-se biomaterial a substituição funcional de um tecido ou órgão do corpo. Interação de Agentes Físicos com Sistemas Biológicos- acredita-se que os agentes físicos exógenos participem da regulação de forma e função dos tecidos biológicos, afetando remodelamento, metabolismo, reparo e crescimento. Tecnologias Clínicas e de Reabilitaçãodesenvolve pesquisas básicas e aplicadas, envolvendo profissionais de diversas áreas de tecnologia da saúde, em trabalhos multidisciplinares nas áreas de Engenharia Clínica e Informática em Saúde, além de Inovação Tecnológica Assistiva

e Recursos Terapêuticos. Fonoengenharia- Relaciona a qualidade vocal com as características fisiológicas do aparelho fonador (PPGIB-2013). 


\subsection{DISSERTAÇÕES DO PROGRAMA PÓS-GRADUAÇÃO INTERUNIDADES BIOENGENHARIA EESC-IQSC-FMRP-USP 1980 A 2012.}

Gráfico 1: Total de dissertações ao longo do período pesquisado

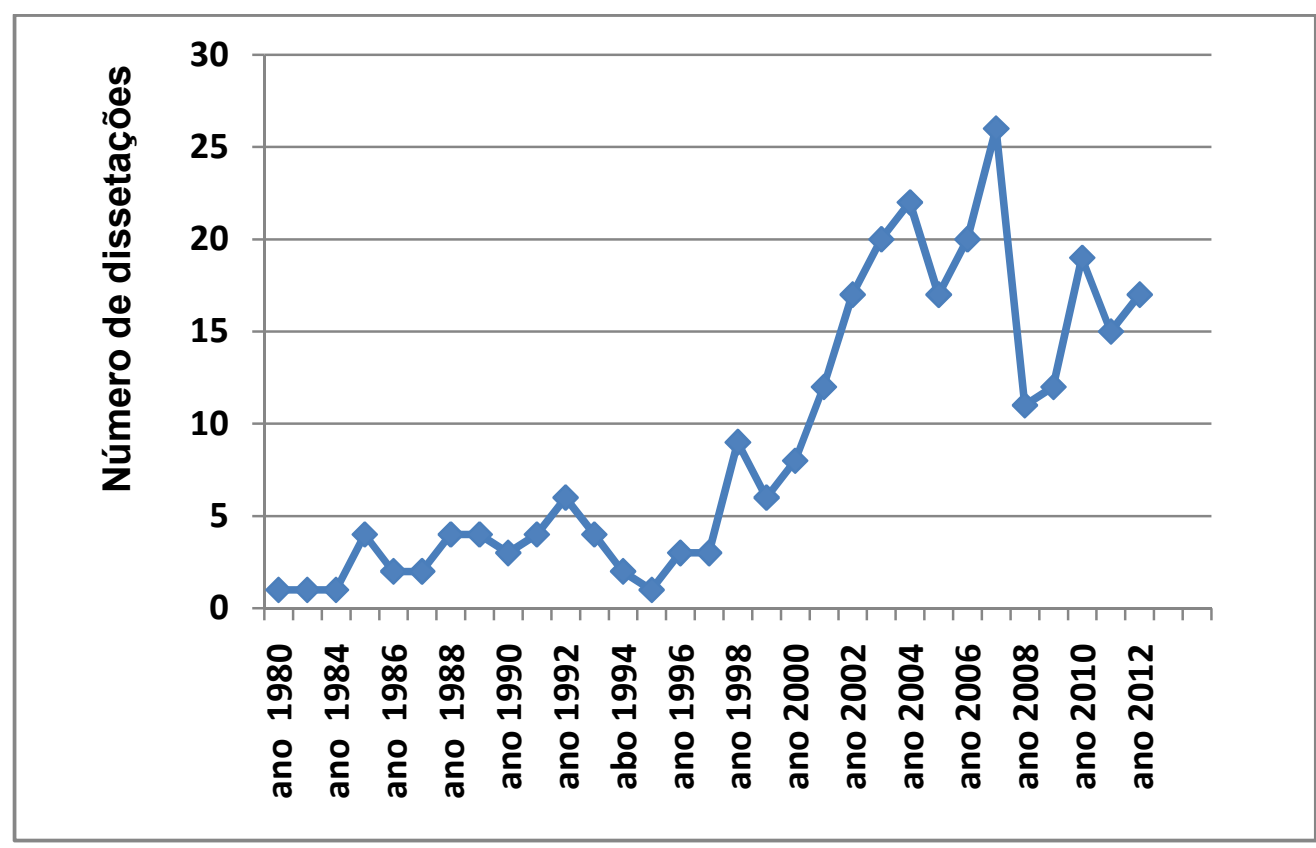

Fonte: Pesquisa com Egressos 2013- PPGIB-EESC-IQSC-FMRP-USP

O PPGIB iniciou suas atividades com a primeira dissertação no ano de 1980 e alcançou o numero máximo de dissertações no ano de 2006.

\section{PÓS-GRADUAÇÃO NO BRASIL}

As primeiras experiências de estudos de Pós-Graduação no Brasil constituíram-se em iniciativas de dimensões limitadas. Professores estrangeiros que aqui aportavam, seja como membros de missões acadêmicas ou foragidos da Segunda Guerra Mundial, estabeleceram o primeiro núcleo institucional para os estudos pós-graduados. Balbachevsky (2005) lembra que o elemento central desse modelo era a relação tutorial que se estabelecia entre o professor catedrático [brasileiro ou não] e o pequeno numero de discípulos, os quais também atuavam 
como auxiliares do professor nas atividades de ensino e pesquisa. Como se sabe, o Estatuto das Universidades Brasileiras, de 1931 - que vigorou até a promulgação da Lei 5.540, de 1968 - estabelecia o sistema de cátedra e a pesquisa e o ensino eram, prioritariamente, tarefas do professor catedrático, o qual era agraciado com contrato de dedicação integral (Fávero, 1999 e Moraes, 2002).

\section{PRODUÇÃO E APLICAÇÕES DA ENGENHARIA BIOMÉDICA E BIOENGENHARIA NO BRASIL}

\subsection{MAPEAMENTO DA ENGENHARIA BIOMÉDICA E BIOENGENHARIA NO BRASIL}

O desenvolvimento de pesquisas no Brasil mostra como a Engenharia Biomédica/ Bioengenharia evoluiu no país e como ela vem se tornando um diferencial na qualidade da prestação de serviços de saúde para todo o mundo, através dos Núcleos, Grupos, Cursos Extensão e Cursos de Graduação, PósGraduação, Mestrado Profissionalizante (SBEB, 2013)

Abaixo se encontra descrita a situação por estado brasileiro, referente à engenharia biomédica/ bioengenharia.

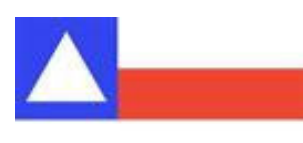

\section{Bahia}

Salvador - início em 2012 do Núcleo de Pesquisa- Parque Tecnológico da Bahia- Plataforma de Pesquisa e Inovação em Bioengenharia- Laboratórios de Bioengenharia e Biomecânica. 


\section{Distrito Federal}

Brasília - Engenharia Biomédica Pós-Graduação em nível de mestrado Universidade de Brasília-UNB Gama.

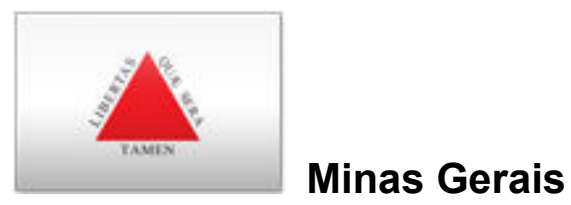

Belo Horizonte - Iniciou em 2010 o Curso de graduação em Engenharia Biomédica - Fundação Mineira de Educação e Cultura-FUMEC/FEA.

Belo Horizonte - iniciou 2008, junto ao Programa de Pós-Graduação em Engenharia Elétrica - PPGEE o Núcleo de Estudos e Pesquisa em Engenharia Biomédica - NEPEB, da Universidade Federal de Minas Gerais - UFMG.

Itajubá - cursos de especialização em Engenharia Clínica. Grupo de Pesquisa em Engenharia Biomédica - GEB - do Instituto de Engenharia de Sistemas e Tecnologia de Informação - IESTI- Universidade Federal de Itajubá UNIFEI. do Instituto de Engenharia de Sistemas e Tecnologia de Informação - IESTIUniversidade Federal de Itajubá UNIFEI.

Montes Claros - curso de graduação em Engenharia Biomédica- 2007Faculdades Integradas do Norte de Minas - FUNORTE.

São João Del Rei -iniciou em 2008, mestrado e doutorado Departamento de Engenharia Biomédica- DEB e no Departamento de Engenharia de BiossistemasDEPEB, da Universidade de São João Del Rei - USJ/ Programa institucional em Bioengenharia - Campus Sete Lagoas.

Uberlândia - iniciou em 2006, o curso de graduação em Engenharia Biomédica - Universidade Federal de Uberlândia- UFU. 
Uberlândia - iniciou suas atividades em pesquisa de instrumentação biomédica, no Biolab em 1997, sediado na Faculdade de Engenharia Elétrica FEELT. Programa de Pós-Graduação em Engenharia Biomédica - PPGEB nível mestrado - Universidade Federal de Uberlândia - UFU.

Santa Rita do Sapucaí- Curso de extensão presencial em engenharia biomédica- Instituto Nacional de Telecomunicações- INATEL.

NEGO

Paraíba

João Pessoa - em 2007 foi desativado, o Núcleo Estudos e Tecnologia em Engenharia Biomédica e Instrumentação Biomédica e Eletrônica - NETEBUniversidade Federal da Paraíba - UFPB.

João Pessoa - iniciou e 2005, o Núcleo de pesquisa em materiais biomédicos, no Programa de Pós Graduação em Engenharia MecânicaUniversidade Federal da Paraíba - UFPB.

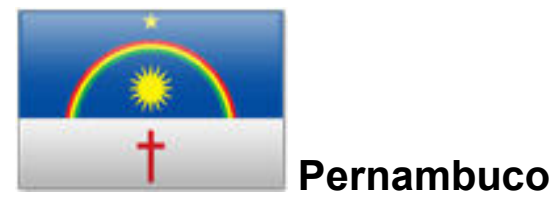

Recife - iniciou em 2002, a graduação em Engenharia BiomédicaUniversidade Federal de Pernambuco - UFPE.

Recife - iniciou em 1974, o núcleo de pesquisa. Departamento de Biofísica e Radiologia - DBR- Universidade Federal de Pernambuco- UFPE.

Recife - iniciou em 2004, o núcleo de pesquisa - Departamento de Engenharia Nuclear/Grupo de Dosimetria e Instrumentação Nuclear DENUniversidade Federal de Pernambuco - UFPE. 
Recife - iniciou em 2008, o núcleo de pesquisa - Departamento de Eletrônica e Sistemas /Grupo de Fotônica- Universidade Federal de Pernambuco - UFPE.

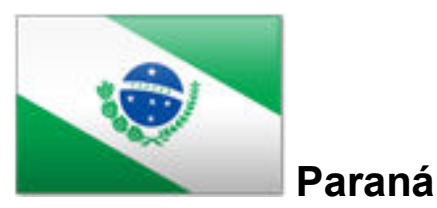

Curitiba - núcleo de Pesquisa no Programa de Pós-Graduação em Engenharia Elétrica e Informática Industrial CPGEI - Universidade Tecnológica Federal do Paraná - UTFPR.

Curitiba - programa de Pós- Graduação em Engenharia Biomédicamestrado profissional- Universidade Tecnológica Federal do Paraná - UFTPR.

Curitiba - núcleo de Pesquisa no Programa de Pós- Graduação em Tecnologia em Saúde - PPGTS- Programa Interdisciplinar- Pontifícia Universidade Católica - PUC-PR.

Londrina - núcleo de pesquisa no Centro de Ciências Exatas/Departamento de Física- Universidade Estadual de Londrina - UEL.

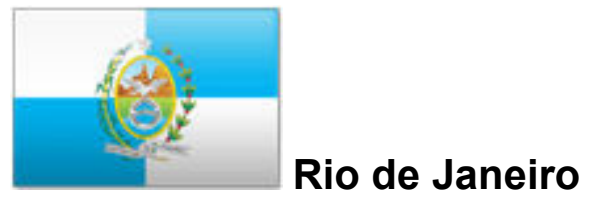

Duque de Caxias - Xerém - Laboratório de Ultra-som / Diavi / Dimci /Inmetro Laboratório de Ultra-som - LABUS - Divisão de Metrologia Acústica e de Vibrações - DIAVI - Diretoria de Metrologia Cientifica e Industrial - DIMCI / Instituto Nacional de Metrologia, Normalização e Qualidade Industrial - INMETRO.

Niterói - iniciou em 1998, o núcleo de Pesquisa em Ciência da Computação - Instituto de Computação- IC- Universidade Federal Fluminense - UFF. 
Rio de Janeiro - iniciou em 1900, a Instituição de Pesquisa- Fundação Osvaldo Cruz - FIOCRUZ.

Rio de Janeiro - iniciou em 1980 uma Instituição não UniversitáriaDepartamento de Pesquisa do Instituto Nacional Fernandes Figueira - IFF. FIOCRUZ.

Rio de Janeiro - iniciou em 2003, Estudos de Instrumentação BiomédicaLaboratório de Biometrologia- Pontifícia Universidade Católica - PUC/RJ.

Rio de Janeiro - Instituto de Pesquisa Biomédica Gonzaga de Gama FilhoLEB- Universidade Gama Filho- UGF.

Rio de Janeiro - iniciou em 2011, o Laboratório Médico de Pesquisas Avançadas LAMPADA- Universidade do Estado do Rio de Janeiro - UERJ.

Rio de Janeiro - iniciou em 1970, o Programa de Engenharia Biomédica PEB- Coordenação dos Programas de Pós-Graduação em Engenharia- COPPE- em 1981, a curso mestrado, e em 1995, o curso doutorado - Universidade Federal do Rio de Janeiro - UFRJ. A partir de 2001 passou a ministrar disciplinas na graduação em Física Médica. Oferece disciplina de Engenharia Biomédica (COB502) aberta a todos os cursos de Engenharia da POLI/UFRJ.

Rio de Janeiro -- iniciou a Graduação em Engenharia Biomédica Faculdade Estácio de Sá.

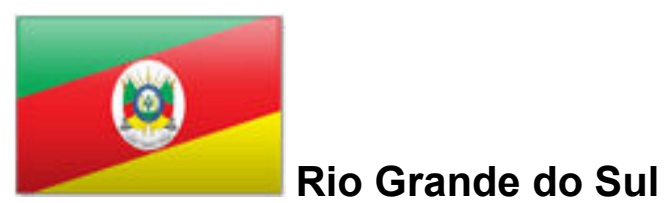

Caxias do Sul - Centro de Engenharia Biomédica - CEB do Hospital Geral 
Passo Fundo - Centro de Engenharia Biomédica - CEB do Hospital São Vicente de Paula- HSVP

ljuí - Centro de Engenharia Biomédica - CEB do Hospital Caridade.

Pelotas - Laboratório de Engenharia Biomédica- LEB- vinculado ao curso Engenharia Elétrica e ao Centro Universitário Católico de Pelotas criado em 1987, como Grupo de Pesquisa e Desenvolvimento em Instrumentação Biomédica GPDIB- Universidade Católica de Pelotas-UCPel.

Porto Alegre - iniciou o Programa Pós-Graduação Engenharia Elétrica, nos anos 80. O curso de mestrado em Engenharia Elétrica iniciou atividades em 1993, na linha de pesquisa em Engenharia Biomédica- DEB- Pontifícia Universidade Católica- PUC/RS.

Porto Alegre - Laboratório de Instrumentação Eletrônica - IEE/ Programa de Pós-Graduação em Engenharia Elétrica - PPGEE- Universidade Federal do Rio Grande do Sul-UFRGS.

Porto Alegre - Núcleo de Pesquisa em Imagens Médicas - NIMED Pontifícia Universidade Católica - PUC/RS.

Porto Alegre- iniciou em 2000, o Programa de Pós- Graduação em Gerontologia Biomédica, Pontifícia Universidade Católica - PUC/RS.

Santa Maria - iniciou em 2010, o curso de graduação em Engenharia Biomédica -Centro Universitário Franciscano - UNIFRA.

Vacaria - Centro de Engenharia Biomédica no Hospital Nossa Senhora da Oliveira. 


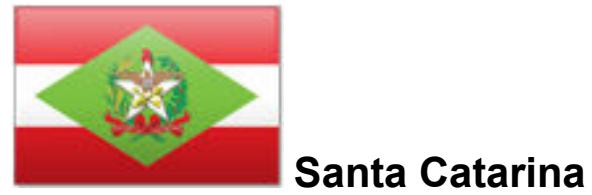

Florianópolis - iniciou em 1974, em parceria com o Grupo de Pesquisa em Engenharia Biomédica- GPEB, o Departamento de Engenharia Elétrica - Instituto Engenharia Biomédica - IEB - criaram em 2008, o Laboratório de Engenharia Biomédica -LEEB.

Florianópolis - Pós-Graduação em Engenharia Elétrica- PGEEL Universidade Federal de Santa Catarina-UFSC.

Florianópolis - Laboratório de Pesquisa em Processamento Digital de Sinais- Universidade Federal de Santa Catarina-UFSC.

Joinville - Grupo de Pesquisa em Engenharia Biomédica - GPEB Departamento de Engenharia Elétrica- Universidade do Estado de Santa Catarina UDESC.

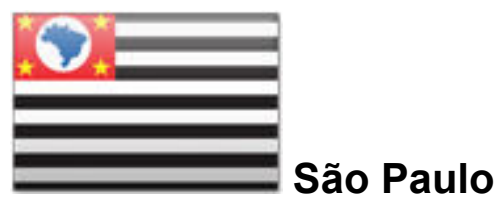

Campinas - Departamento de Engenharia Biomédica- DEB- Faculdade de Engenharia Elétrica e Computação- FEEC- Universidade de Campinas- UNICAMP.

Campinas - iniciou em 1982, o Centro de Engenharia Biomédica- CEBUniversidade de Campinas- UNICAMP.

Mogi das Cruzes - Programa Integrado de Pós-Graduação em Engenharia Biomédica- mestrado e doutorado- Universidade Mogi das Cruzes - UMC.

Ribeirão Preto - Laboratório de Bioengenharia. Faculdade de Medicina de Ribeirão Preto- FMRP- Universidade de São Paulo-USP. 
São Carlos - iniciou em 2012, o Centro de Engenharia Aplicada a Saúde Escola de Engenharia São Carlos-EESC- Universidade de São Paulo - USP.

São Carlos- iniciou em 1977, o Programa de Pós Graduação Interunidades em Bioengenharia- Escola de Engenharia de São Carlos -EESC- Faculdade de Medicina de Ribeirão Preto- FMRP - Instituto de Física e Química de São Carlos IFQSC- Instituto de Ciências Matemáticas - ICM - Universidade de São Paulo-USP; o curso de mestrado. Atualmente, fazem parte do Programa de Pós-Graduação Interunidades a EESC- IQSC-FMRP- Universidade de São Paulo-USP. Em 2009, teve inicio o curso de doutorado.

São Carlos - Núcleo de pesquisa em Bioengenharia- Laboratório do Departamento de Engenharia Elétrica -Escola de Engenharia de São Carlos-EESC/ Universidade de São Paulo-USP.

São Carlos - Núcleo de pesquisas em bioengenharia-Instituto de Física de São Carlos- IFSC -Escola de Engenharia de São Carlos-EESC/ Universidade de São Paulo-USP.

São José dos Campos - iniciou o Programa de Pós-Graduação em Engenharia Biomédica, curso mestrado em 1998 e em 2003 o curso doutoradoUniversidade Camilo Castelo Branco - UNICASTELO.

São José dos Campos - iniciou em 2001, o Programa de Pós-Graduação em Bioengenharia- mestrado profissionalizante - Universidade Camilo Castelo Branco - UNICASTELO.

São José dos Campos - iniciou em 1998 o curso de mestrado e em 2002 o curso de doutorado- Grupo de pesquisa em Engenharia Biomédica - IPDUniversidade do Vale do Paraíba- UNIVAP.

São José dos Campos - Programa de Pós- Graduação em Bioengenhariamestrado Profissional- IPD/Universidade do Vale do Paraíba- UNIVAP. 
São José dos Campos -- Centro de Pesquisa em Engenharia BiomédicaIPD/Universidade do Vale do Paraíba- UNIVAP.

São José dos Campos - Iniciou curso de graduação em Engenharia Biomédica- Universidade do Vale do Paraíba - UNIVAP.

São José dos Campos - Graduação em Engenharia Biomédica-Escola Paulista de Medicina -EPM- Universidade Federal de São Paulo- UNIFESP.

São Paulo - Núcleo de Pesquisa. Centro de Estudos em Informática em Saúde CIS - Escola Paulista de Medicina - EPM- Universidade Federal de São PAULO- UNIFESP.

São Paulo - iniciou em 1995, o Laboratório de Ensaio de Equipamentos Biomédicos - atual Instituto de Energia e Ambiente- IEA - Universidade de São Paulo- USP.

São Paulo - iniciou em 1950, o Núcleo de Pesquisa Oficina CoraçãoPulmão- atualmente Centro Pesquisa Engenharia Biomédica- CPEB- Divisão de Bioengenharia INCOR.

São Paulo- Iniciou em 1977, o Instituto Nacional do Coração- INCOR. Universidade de São Paulo-USP.

São Paulo - iniciou em 1960, o Centro de Bioengenharia do Instituto Dante Pazzanesi de Cardiologia.

São Paulo- iniciou em 1944, a Oficina de Ortopedia do Hospital de Clínicas da Faculdade de Medicina da USP. Em 1977 foi criado, o Laboratório de Biomecânica do Aparelho Locomotor, que integra o conjunto de Laboratórios de Investigação Médica do Hospital das Clínicas. Em 1990 recebe nova denominação, passando então a se chamar Instituto de Ortopedia e Traumatologia "Prof. Francisco 
Elias de Godoy Moreira". Em 2006, inaugurado o Laboratório de Bioengenharia e Tecnologia Assistiva.

São Paulo - iniciou em 1981, o Laboratório de Engenharia Biomédica e em 1994, o Laboratório de Engenharia Ambiental e Biomédica- LEB- Escola Politécnica- Universidade de São Paulo-USP.

São Paulo- iniciou em 1968, o núcleo de pesquisa- Instituto de Ciências Biomédicas- ICB da Universidade de São Paulo-USP.

São Paulo - iniciou em 2008, a graduação em Engenharia Biomédica Pontifícia Universidade Católica - PUC/SP.

São Paulo - iniciou em 2012, a Pós-Graduação em Engenharia Biomédicamestrado 2012- Pontifícia Universidade Católica - PUC/SP.

Santo André - iniciou em 2009, a graduação em Engenharia Biomédica Universidade Federal do ABC-UFABC.

\section{MÉTODO}

\subsection{ASPECTOS ÉTICOS}

Esta pesquisa foi aprovada pelo Comitê de Ética em Pesquisa, do Centro de Saúde Escola da Faculdade de Medicina de Ribeirão Preto da Universidade de São Paulo-CEP/CSE-FMRP-USP, (CAAE: 16327513.2.0000.5414). 


\subsection{PARTICIPANTES}

Foram sujeitos desta pesquisa os egressos que concluíram o curso de Mestrado do Programa de Pós-Graduação Interunidades em Bioengenharia da Escola de Engenharia de São Carlos Faculdade de Medicina de Ribeirão Preto e Instituto de Química de São Carlos, no período de 1980 a 2012, foram entrevistados 276 egressos, sendo que quatro haviam falecido, totalizando então 272 participantes da pesquisa

\subsection{PROCEDIMENTOS PARA A COLETA DE DADOS.}

Inicialmente, os egressos foram contatados via email ou telefone. Após aceitarem participar do trabalho, os questionários foram então, enviados por email.

Para a coleta de dados foi elaborado um questionário padronizado com questões fechadas e abertas, que incluíam a formação acadêmica (graduação, especialização e Pós-Graduação); a atividade profissional (em ensino superior, setor público e setor privado); a produção científica (publicação de artigos em revistas nacionais e estrangeiras, livros, capítulos de livros e realização de pesquisas); a opinião do egresso sobre o curso (disciplinas, professores, orientador, bolsa, dificuldades e objetivos) e o mercado de trabalho (objetivos posteriores ao término do curso mestrado, atual ocupação no mercado de trabalho, como ingressou no emprego, quantas vezes mudou de emprego, salário, condições de trabalho, prestigio, atividades desempenhadas, estabilidade, aptidão para o mercado de trabalho).

Os resultados foram transferidos para um banco de dados, no Microsoft Office Excel. As respostas dadas pelos participantes foram analisadas de acordo com a 
sua natureza. Para as questões fechadas, foram calculadas as freqüências das respostas em cada categoria.

\subsection{INSTRUMENTO PARA A COLETA DE DADOS.}

Para coletar os dados requeridos junto aos egressos, o procedimento escolhido foi o questionário. Este trabalho baseou-se na metodologia utilizada pela professora Dra. Maria Immacolata Vassallo de Lopes, em seu trabalho intitulado "Mercado de Trabalho dos Egressos dos Cursos de Comunicação Social no Brasil", apresentado como Tese de Livre-Docente, junto o Departamento de Comunicação e Artes da Escola de Comunicação e Artes da Universidade de São Paulo. Essa mesma pesquisadora desenvolveu um método de avaliação e a construção de um banco de dados para uma pesquisa nacional de diagnostico e avaliação (LOPES, 1998).

O questionário utilizado no presente trabalho foi preparado, tanto com questões fechadas e de escala, quanto com questões abertas, constituindo uma pesquisa estruturada, na qual os dados foram obtidos sem identificação do participante. O questionário continha 51 questões, sendo 40 fechadas e 11 abertas.

As questões foram organizadas em quatro módulos: 1) perfil dos egressos; 2) perfil educacional e avaliação do curso feito (mestre em Ciência: área Bioengenharia); 3) perfil ocupacional; 4) mercado de trabalho.

\subsection{PERFIL DOS EGRESSOS.}

Este módulo trata de indicadores simples, tais como a caracterização do ensino médio, curso de graduação, dados pessoais (formação geral, motivação, 
adequação da pesquisa, adequação da orientação, contribuição para a formação profissional, avaliação feita pelo egresso).

\subsection{PERFIL DO MESTRE EM CIÊNCIA: ÁREA BIOENGENHARIA.}

Este módulo apresenta indicadores de desempenho, como o tempo de permanência no curso, a escolha do mesmo, aspectos positivos e negativos do curso, publicações.

\subsection{PERFIL OCUPACIONAL.}

Neste modulo encontram-se alguns dos indicadores mais importantes da pesquisa, aqueles que dizem respeito às publicações, patentes, livros, preparo para formação profissional, carreira docente, etc.

\subsection{MERCADO DE TRABALHO.}

Neste módulo encontram-se alguns indicadores que dizem respeito ao mercado de trabalho: objetivos posteriores ao término do curso mestrado, atual ocupação no mercado de trabalho, como ingressou no emprego, quantas vezes mudou de emprego, salário, condições de trabalho, prestígio, atividades desempenhadas, estabilidade, aptidão para o mercado de trabalho. 


\section{RESULTADOS e DISCUSSÃO}

Com relação a idade dos egressos entrevistados, observa-se no Gráfico 2 que a maioria dos egressos nasceu no final da década de 1970 e início da década de 1980 e a minoria nasceu na década de 1940 a 1950.

Gráfico 2: Ano de nascimento dos egressos.

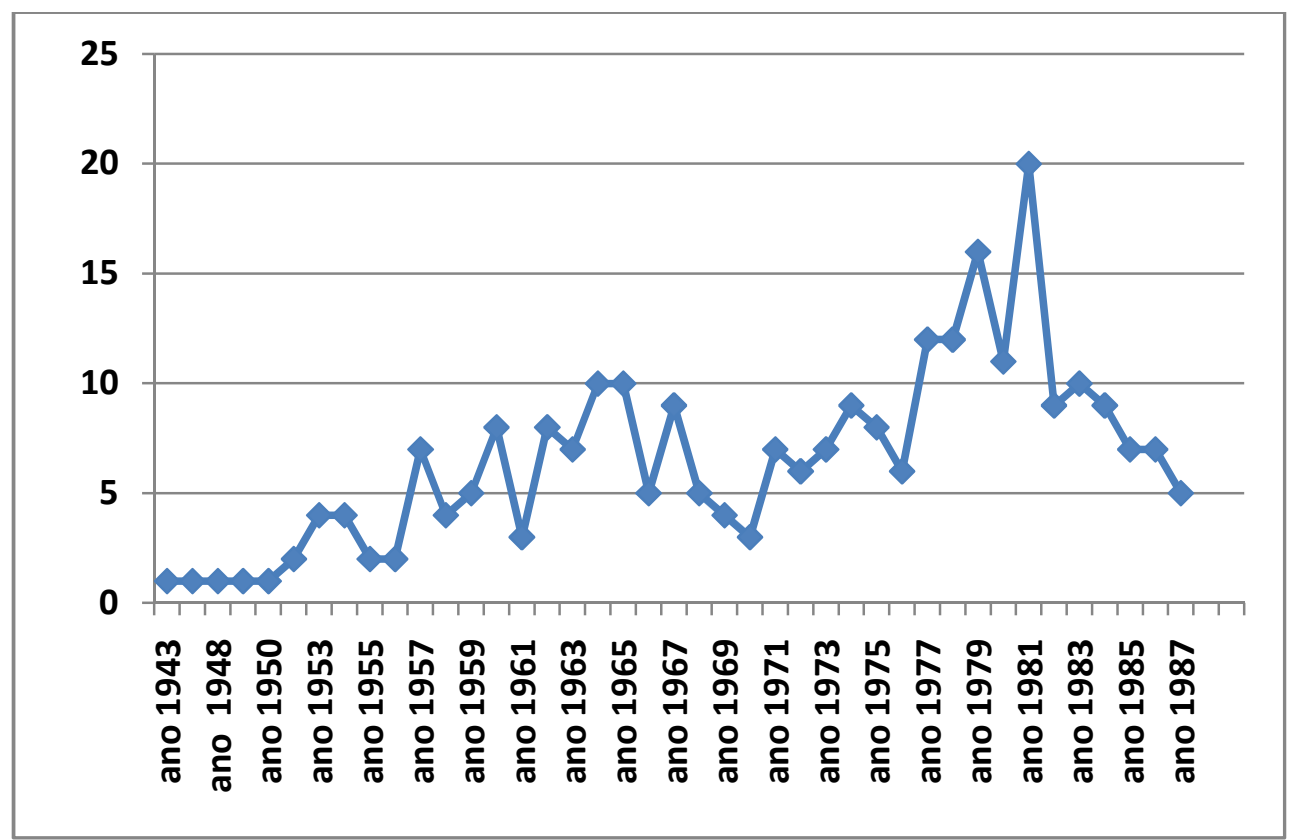

Fonte: Pesquisa com Egressos 2013- PPGIB-EESC-IQSC-FMRP- USP

Esses egressos tiveram diferentes formações na graduação como pode ser observado no Gráfico 3. O curso de fisioterapia predomina na formação dos entrevistados, seguidos de odontologia e fonoaudiologia. Observa-se também que a procura pela pós- graduação em bioengenharia é feita por diferentes profissionais seja eles da área de exatas ou biológicas. 
Gráfico 3: Formação dos egressos na graduação

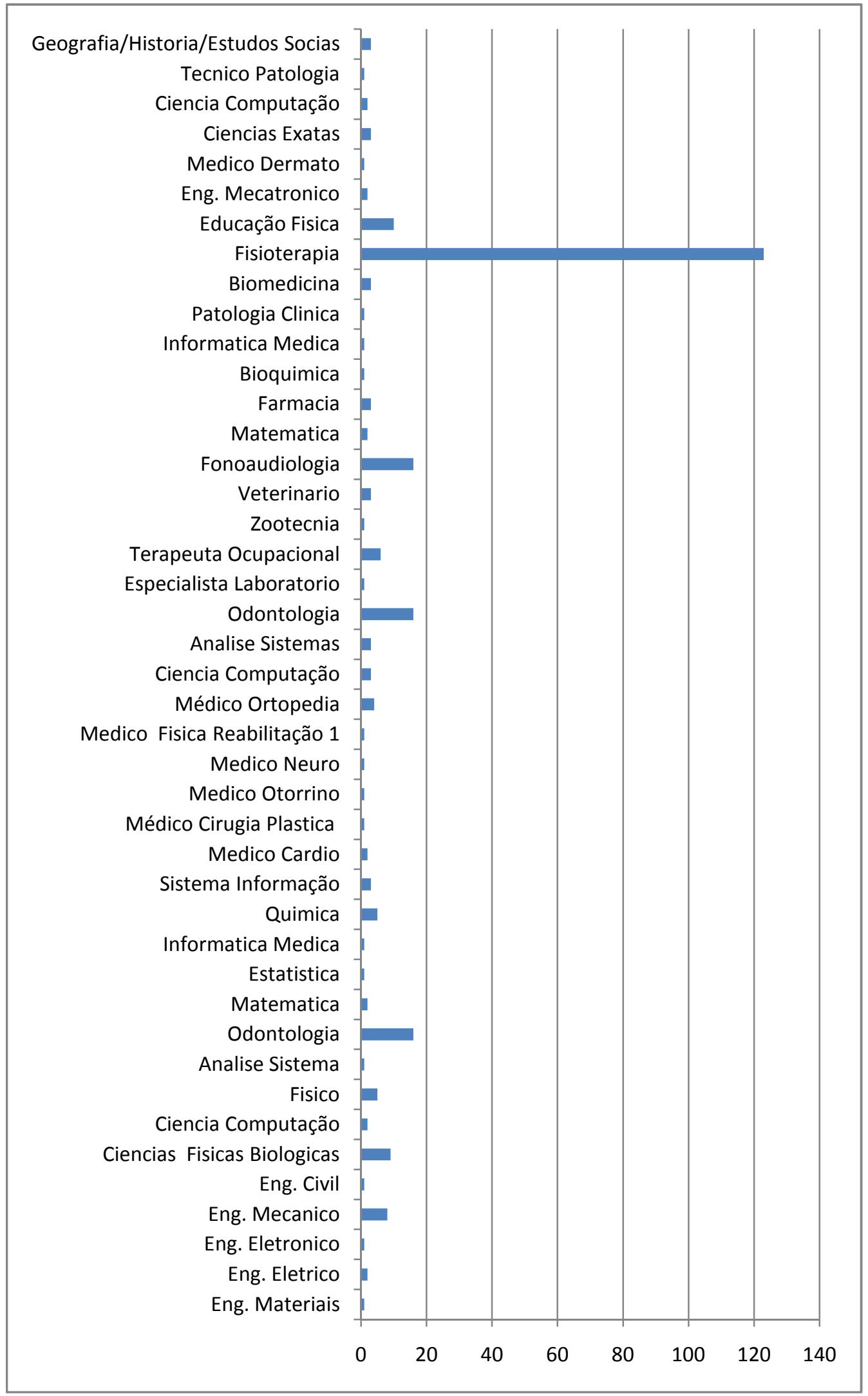

Fonte: Pesquisa com Egressos 2013- PPGIB-EESC-IQSC-FMRP-USP 


\subsection{Perfil dos Egressos}

\section{Ensino médio e graduação.}

Informações sobre o ensino médio foram coletadas no formulário através de 04 questões e sob diversos ângulos: o tipo de escola (pública ou privada), o tipo do ensino médio (comum, técnico, magistério) e o período de estudo cursado no ensino médio (diurno ou noturno). A seguir, apresenta-se a análise destes dados e os gráficos correspondentes.

Gráfico 4: Porcentagem dos egressos segundo o tipo de escola que cursou o ensino médio.

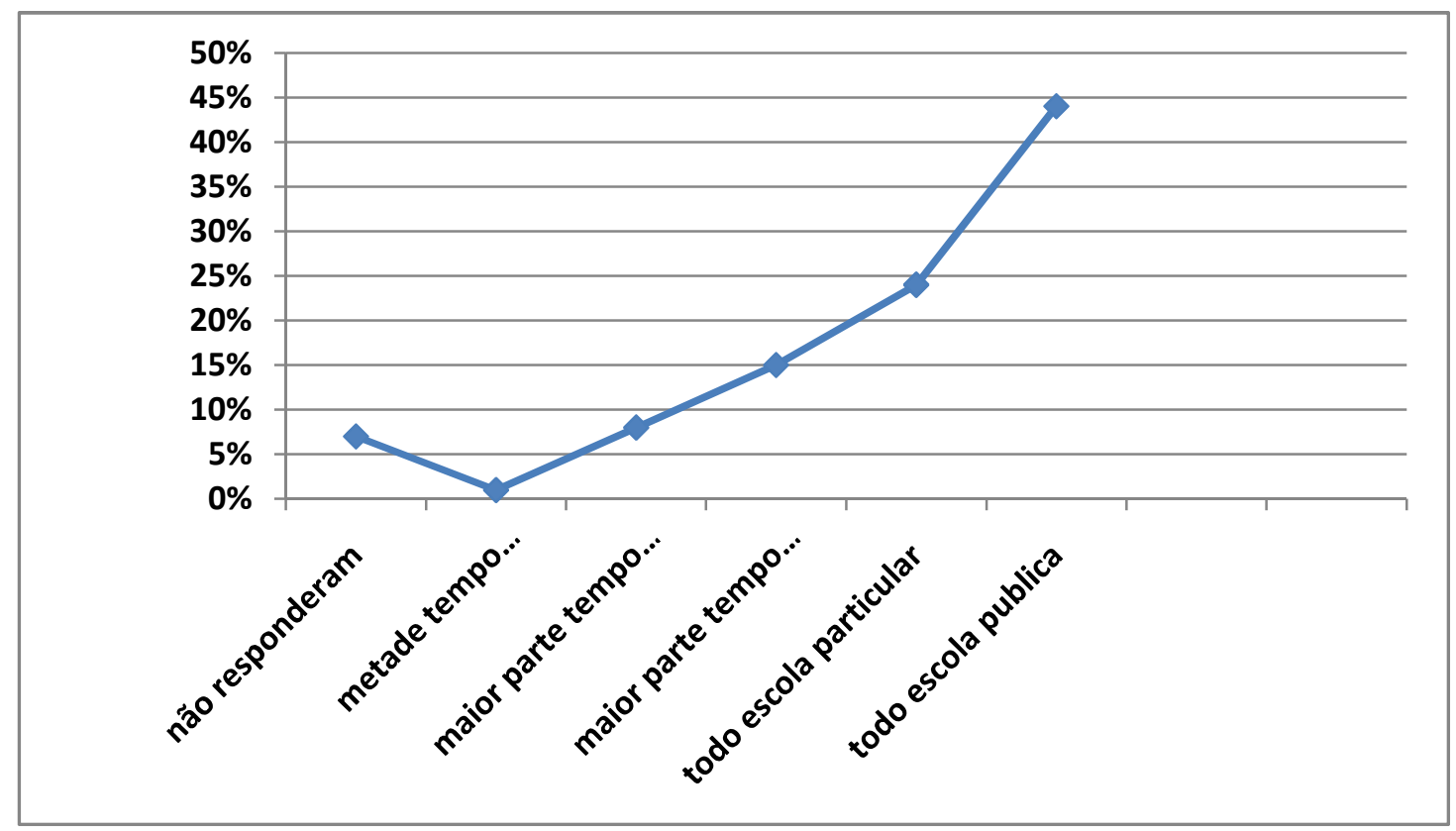

Fonte: Pesquisa com Egressos 2013- PPGIB-EESC-IQSC-FMRP-USP 
Gráfico 5: Porcentagem dos egressos segundo o tipo de ensino médio que concluiu.

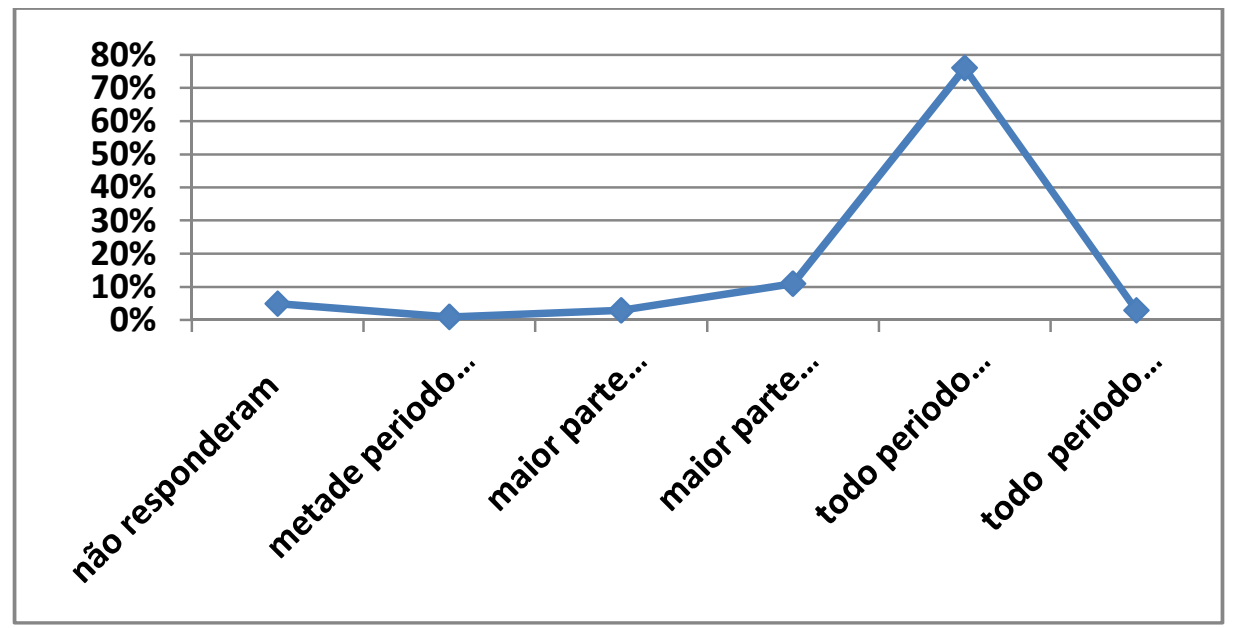

Fonte: Pesquisa com Egressos 2013- PPGIB-EESC-IQSC-FMRP-USP

Gráfico 6: Porcentagem dos egressos segundo o período que freqüentou o ensino médio

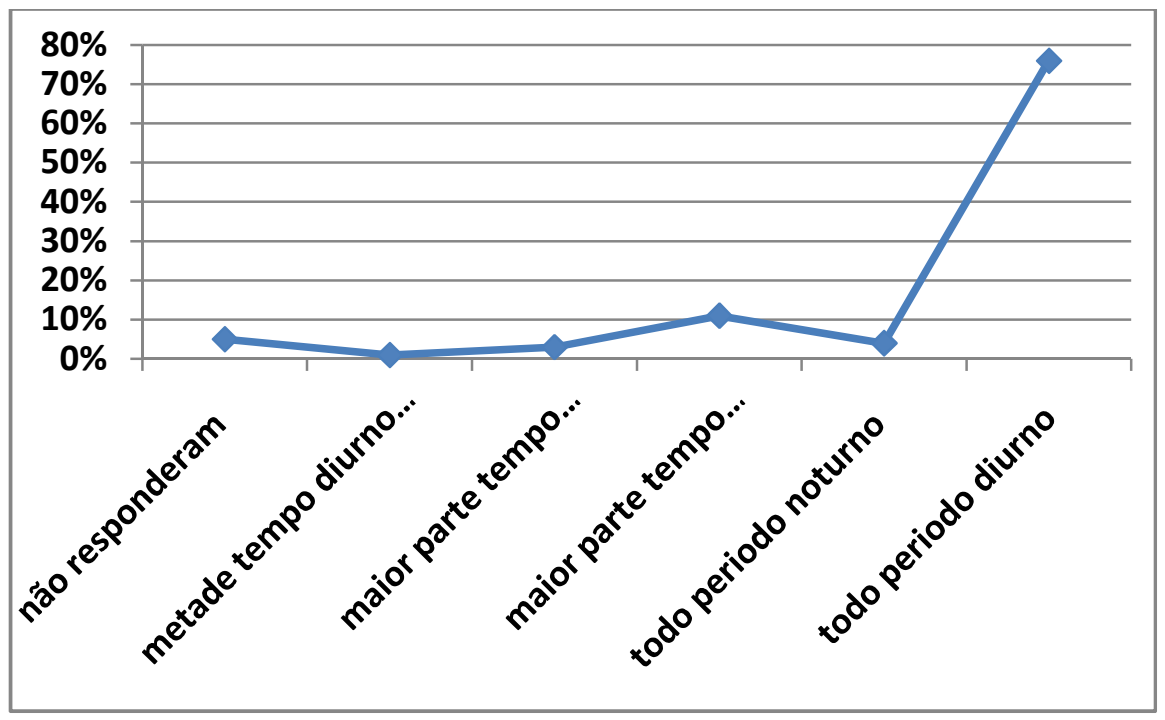

Fonte: Pesquisa com Egressos 2013- PPGIB-EESC-IQSC-FMRP-USP

Quando se trata de refletir sobre o sistema educacional brasileiro, é consensual a percepção de que o ensino médio é o nível de ensino que provoca os debates mais controversos, seja pelos persistentes problemas do acesso e da permanência, seja pela qualidade da educação oferecida, ou, ainda, pela discussão sobre a sua identidade. 
Ao analisarmos os dados sobre a educação no nível médio dos egressos pesquisados neste trabalho, observamos que a maioria, $44 \%$ realizou seus estudos totalmente em escola pública, contrapondo-se aos $15 \%$ que realizaram seus estudos apenas em escola particular (Gráfico 5). Quando perguntados sobre o tipo de ensino médio cursado, observa-se que a maioria, $83,3 \%$ realizou ensino médio comum (Gráfico 6). Em relação aos dados obtidos neste quesito, observa-se que a grande maioria dos egressos, $76 \%$ freqüentou o ensino médio durante o período diurno, 11 $\%$ freqüentaram a maior parte do ensino médio no período diurno, e $4 \%$ dos egressos cursaram o ensino médio no período noturno (Gráfico 6).

Desta forma, podemos observar que os gráficos de 1 a 3 refletem a mesma realidade educacional dos egressos, nos diferentes questionamentos feitos sobre o ensino médio. Esse perfil demonstra que a maioria estudou no período diurno.

\section{A análise das variáveis deste tópico referente à origem do ensino médio leva- nos a efetuar as seguintes conclusões parciais:}

1) As deficiências atuais do ensino médio no país são expressões da presença tardia de um projeto de democratização da educação pública no Brasil ainda inacabado, que sofre os abalos das mudanças ocorridas na segunda metade do século $X X$, que transformaram significativamente a ordem social, econômica e cultural, com importantes conseqüências para toda a educação pública. O tipo de escola onde o aluno de Pós-Graduação mestre em bioengenharia cursou o ensino médio foi na sua maioria escola publica.

2) A inclusão do ensino médio no âmbito da educação básica e o seu caráter progressivamente obrigatório demonstram o reconhecimento da importância política e social que ele possui. O país já não suporta tamanha desigualdade educacional. 
Trata-se de uma demanda crescente de escolarização diante da desvalorização dos diplomas em virtude da expansão do ensino e da necessidade de competir no exíguo mercado laboral, bem como de socializar a população em uma nova lógica do mundo do trabalho.

3) O ensino médio representa apenas os três ou quatro últimos anos da educação básica, e há dificuldades na definição de políticas para essa etapa da escolarização. Fala-se da perda da identidade, quando na verdade o ensino médio nunca teve uma identidade muito clara, que não fosse o trampolim para a universidade ou a formação profissional.

\subsection{Características do Curso de Graduação.}

O curso de graduação dos egressos foi inquirido através de 03 questões e sob diversos ângulos: o tipo de organização acadêmica, a categoria administrativa da instituição e o período de estudo que o egresso cursou. 
Gráfico 7: Porcentagem dos egressos segundo o tipo de organização acadêmica que freqüentou no curso de graduação.

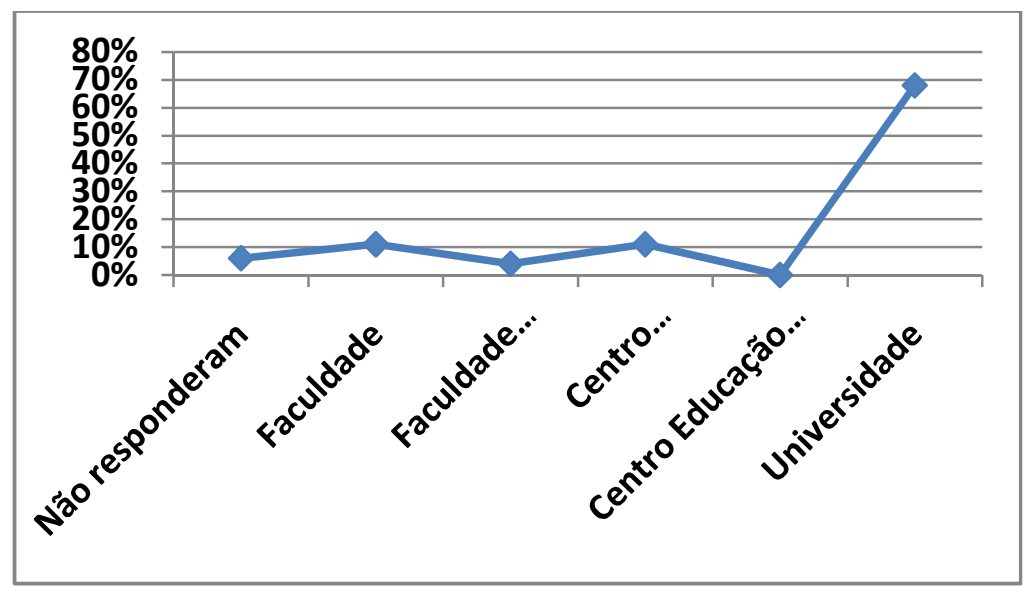

Fonte: Pesquisa com Egressos 2013- PPGIB-EESC-IQSC-FMRP-USP

Em relação ao tipo da organização acadêmica, na qual o egresso cursou a graduação, observa-se que a grande maioria, $68 \%$, freqüentou a Universidade (instituição pluridisciplinar de formação dos quadros de profissionais de nível superior, de pesquisa, de extensão e de domínio cultivo do saber humano. Empatados em 11\% estão àqueles egressos que freqüentaram Centro Universitário (instituições de ensino superior pluricurriculares, abrangendo uma ou mais áreas do conhecimento) ou Faculdade (faculdade de uma universidade está vocacionada para uma área do conhecimento), sendo o menor percentual entre as respostas obtidas, 4 $\%$, aqueles que cursaram Faculdades Integradas (instituições de ensino com propostas curriculares em mais de uma área do conhecimento, organizadas sob o mesmo comando). Nota-se também que nenhum dos egressos que participaram da pesquisa cursou Centro de Educação Tecnológica (institutos de ensino brasileiros, pertencentes à esfera federal e diretamente ligados ao Ministério da Educação, que oferecem cursos em diversos níveis, como ensino médio, técnico e superior) Fato 
que chama atenção, é que $6 \%$ dos alunos não responderam a nenhuma das opções (Gráfico 7).

As instituições de ensino superior brasileiras podem ser públicas ou privadas. As instituições públicas de ensino são aquelas mantidas pelo Poder Público, nas esferas Federal, Estadual ou Municipal. Essas instituições são financiadas pelo Estado, e não cobram matrícula ou mensalidade. Já nas instituições privadas, os alunos pagam sua matrícula e mensalidade.

As universidades devem oferecer, obrigatoriamente, atividades de ensino, pesquisa e extensão (serviços ou atendimentos à comunidade) em várias áreas do saber. Elas têm autonomia e podem criar cursos sem pedir permissão ao MEC (LDB-52). As universidades Federais são criadas somente por lei, com aprovação do Congresso Nacional. Já as universidades particulares podem surgir a partir de outras instituições como centros universitários. Os centros universitários, assim como as universidades, têm graduações em vários campos do saber e autonomia para criar cursos no ensino superior. As faculdades são instituições de ensino superior que atuam em um número pequeno de áreas do saber. Muitas vezes, são especializadas e oferecem apenas cursos na área de saúde ou de economia e administração, por exemplo, (LDB-52).

Primeiramente é preciso olhar dentro de si e analisar suas habilidades, gostos e personalidades e então depois, procurar as carreiras que possam combinar com a personalidade do indivíduo, buscando a maior quantidade possível de informações, referências com amigos, familiares e outras pessoas que já estão no mercado de trabalho ou na faculdade. Hoje, mais importante do que a profissão é a carreira que você constrói. 
Gráfico 8: Porcentagem dos egressos segundo o tipo de categoria administrativa da instituição em que freqüentou o curso de graduação.

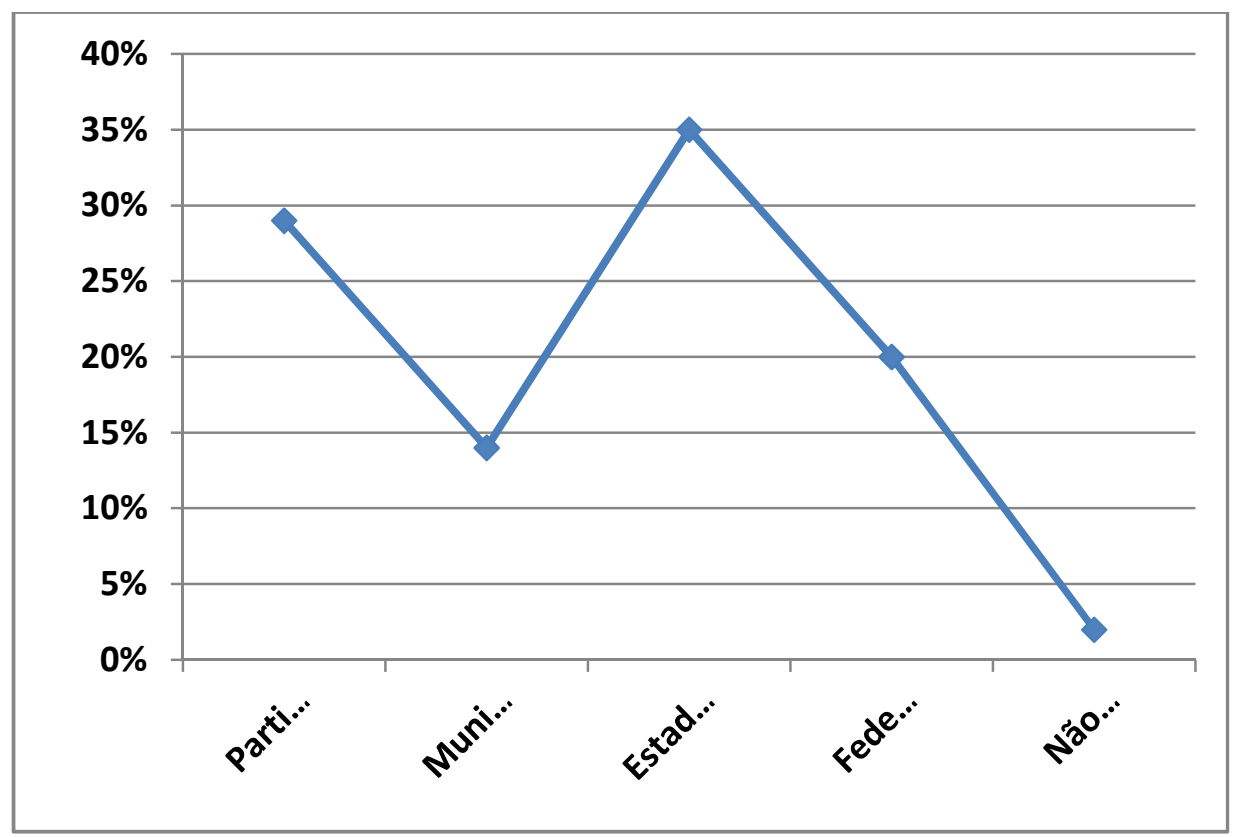

Fonte: Pesquisa com Egressos 2013- PPGIB-EESC-IQSC-FMRP-USP

Por meio dos dados dispostos no Gráfico 8, é possível concluir que os egressos na sua grande maioria, $35 \%$, freqüentaram ensino Estadual, seguido de, $29 \%$ que cursaram ensino particular, e $20 \%$ cursaram ensino Federal e 14\% ensino Municipal. 
Gráfico 9: Porcentagem de egressos segundo o período de estudo do curso de graduação que freqüentou.

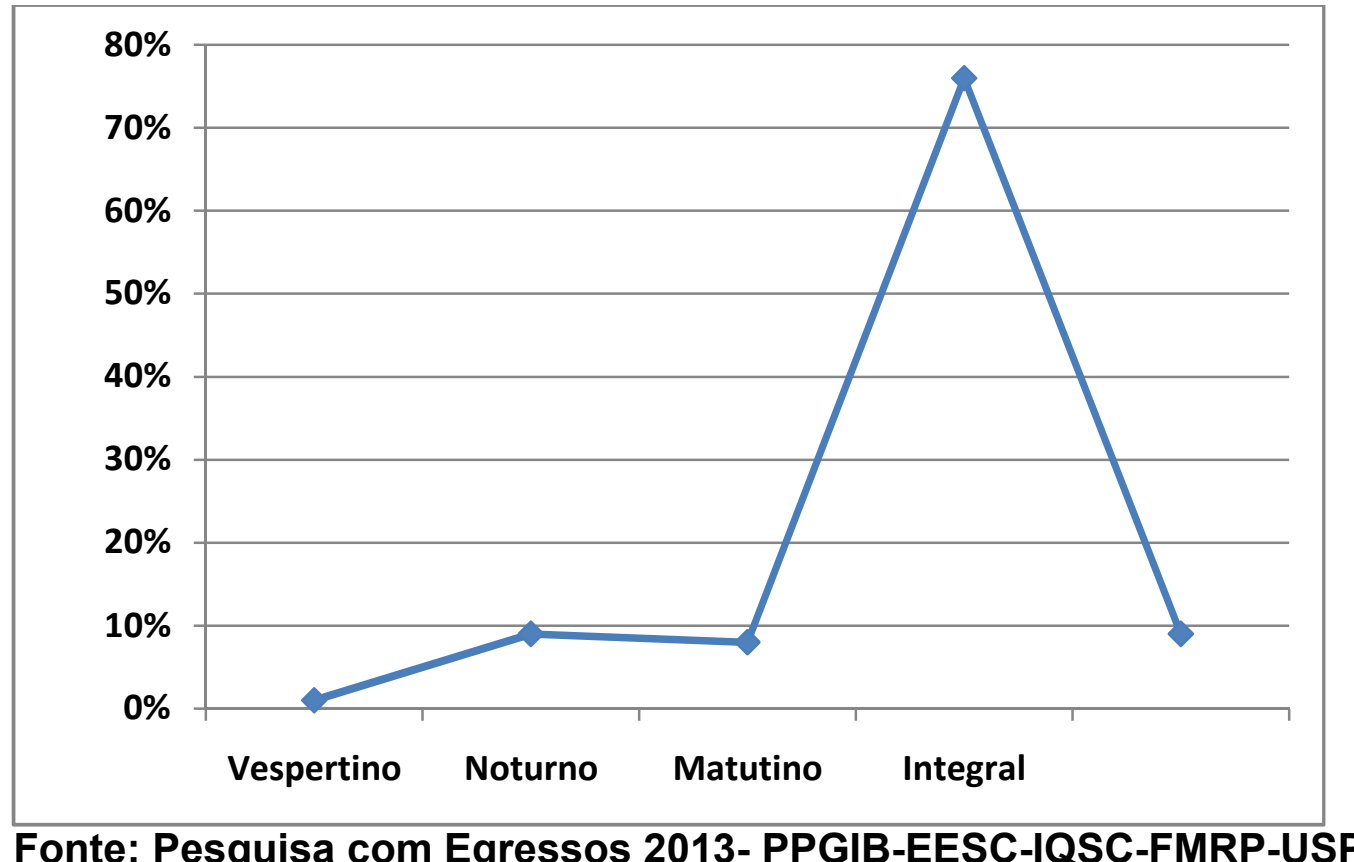

Os egressos, em sua grande maioria, $76 \%$ cursaram sua graduação em tempo integral, $9 \%$ cursaram em período noturno, seguido de $8 \%$ que cursaram no período matutino. Observa-se também que 1\% apenas dos egressos cursou em período vespertino e $5 \%$ dos pesquisados não responderam.

Diante dos resultados obtidos em termos da educação dos egressos, prémestrado, ou seja, ensino médio e graduação observa-se que um mesmo perfil se repete, uma vez que, tanto no ensino médio, quanto na graduação a maioria dos egressos, os cursou em instituições públicas e em período diurno.

O ensino superior no Brasil começou ainda no período colonial, com a criação das escolas superiores especializadas, baseadas em escolas semelhantes existentes na Metrópole Portuguesa. Uma das primeiras foi a Real Academia de Artilharia, cuja fortificação e desenho foram criados em 1792, no Rio de Janeiro, pela Rainha D. Maria I de Portugal, com fim principal de formar oficiais técnicos e 
engenheiros militares. Considera-se esta Academia como sendo a primeira escola superior de engenharia das Américas e uma das primeiras do mundo, estando na origem remota dos atuais, Instituto Militar de Engenharia e Escola Politécnica da Universidade Federal do Rio de Janeiro.

A nenhuma destas escolas foi atribuída o status de Universidade, o qual era reservado em todo o Império Português à Universidade de Coimbra; mesmo em Portugal, com exceção da Universidade de Évora, com existência breve, as diversas instituições de ensino superiores existentes fora de Coimbra só alcançaram o status de Universidade em 1911(UNIVERSIA 2013).

Por definição da Lei de Diretrizes e Bases- LDB, as universidades gozam de autonomia plena, e por isso, não necessitam de autorização do Ministério da Educação para criar novos cursos, sedes, aumentar ou diminuir o número de vagas, fecharem cursos, expedir diplomas. Mais do que a formação na graduação, as universidades oferecem pesquisa e extensão. Além disso, elas precisam ter $70 \%$ do corpo docente formado por professores titulados e oferecer cursos em pelo menos cinco áreas do conhecimento (Artigo 52 - LDB).

No Brasil, a mais antiga instituição com o status de universidade é a Universidade de Manaus, criada em 1909 e hoje chamada Universidade Federal do Amazonas. Há outras instituições de ensino superior brasileiras mais antigas, porem não gozavam do status de universidade antes de 1909.

Uma universidade promove educação tanto terciária (graduação) quanto quaternária (Pós-Graduação). Segundo Mazzari Junior (2009), "as universidades gozam de autonomia para executar suas finalidades, em estrita observância ao texto constitucional, porem este direito não proíbe o Estado de verificar o uso desta prerrogativa nas atividades que lhes são próprias". 
Observa-se no Gráfico 10, que as atividades das quais os egressos participaram durante o período acadêmico, foram em sua maioria as atividades culturais no Brasil, como palestras ou conferências, perfazendo um total de $35 \%$ dos egressos. Em segundo lugar, com $25 \%$ do total estão as atividades do movimento estudantil, fato curioso, uma vez que este ítem teve maior participação que outros itens, tidos como importantes, para a formação acadêmica, como por exemplo, o estudo de língua estrangeira (11\%), estágios (2\%), grupos de pesquisa (1\%), entre outros.

Gráfico 10: Porcentagem de egressos segundo as atividades que participou durante a graduação.

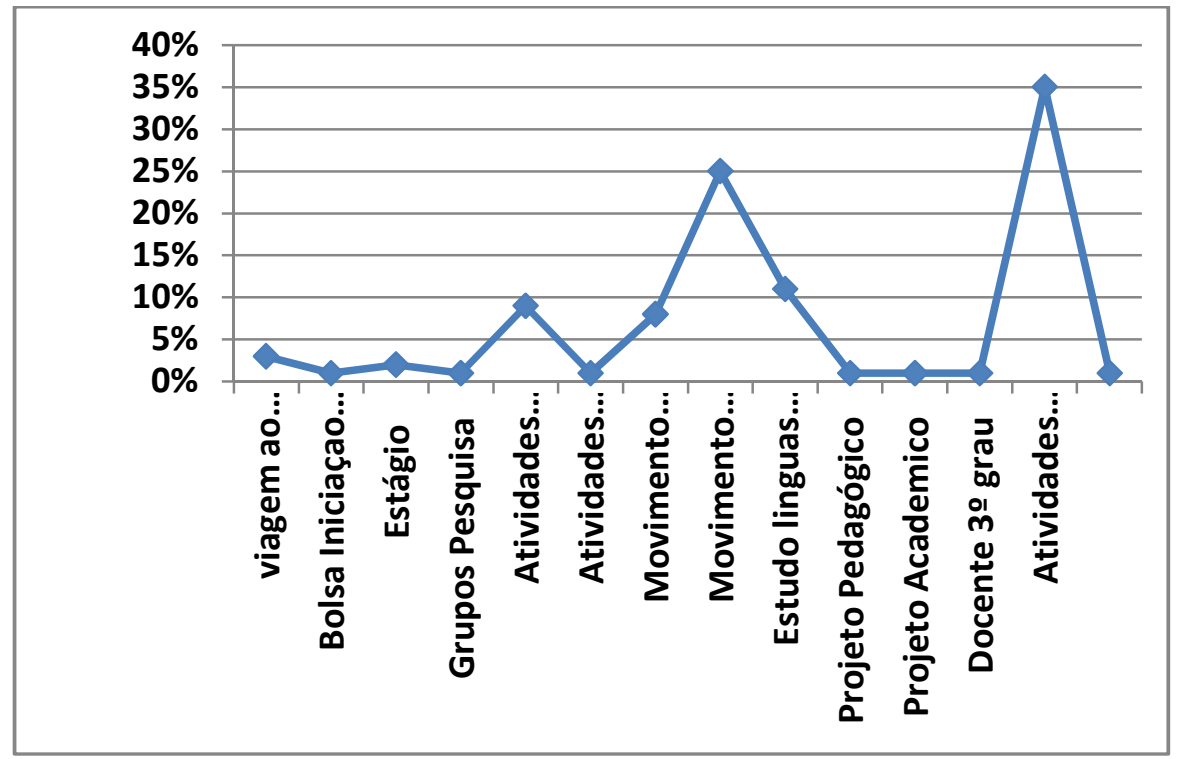

Fonte: Pesquisa com Egressos 2013- PPGIB-EESC-IQSC-FMRP-USP 
Gráfico 11: Porcentagem dos egressos segundo o conhecimento de língua inglesa no inicio da pós-graduação.

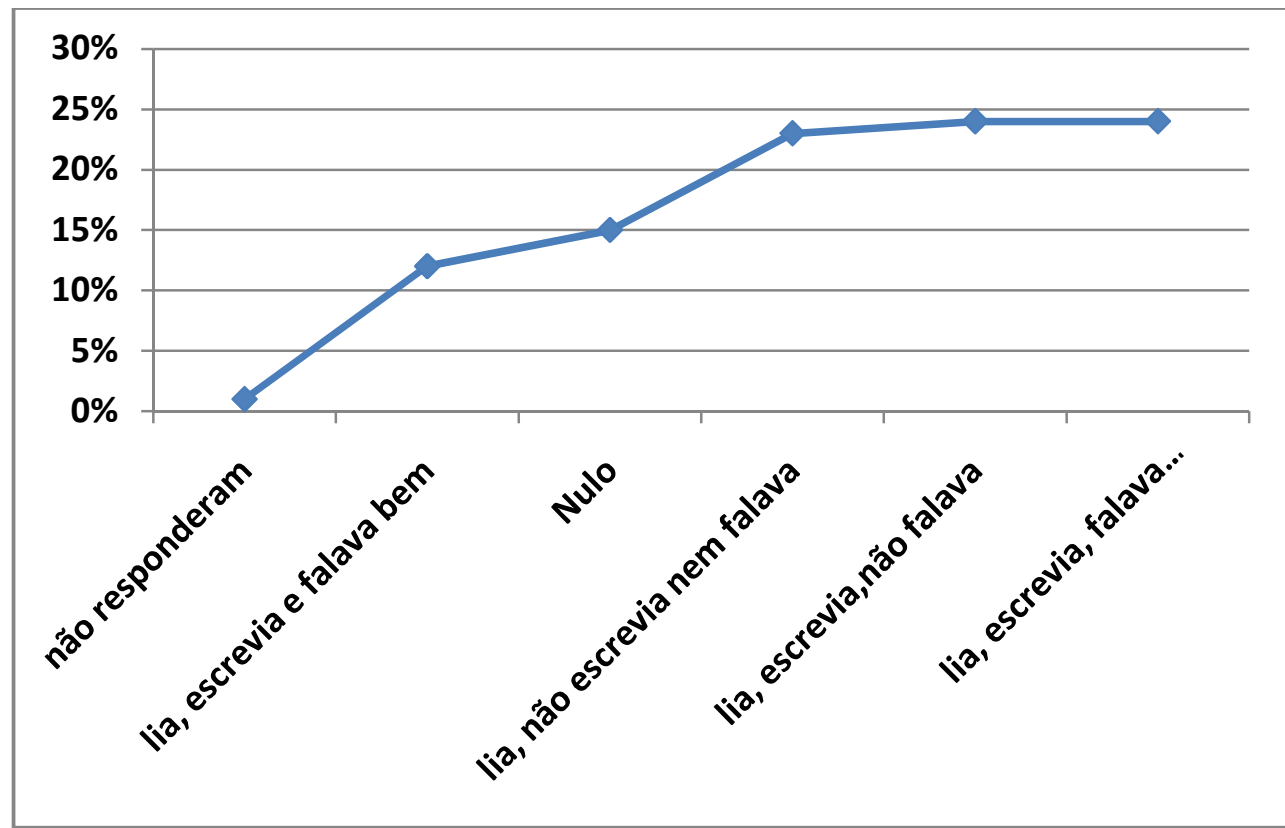

\section{Fonte: Pesquisa com Egressos 2013- PPGIB-EESC-IQSC-FMRP-USP}

Solicitados aos egressos para apresentar o nível do seu conhecimento de língua inglesa, quando do inicio do curso de mestrado, praticamente empatados com $24 \%$, estão àqueles egressos que lia, escrevia e falavam medianamente, aqueles que liam, escreviam, mas não falavam e os que liam, mas não escreviam nem falavam. Com metade desta porcentagem, $12 \%$ estão os egressos que dominavam a língua inglesa, os quais liam, escreviam e falavam bem. Ligeiramente maior, estão os $15 \%$ dos egressos que praticamente tinham conhecimento nulo da língua inglesa, no referente, a leitura, escrita e fala. Podemos concluir então, que a maioria, $71 \%$ tinha conhecimento da língua inglesa, de forma intermediária, enquanto que os outros extremos, ou seja, um conhecimento ótimo e nenhum conhecimento da língua inglesa encontram-se quase que empatados (Gráfico 11). 


\section{Esses resultados nos levam a concluir que:}

1) no contexto de globalização econômica em que vivemos, destaca-se o ritmo da mudança no perfil das habilidades e conseqüente necessidade de emprego cada vez mais qualificado. Essa qualificação torna-se cada vez menos possível de ser suprida, apenas pela faculdade ou por curso de graduação. Por tornarem-se os cursos complementares uma necessidade constante é que quisemos fazer um diagnóstico desse programa de Pós-Graduação entre os egressos.

2) A comparação entre os cursos de Pós-Graduação sugere algumas digressões. Por um lado os objetivos da Pós-Graduação stricto sensu despertam pouco interesse para os profissionais que estão atuando no mercado de trabalho, por esta ser a formação acadêmica considerada eminentemente teórica e pouco valorizada pelos empregadores das instituições não educacionais, isto é, as empresas em geral. Fica, portanto registrado que o processo de qualificação de nível superior na Pós-Graduação continua sendo visto pelos empresários como um problema que concerne, quase que exclusivamente á universidade e aos indivíduos, pouco investindo na qualidade de recursos humanos no ambiente de trabalho.

3) Seria interessante investigar os conteúdos que são tratados nos cursos de Pós-Graduação lato sensu e complementares, pois estes são uma continuidade do processo de formação oferecido pela escola. Este trabalho exigiria uma mobilização do corpo docente para acompanhar os últimos avanços na profissão de Engenharia Biomédica. Além disso, facilitaria a integração da universidade com o sistema produtivo. Como conseqüência, os cursos de graduação seriam beneficiados com a inserção de conteúdos mais atualizados e mais equilibrados entre teoria e prática, além de se aproximarem mais da realidade ocupacional. 


\subsection{A pós-graduação em Bioengenharia.}

O curso foi enfocado no formulário através de 05 questões e sob diversos anglos: curso de graduação o preparou adequadamente, o tipo de organização acadêmica, o tipo de categoria administrativa, o período cursou a graduação, o seu grau de satisfação.

Gráfico 12: Avaliação em porcentagem dos egressos oriundos do curso de graduação quanto ao preparo para a realização da pós-graduação.

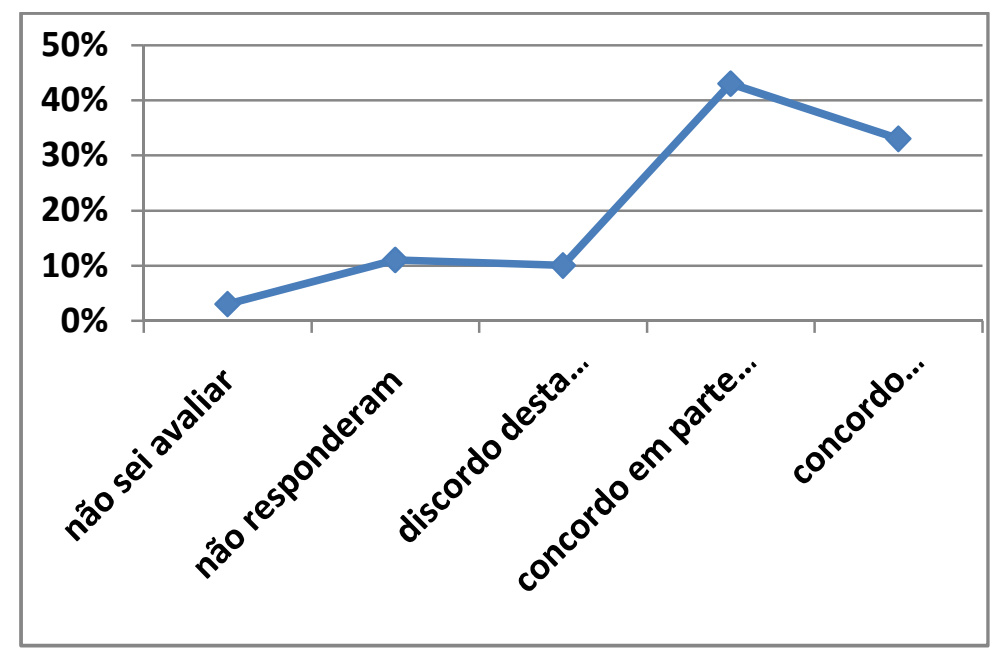

Fonte: Pesquisa com Egressos 2013- PPGIB-EESC-IQSC-FMRP-USP

O percentual dos egressos que concordam plenamente ou em partes que o curso de graduação os preparou adequadamente para esta etapa acadêmicamestrado foi de $43 \%$ e $33 \%$, respectivamente. É possível observar também, pelos dados do Gráfico 12, que $10 \%$ discorda desta declaração e $3 \%$ não souberam avaliar a questão. Nota-se que $11 \%$ não responderam, percentual praticamente igual aquele dos que discordaram da declaração. 
Convidados a apresentar suas opiniões a respeito da afirmação de que o tipo de organização acadêmica da instituição, na qual o egresso cursou a graduação foi um fator que contribuiu de maneira positiva para seu desempenho nesta etapa acadêmica, as opiniões relatadas encontram-se no Gráfico 13.

Gráfico 13: Porcentagem dos egressos segundo o tipo de organização acadêmica que freqüentou o curso de graduação. Fator que contribui positivamente para seu desempenho na Pós-Graduação.

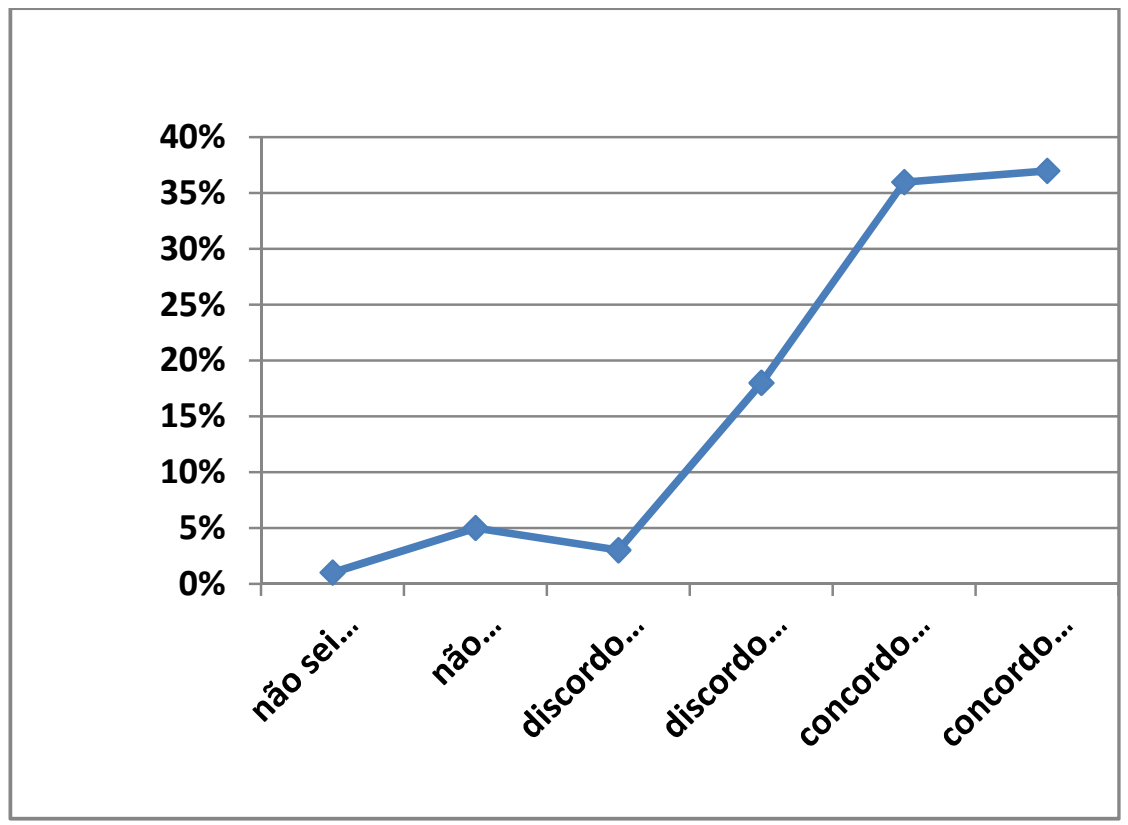

Fonte: Pesquisa com Egressos 2013- PPGIB-EESC-IQSC-FMRP-USP

Nota-se que praticamente empatados, encontram-se os alunos que concordam plenamente com esta declaração- $37 \%$ e aqueles que concordam parcialmente com a mesma- $36 \%$. Percentual que cai pela metade- $18 \%$, quando relacionado àqueles que discordam de tal afirmação. Neste caso, diferente da questão anterior, apenas $1 \%$ dos pesquisados não soube avaliar.

Já quando questionados sobre a categoria administrativa da instituição na qual cursou a graduação, ter contribuído de maneira positiva para seu desempenho 
no mestrado, os egressos em sua maioria, $42 \%$ concordaram plenamente com esta afirmação. Aqueles que concordaram em partes foram $28 \%$, os discordantes foram $11 \%$, praticamente o mesmo percentual daqueles que não responderam- $13 \%$. Apenas 2\% não souberam avaliar (Gráfico 14).

Gráfico 14: Porcentagem dos egressos segundo a categoria administrativa que freqüentou a graduação. Fator que contribuiu positivamente para o desempenho na Pós-Graduação

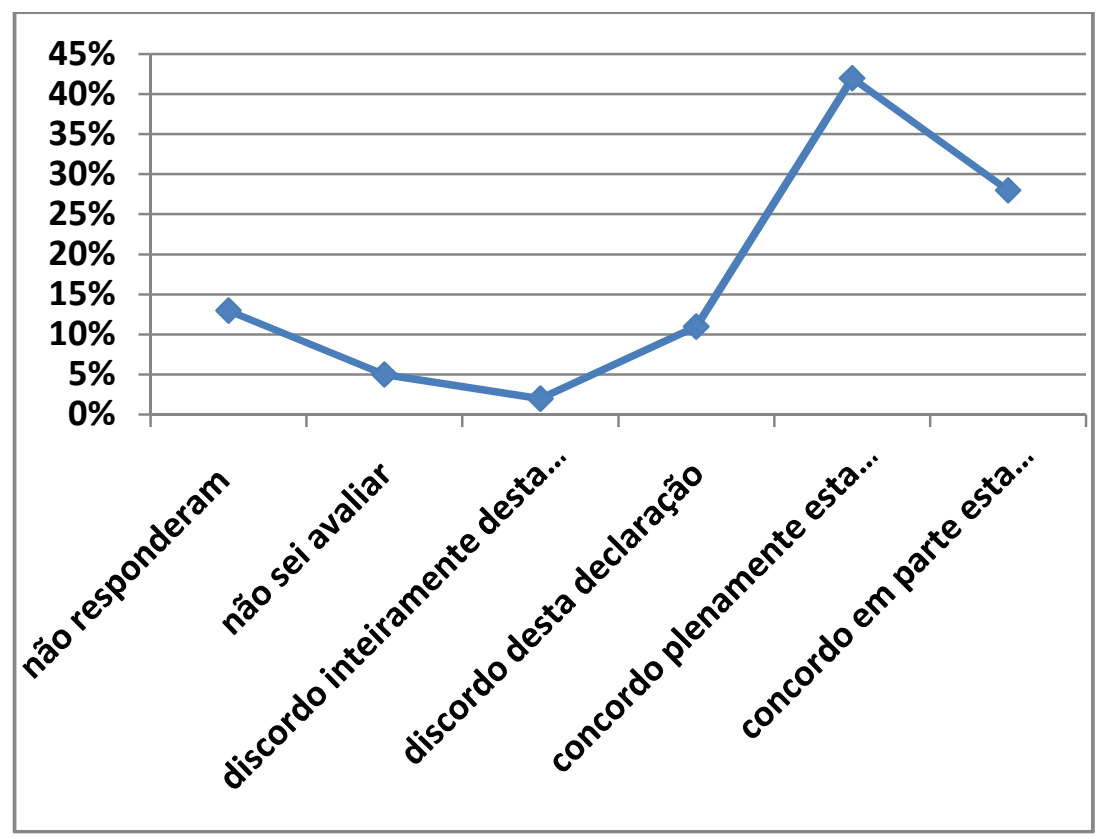

Fonte: Pesquisa com Egressos 2013- PPGIB-EESC-IQSC-FMRP-USP

Os egressos ao serem questionados quanto à possível influência positiva do período em que freqüentaram a graduação, sobre seu desempenho no mestrado, $49 \%$, a grande maioria concordou plenamente com esta declaração. Posteriormente 45\% concordam em parte com esta declaração (Gráfico 15). 
Gráfico 15: Porcentagem dos egressos segundo o período em que freqüentou a graduação. Fator que contribuiu positivamente para 0 desempenho na Pós-Graduação

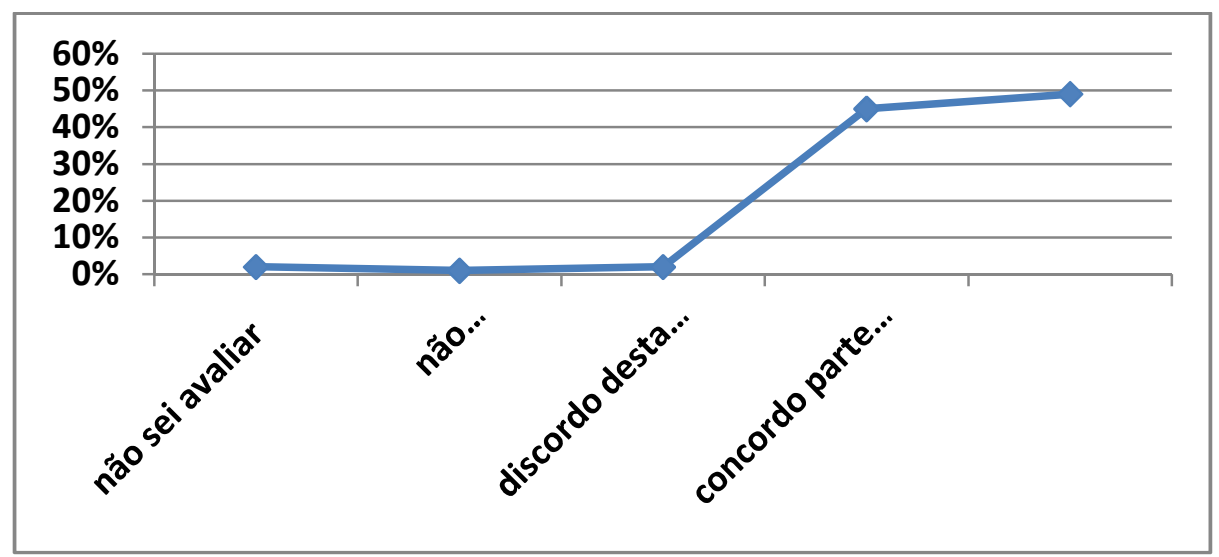

Fonte: Pesquisa com Egressos 2013- PPGIB-EESC-IQSC-FMRP-USP

Gráfico 16: Porcentagem dos egressos segundo o grau de satisfação do seu desempenho na pós-graduação (nota de 01 a 10)

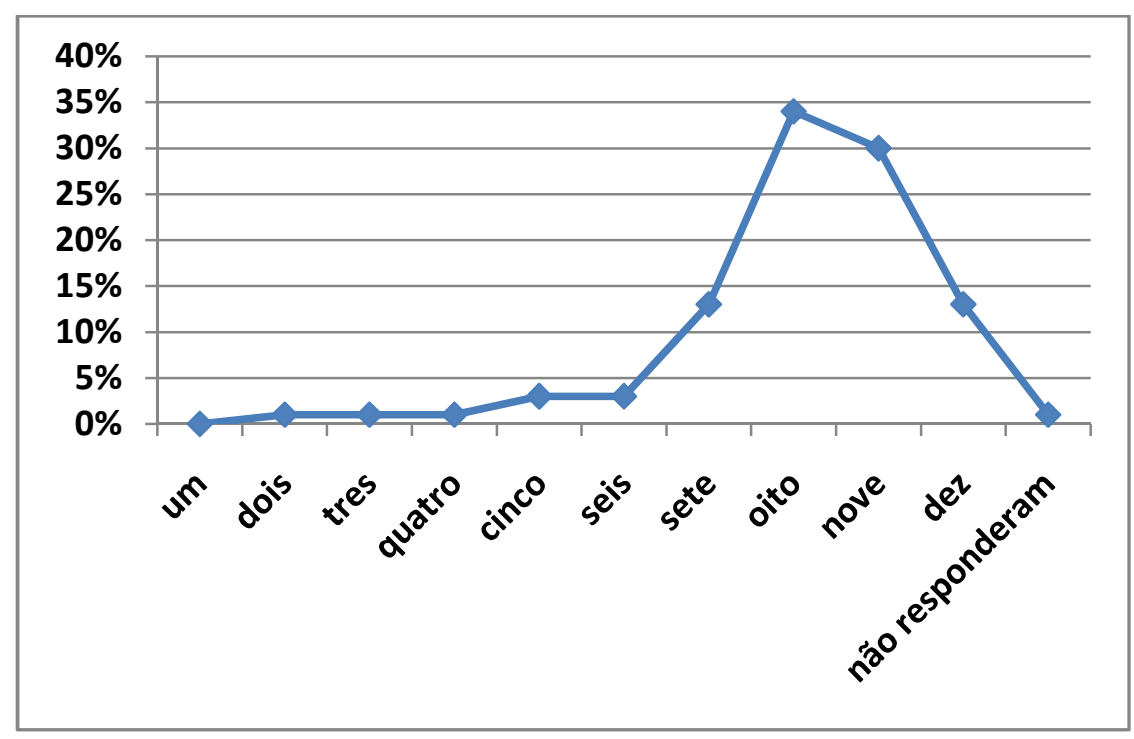

Fonte: Pesquisa com Egressos 2013- PPGIB-EESC-IQSC-FMRP-USP

O grau de satisfação dos egressos, na escala de 01 a 10, (na escala o numero um é ruim e dez é o melhor) relação ao seu desempenho acadêmico, alcançou a maior percentagem, 34\% com o grau 08, seguido, pelo grau 09, com $30 \%$. Os graus de satisfação 10 e 07 empataram com 13\%. Graus de satisfação 
menores que 07, tiveram pequena adesão dos egressos, e apenas $1 \%$ não responderam a este questionamento (Gráfico 16).

Até agora foi possível concluir que os dados obtidos na pesquisa estão obedecendo ao mesmo perfil. Tanto no bloco de perguntas inicial, sobre a formação pré- mestrado dos egressos, quanto neste último bloco, referentes à influência do tipo de organização acadêmica, categoria administrativa, período da graduação, no desempenho acadêmico durante o mestrado, os egressos concordam que cursarem universidades, estaduais, em período integral, possibilitou que tivessem melhor desempenho acadêmico durante o mestrado, sendo que este desempenho alcançou em uma escala de 0 a 10, notas altas, como 08 para a maioria.

Gráfico 17: Porcentagem dos egressos segundo razões que influenciaram na decisão ao ingressar no PPGIB

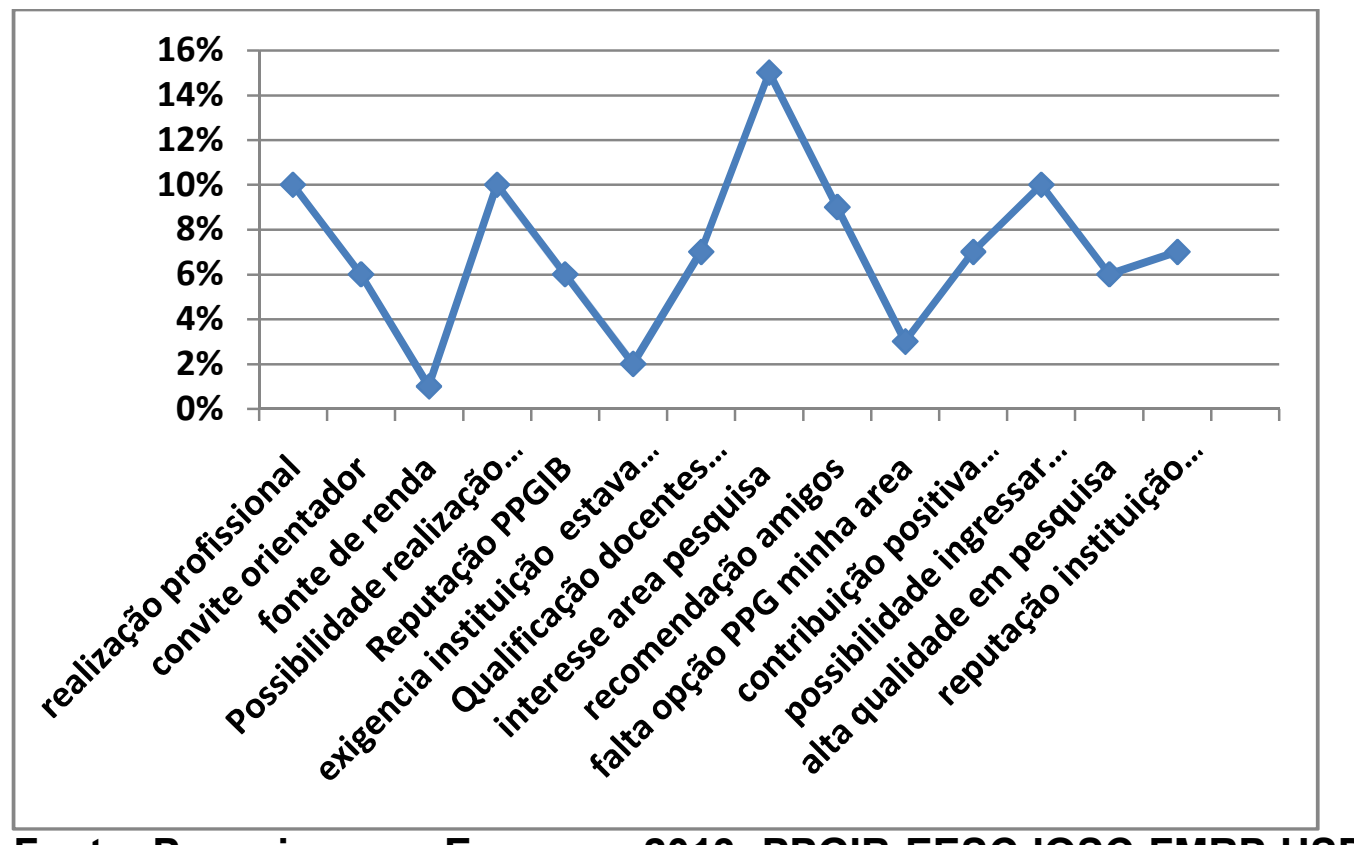

\section{Fonte: Pesquisa com Egressos 2013- PPGIB-EESC-IQSC-FMRP-USP}

Ao perguntar-se aos egressos sobre as razões que influenciaram sua decisão em ingressar no Programa de Pós-Graduação Interunidades em Bioengenharia PPGIB nota-se que as respostas dadas podem ser agrupadas em três conjuntos: razões ligadas ao PPGIB, razões externas ao PPGIB e razões de cunho pessoal 
(Gráfico 17). O primeiro conjunto -razões ligadas ao programa- apresenta o maior percentual das respostas, $54 \%$, enquanto que o segundo conjunto razões externas apresentam percentual de $27 \%$, sendo que $18 \%$ estão relacionados ao terceiro conjunto, que engloba os fatores pessoais. Assim podemos concluir previamente que o PPGIB é um programa atrativo para os recém graduados, ou graduados que desejam ingressar no mestrado em Bioengenharia, oferecendo a estes, excelente corpo docente, linhas de pesquisas atraentes, boa reputação na comunidade acadêmica.

Quando questionados, em que momento de sua vida acadêmica, os egressos entraram no PPGIB, as respostas dadas surpreendem, pois, nota-se que a maioria, $36 \%$, esperou mais de dois anos após a conclusão de sua graduação, para ingressar na pós-graduação. Por outro lado, 24\% ingressaram na pós-graduação imediatamente após a conclusão da graduação. No intervalo entre este fato e até dois anos após, 34\% ainda se decidiam sobre seu ingresso na pós-graduação (Gráfico 18). 
Gráfico 18: Porcentagem dos egressos segundo o intervalo entre a conclusão da graduação e início na Pós-Graduação

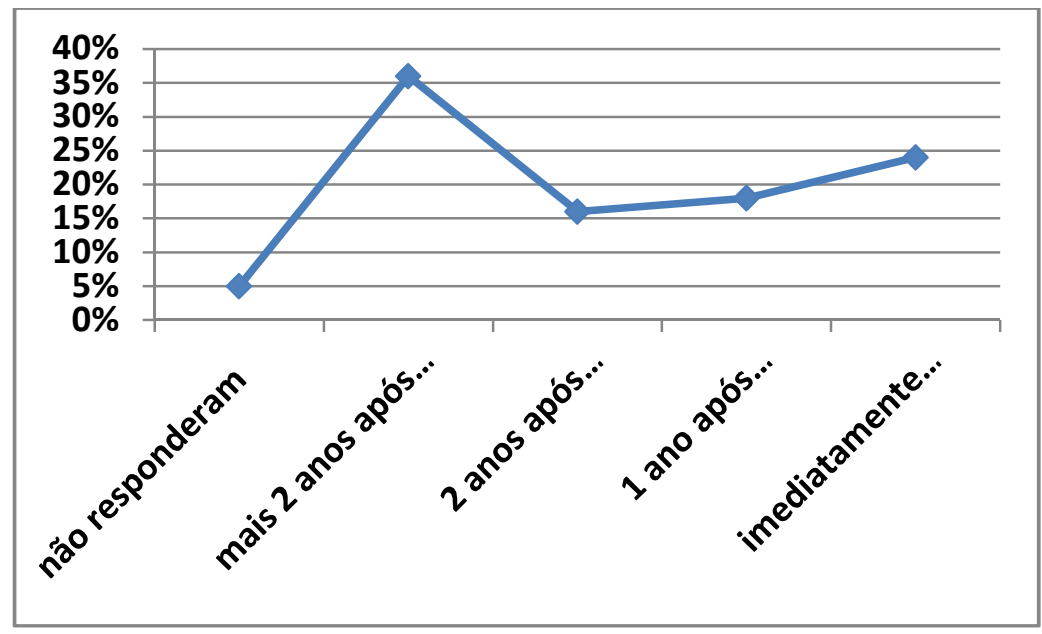

Fonte: Pesquisa com Egressos 2013- PPGIB-EESC-IQSC-FMRP-USP

Gráfico 19: Porcentagem dos egressos segundo sua participação em projeto de iniciação cientifica antes da Pós-Graduação

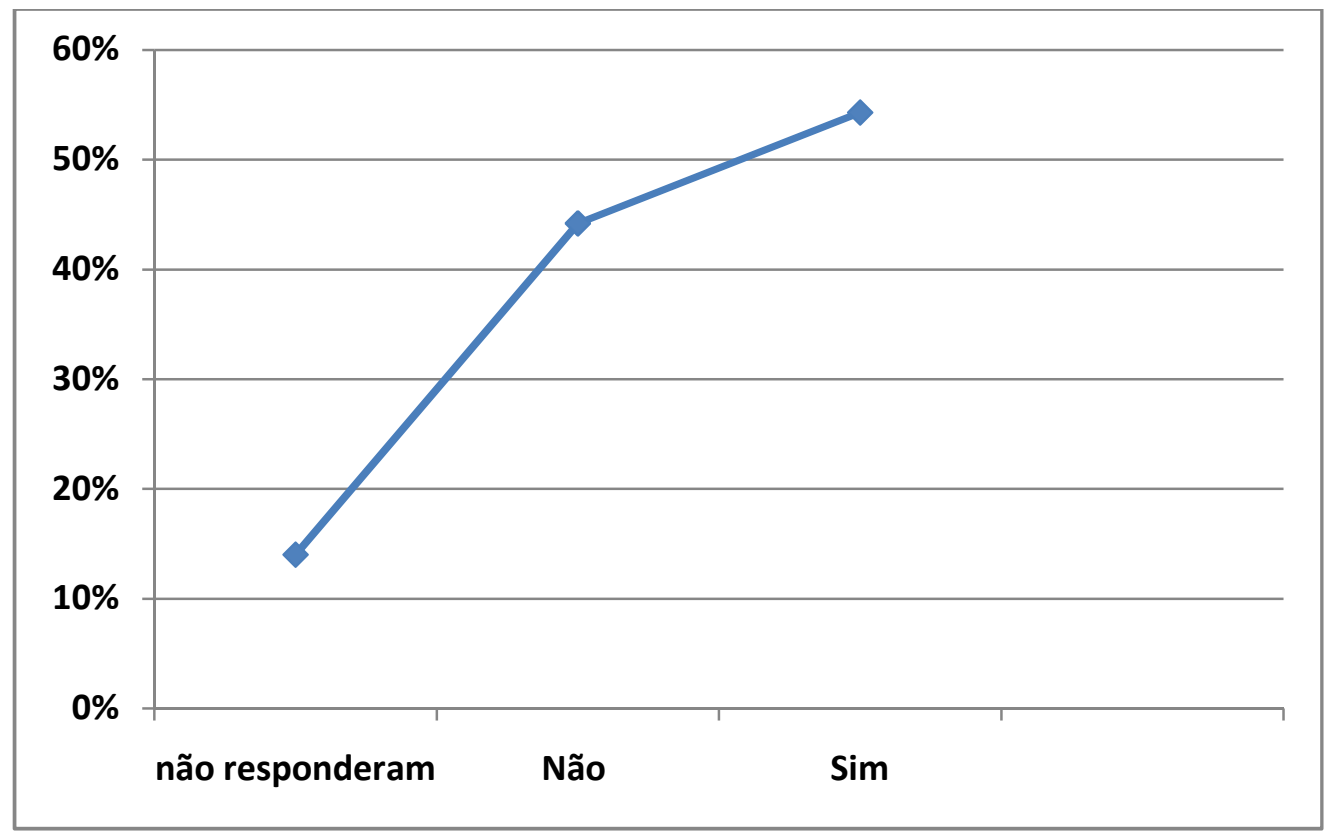

Fonte: Pesquisa com Egressos 2013- PPGIB-EESC-IQSC-FMRP-USP

Também foi perguntado aos egressos, sobre sua participação em algum tipo de pesquisa, no período da graduação, através de participação em projetos de 
iniciação científica, opção que na maioria dos casos, é o primeiro contato efetivo do aluno, com algum projeto científico/ pesquisa. Os dados coletados neste quesito estão dispostos no Gráfico 19. Nota-se que a maioria teve participação em projetos de iniciação científica, perfazendo $54,3 \%$, seguido de $44,2 \%$ que não tiveram a mesma experiência. 


\section{Adequação da Pesquisa (Aberta).}

Gráfico 20: Porcentagem dos egressos segundo característica que melhor descreve o PPGIB

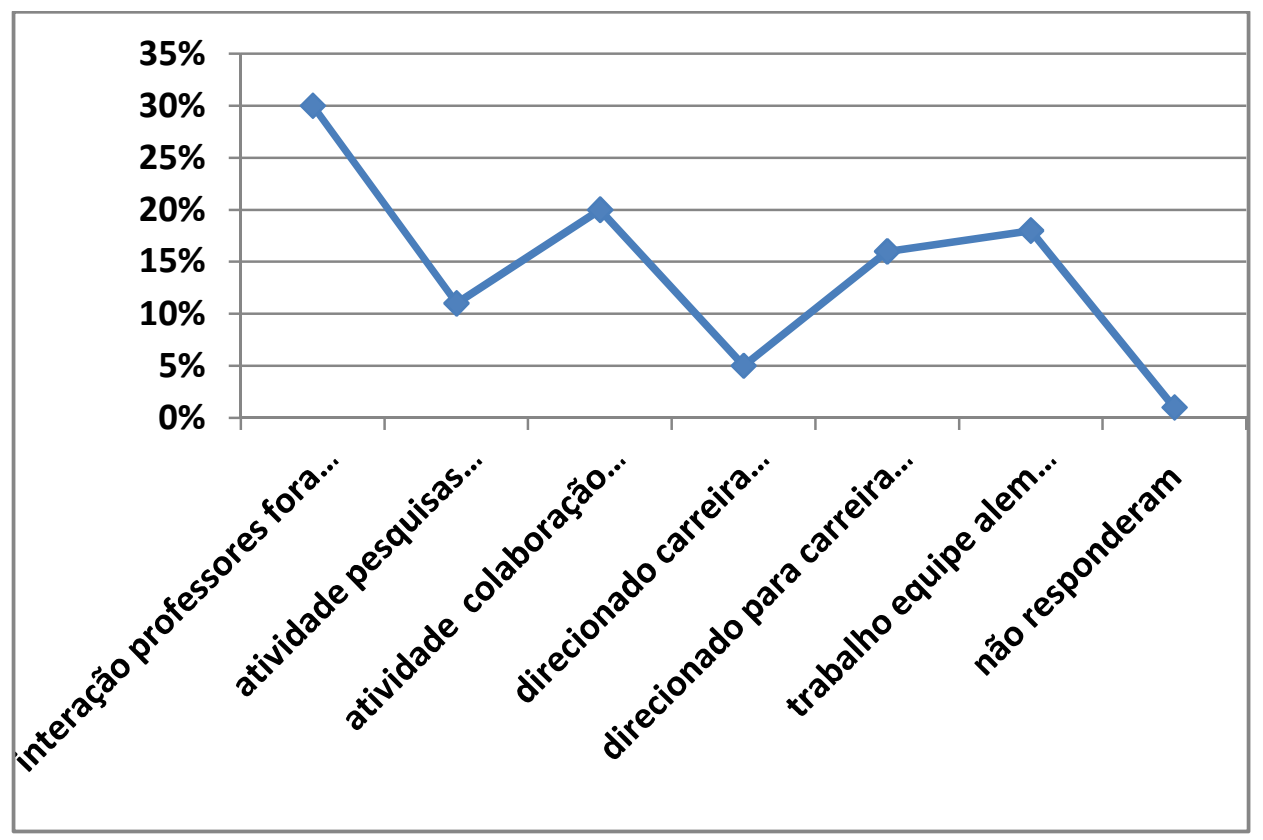

Fonte: Pesquisa com Egressos 2013- PPGIB-EESC-IQSC-FMRP-USP

Os egressos afirmam que o programa de pós-graduação- PPGIB- possibilitou a interação com profissionais fora da área acadêmica, inteirando um total de $30 \%$, sendo essa a característica, segundo os egressos, que melhor descreve o programa de pós- graduação, quando de sua participação. A interação com outros pesquisadores, por meio de colaboração para suas atividades foi escolhida por $20 \%$ dos pesquisados, como melhor característica, seguida de $18 \%$ que afirmaram como sendo, as atividades de trabalho em equipe, a melhor opção. Praticamente empatado, com $16 \%$, os egressos elegeram o fato de o programa ser direcionado principalmente para a carreira acadêmica, como a principal característica; outro aspecto que não teve tanta adesão dos egressos como sendo a característica que melhor descreve o programa, são as atividades de pesquisa interdisciplinar, com 11\% (Gráfico 20). 
Gráfico 21: Porcentagem dos egressos segundo os aspectos relativos PPGIB que considera plenamente satisfatório

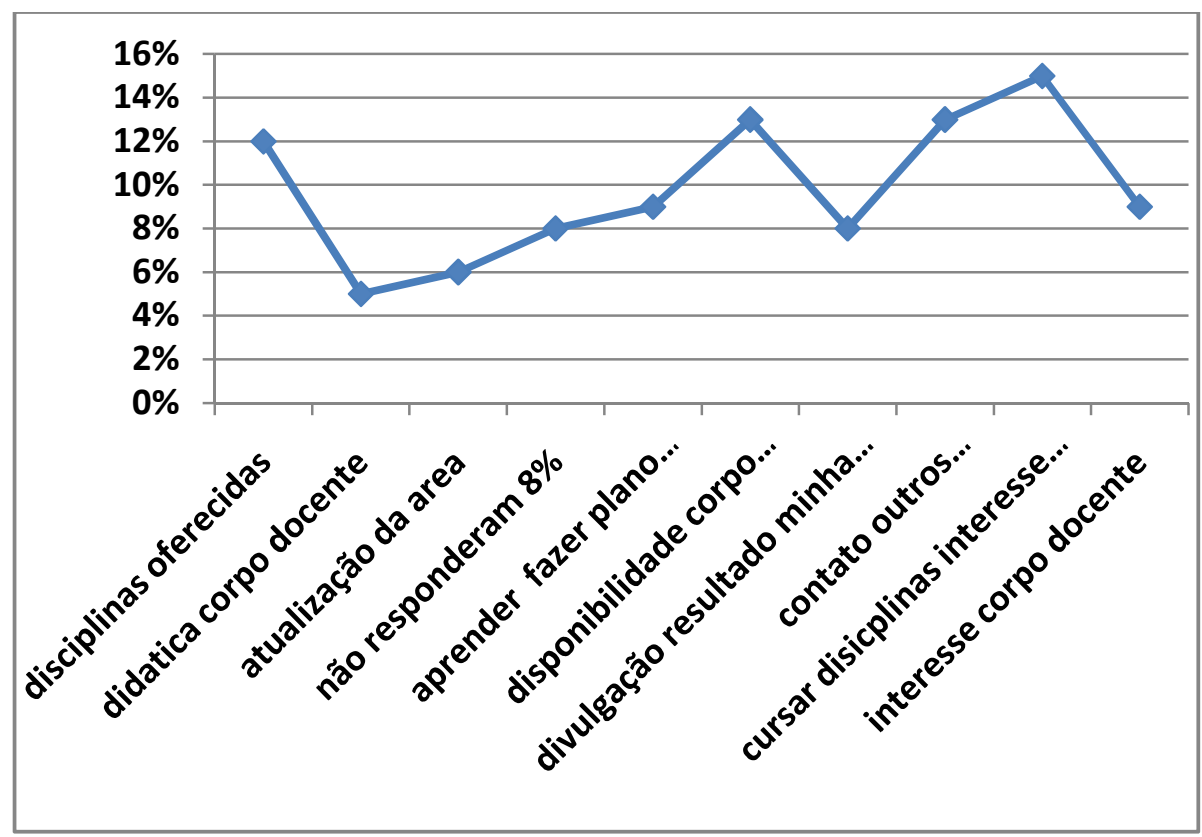

Fonte: Pesquisa com Egressos 2013- PPGIB-EESC-IQSC-FMRP-USP

O questionamento feito aos egressos sobre que aspectos relativos ao programa de pós-graduação, sobre os quais eles consideravam como plenamente satisfatórios, dividiu muito as opiniões, sendo que nenhuma resposta fornecida pela pesquisa como opção apresentou maioria esmagadora, em termos de concordância (Gráfico 21). Observa-se que a maioria, $15 \%$ optou pela possibilidade de ter cursado disciplinas de interesse fora do programa, como principal aspecto plenamente satisfatório, seguido de um empate em $13 \%$ entre a opção de disponibilidade do corpo docente para atendimento do estudante e o contato com outros profissionais da área. Logo em seguida, com 12\%, estão aqueles que julgam como o melhor aspecto relativo ao programa, o hall de disciplinas oferecidas pelo mesmo. Dentre os aspectos oferecidos pela pesquisa para a preferência dos egressos, os que menos foram selecionados, com $5 \%$ e $2 \%$ foram respectivamente, a didática do corpo 
docente e a ajuda financeira fornecida pelo programa para a participação em encontros profissionais, podendo ser estes entendidos como congressos, simpósios.

As respostas deste quesito permitem ao PPGIB observar que aspectos podem ser melhorados, dentre os mais diversos oferecidos aos estudantes de mestrado do programa e melhorar os que não "agradam" tanto os estudantes, para que assim os mesmos possam usufruir melhor das possibilidades oferecidas, fazendo com que o PPGIB atinja cada vez mais a excelência entre os programas de pós-graduação existentes na área.

Um dos quesitos que não agradou tanto aos egressos, a didática do corpo docente, pode ser melhorado pelo PPGIB.

Já em relação ao outro quesito que não agradou tanto os alunos, a ajuda financeira para a participação em encontros relacionados à área, o PPGIB poderia rever os valores e aumentá-los na medida do possível. Isto possibilitaria maior interesse dos alunos em participar de um maior número de encontros profissionais, uma vez que a maioria dos alunos de pós-graduação, em geral, depende quase que exclusivamente para se manter de bolsas de estudo ou ajuda financeira de familiares. Desta forma, o maior incentivo financeiro por parte do programa e conseqüente aumento na participação em eventos científicos agregaria maior conhecimento aos estudantes, sobre suas áreas de pesquisa, através do contato com profissionais de outras instituições nacionais e por que não internacionais, além de uma maior divulgação das linhas de pesquisa do PPGIB. Portanto, haveria benefícios para ambas as partes. 
Gráfico 22: Porcentagem dos egressos segundo considera ser a principal contribuição do PPGIB

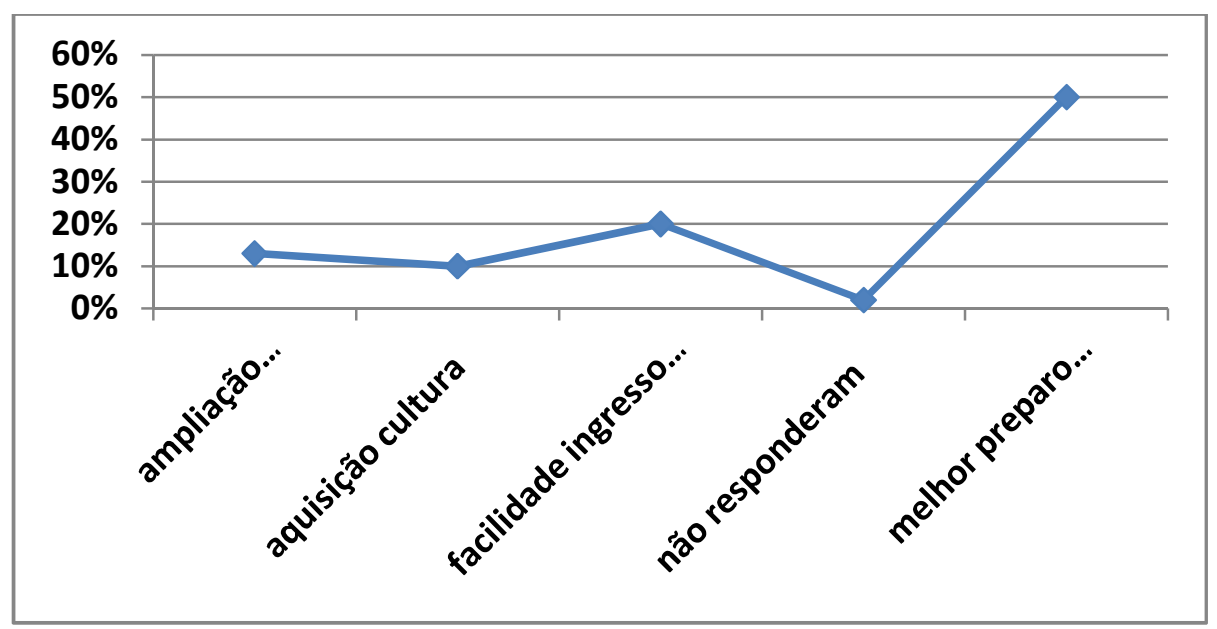

Fonte: Pesquisa com Egressos 2013- PPGIB-EESC-IQSC-FMRP-USP

Os dados apresentados no Gráfico 22, relativos ao questionamento sobre a principal contribuição do programa, para a vida profissional e/ou pessoal dos candidatos, revelam que a grande maioria, 50\% acredita que a principal contribuição do programa foi o melhor preparo para a formação profissional. A facilidade para o ingresso na carreira docente foi indicada por $20,3 \%$ dos candidatos, como sendo a principal contribuição do programa. Já os quesitos como melhora na capacitação pessoal pela aquisição do título de mestre, o fato do grupo de pesquisa ter sido composto por vários profissionais, contato/interação com grupos interdisciplinares, além de melhor preparo para a formação técnica, não alcançaram nem $2 \%$ da escolha dos egressos. Isto nos levar a concluir que o PPGIB tem uma maior declinação em colaborar, mais estreitamente com a formação profissional do aluno.

Quanto à definição da escolha do orientador, podemos observar no Gráfico 23, que a maioria dos egressos teve a atitude de procurar o orientador, correspondendo a $60 \%$ da opção dos mesmos. Nota-se que apenas $1 \%$ dos 
egressos, optou por ser orientado por um professor da graduação, na fase seguinte dos estudos. Isso se deve ao fato de que nem todos os docentes da graduação estão inscritos e habilitados no curso de pós-graduação, ou mesmo, fazendo parte desta não desenvolvem a linha de pesquisa escolhida pelo candidato. Além disso, apenas 3\% escolheram seu orientador em face da falta de opções, indicando provavelmente que os orientadores disponíveis no programa e suas linhas de pesquisa atraem a maioria dos candidatos sendo um ponto positivo a ser considerado.

Por outro lado, $24 \%$ dos egressos responderam terem sido convidados a participar do programa pelo orientador, o que pode indicar que os docentes/orientadores também contribuem com o programa, pois, prestam atenção nos potencias alunos que a graduação oferece, e os convida a fazer parte do PPGIB, aumentando a qualidade do mesmo. Isso também pode ocorrer com os $11 \%$ respondeu ter escolhido o orientador após o processo seletivo, ou isso pode ter ocorrido, devido a indecisão do aluno, frente as várias linhas de pesquisa oferecidas pelo programa. 
Gráfico 23: Porcentagem dos egressos segundo o que define sua orientação no PPGIB

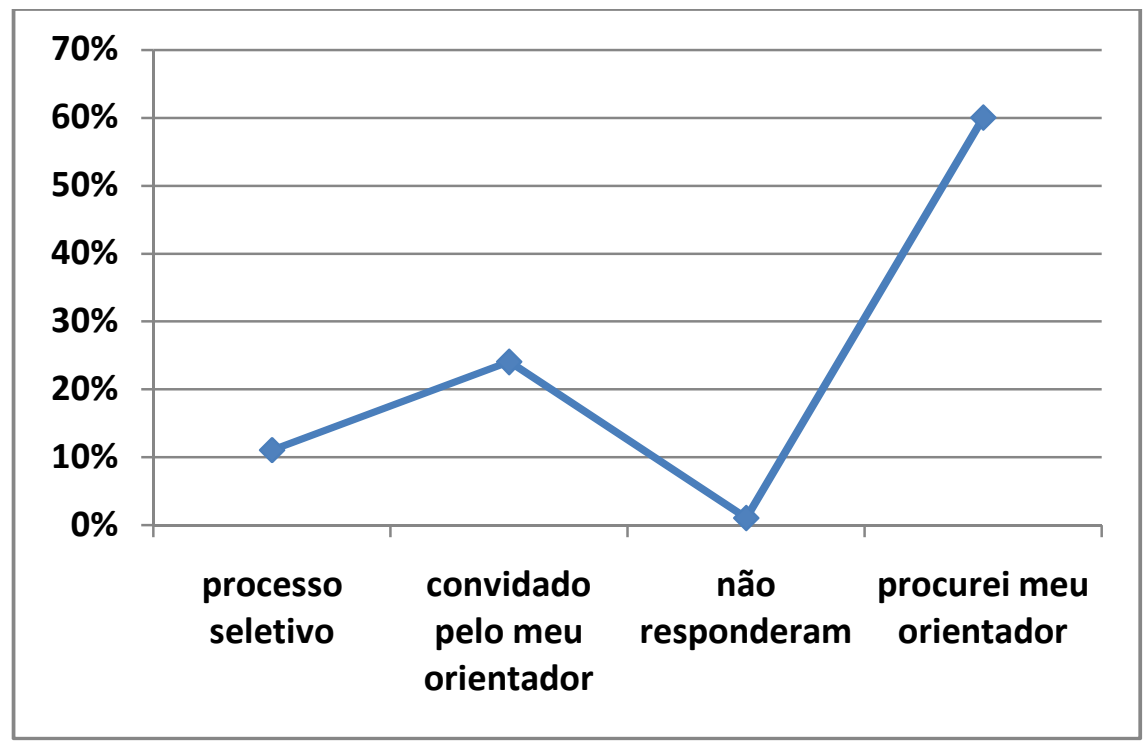

Fonte: Pesquisa com Egressos 2013- PPGIB-EESC-IQSC-FMRP-USP

Dando continuidade ao questionamento entre a relação aluno e orientador, os egressos foram perguntados a respeito da continuidade da parceria entre eles e seus orientadores após o término de suas atividades no programa. Pelos dados apresentados no Gráfico 24 foi possível observar que esta relação, de maneira geral era boa, uma vez que $62 \%$ deram continuidade a parceria, enquanto que $37 \%$ não o fizeram. A relação entre aluno e orientador, quando bem objetivada pode render frutos após o término do programa, como novas parcerias em projetos, quando, por exemplo, o aluno passa a trabalhar em outra instituição que desenvolva a mesma área de pesquisa podendo haver colaboração entre eles; ou mesmo que o egresso possa formar grupos de estudo na área, em outras instituições e contar com a colaboração do orientador para isso. 
Gráfico 24: Porcentagem dos egressos segundo a continuidade da parceria com seu orientador em outros projetos após a conclusão da PósGraduação.

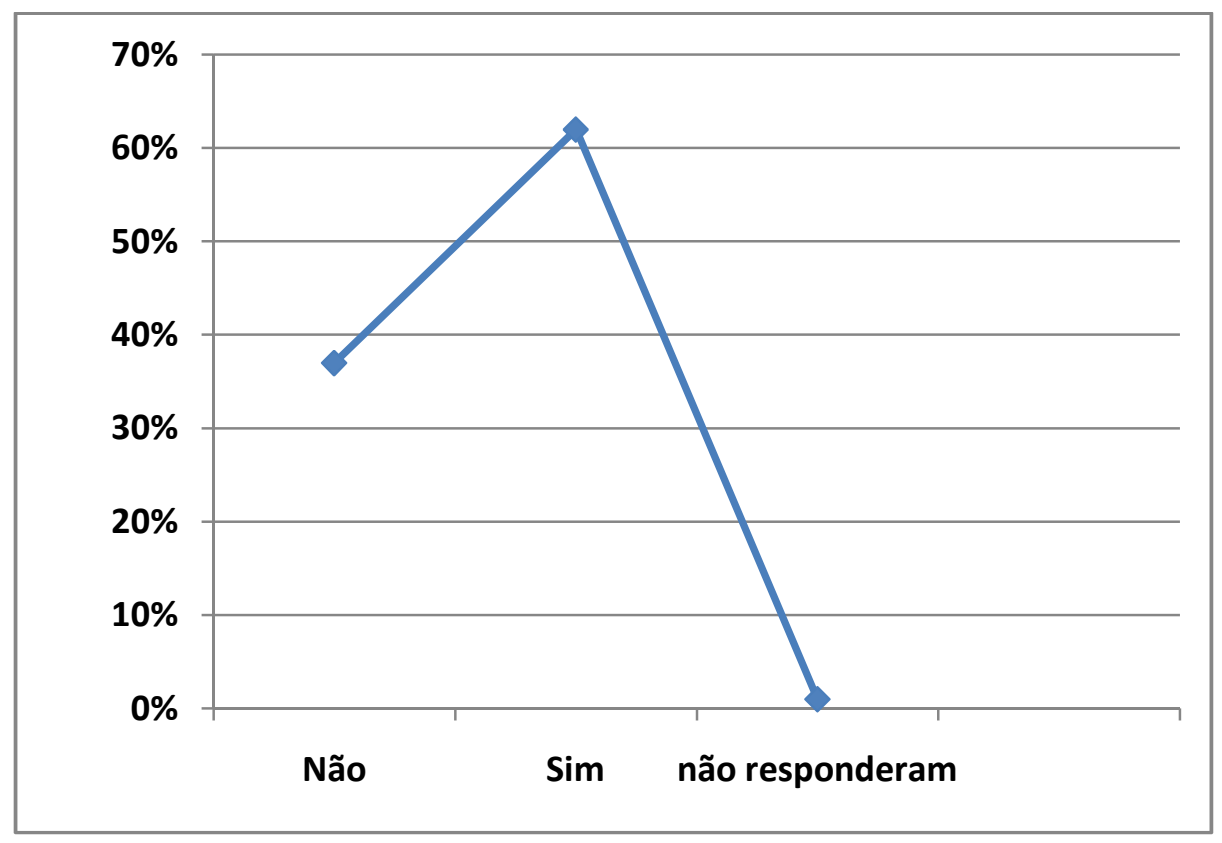

Fonte: Pesquisa com Egressos 2013- PPGIB-EESC-IQSC-FMRP-USP

Ainda continuando a analise da parceria aluno/orientador, os egressos foram questionados sobre como se deu essa parceria. Nota-se pelos dados que $31 \%$ dos egressos apontam que esta parceria se deu por pesquisa conjunta no programa de pós-graduação. Publicações conjuntas em periódicos especializados e pesquisa conjunta fora de programas regulares de pós-graduação empataram com $25 \%$ da opção dos egressos. O desenvolvimento de trabalho conjunto fora do meio acadêmico, o qual pode ser entendido como, por exemplo, trabalho em indústrias, foram escolhidos por $14 \%$ dos egressos (Gráfico 24). Esses resultados são provavelmente reflexos da boa parceria entre aluno/orientador e da continuidade da mesma. 
Gráfico 25: Porcentagem dos egressos segundo sua parceria com orientador PPGIB

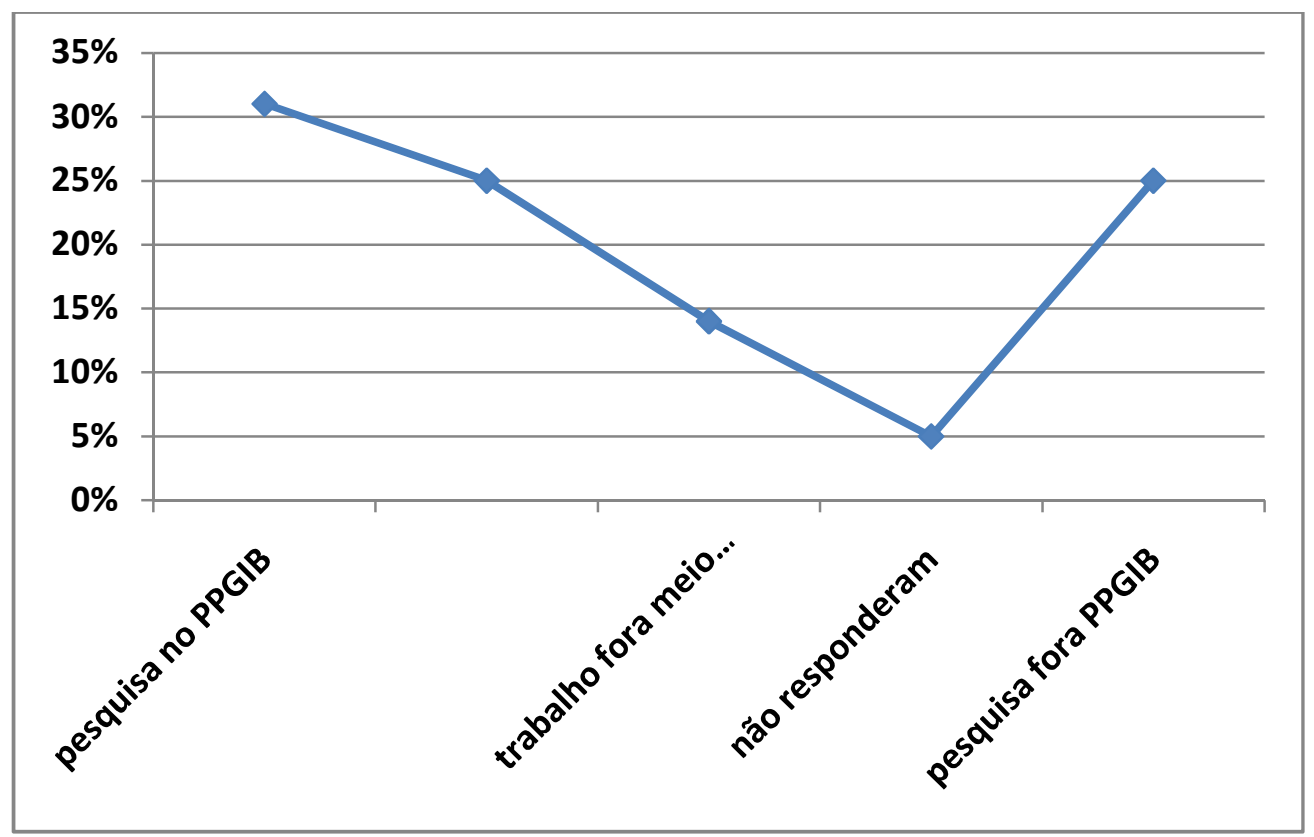

Fonte: Pesquisa com Egressos 2013- PPGIB-EESC-IQSC-FMRP-USP

Os dados apresentados no Gráfico 26 vêm em parte, corroborar as verificações obtidas anteriormente, uma vez que $42 \%$ dos egressos apontam que a disponibilidade para atendimento de seu orientador é o aspecto relativo mais satisfatório, do relacionamento aluno/orientador. Em seguida, 33\% apontam a qualidade da orientação como aspecto mais satisfatório.

Por outro lado, os outros quesitos são apontados por bem menos egressos como aspectos plenamente satisfatórios. Alguns deles provocam questionamentos pertinentes à qualidade da orientação e também da relação entre algumas atitudes dos orientadores e alguns pontos apontados pelos egressos como não satisfatórios dentro do programa.

Alguns exemplos, como falta de apoio em congressos e simpósios, pequena assistência na solicitação de bolsas ou na renovação das mesmas, podem ter, mesmo que inconscientemente, relação com a falta de incentivo financeiro do programa para a participação em reuniões profissionais, desmotivando o aluno; e 
também a falta de colaboração do orientador em buscar com o aluno a obtenção de bolsas de estudo ou a renovação da mesma quando necessário.

Outro ponto que chama a atenção é o pequeno número de egressos que optou pela publicação internacional, apenas $1 \%$. Isto também precisa ser mudado, pois afeta diretamente a qualidade do programa de pós-graduação. Além disso, apenas $2 \%$ optaram pela disponibilidade de atendimento do orientador na etapa de conclusão do trabalho, fato que de certa forma pode afetar a qualidade do trabalho desenvolvido pelo aluno. Outro ponto que também pode ser mudado é o fato de apenas $2 \%$ dos egressos optou pela parceria, amizade sem distâncias ou barreiras para o relacionamento com o orientador. De certa forma, isto pode afetar a relação entre eles e desmotivar o aluno a seguir na parceria com o orientador, após o término do programa, ou mesmo continuar nele.

Gráfico 26: Porcentagem dos egressos segundo seu relacionamento com seu orientador no PPGIB considerado satisfatório

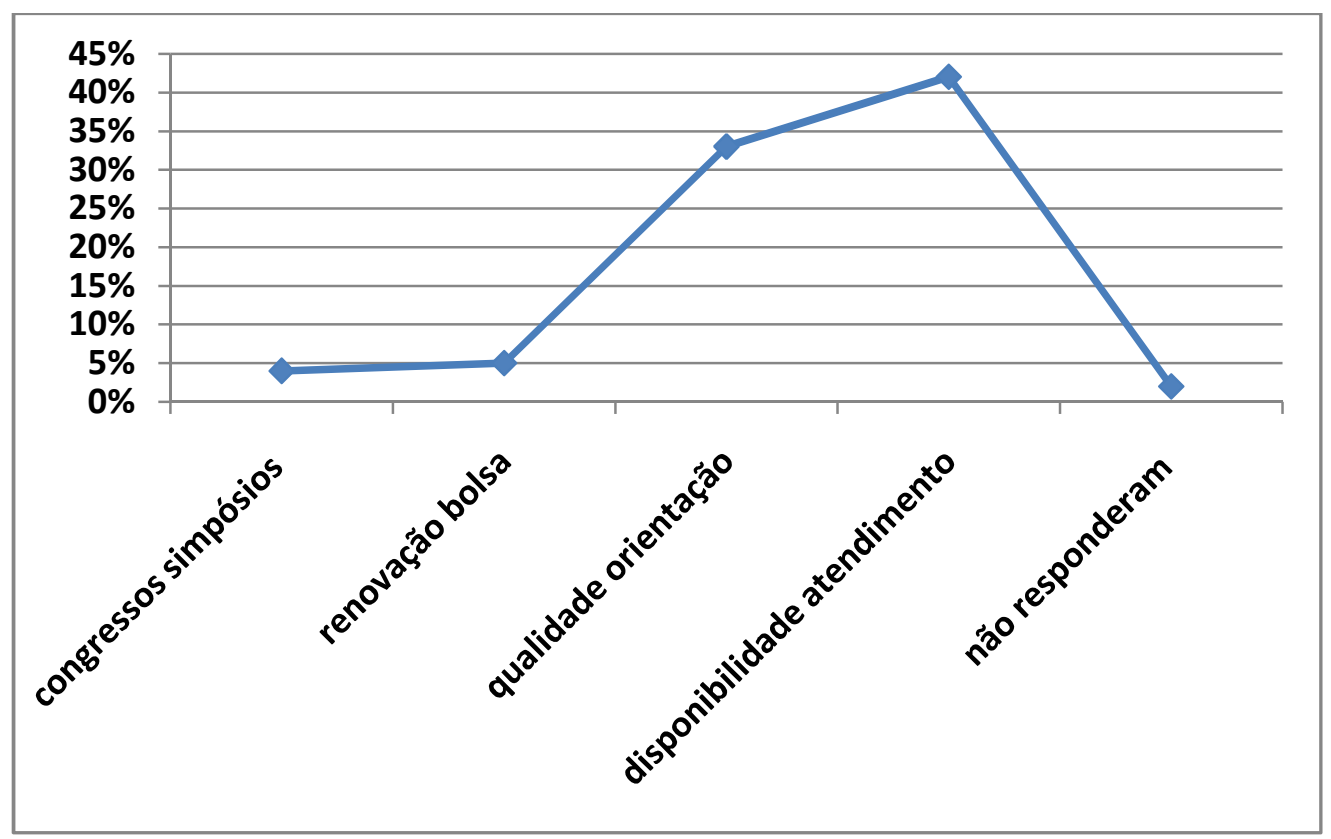

Fonte: Pesquisa com Egressos 2013- PPGIB-EESC-IQSC-FMRP-USP 
Com relação à contribuição positiva que o programa trouxe para sua formação profissional, $80 \%$ dos egressos afirmam que houve contribuição positiva, enquanto que $9 \%$ não consideram que o programa contribuiu de maneira positiva para sua formação profissional (Gráfico 27).

Gráfico 27: Porcentagem dos egressos segundo contribuições positivas do PPGIB para a sua formação profissional

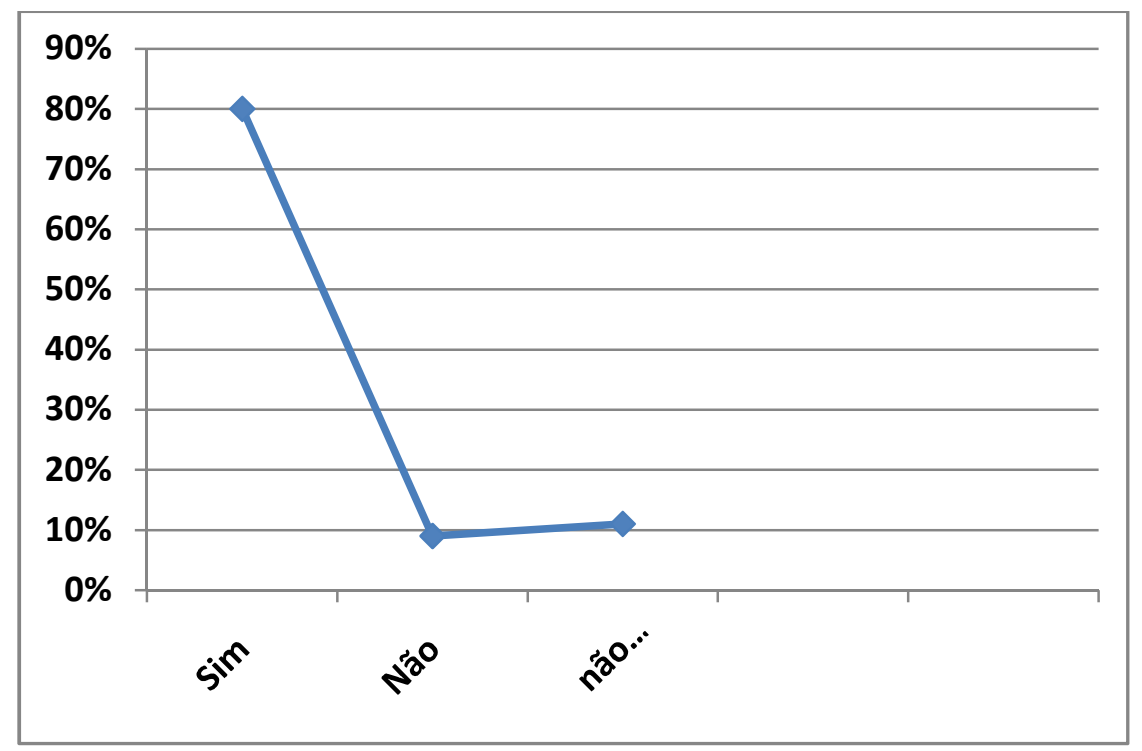

Fonte: Pesquisa com Egressos 2013- PPGIB-EESC-IQSC-FMRP-USP

A maioria dos egressos, 11,4\%, aponta o desenvolvimento da habilidade de pensar criticamente como a contribuição do programa para sua formação. Em segundo lugar estão empatados, a preparação em metodologia de pesquisa e a preparação para a docência, com $11,2 \%$, seguidos de autonomia em pesquisa, desenvolvimento de capacidade de organização, expressão e comunicação do pensamento, com $10 \%$. O que chama a atenção é que apenas $6,4 \%$ dos egressos apontam que a articulação do conhecimento da área com temas gerais e situações do cotidiano, como contribuição do programa. Este ponto precisa ser revisto pelo mesmo, uma vez que isto pode influenciar na qualidade do profissional formado, 
quando este ingressar no mercado de trabalho e necessitar desta contribuição (Gráfico 28).

Gráfico 28: Porcentagem dos egressos segundo a contribuição para sua formação que considera ser atribuída ao PPGIB.

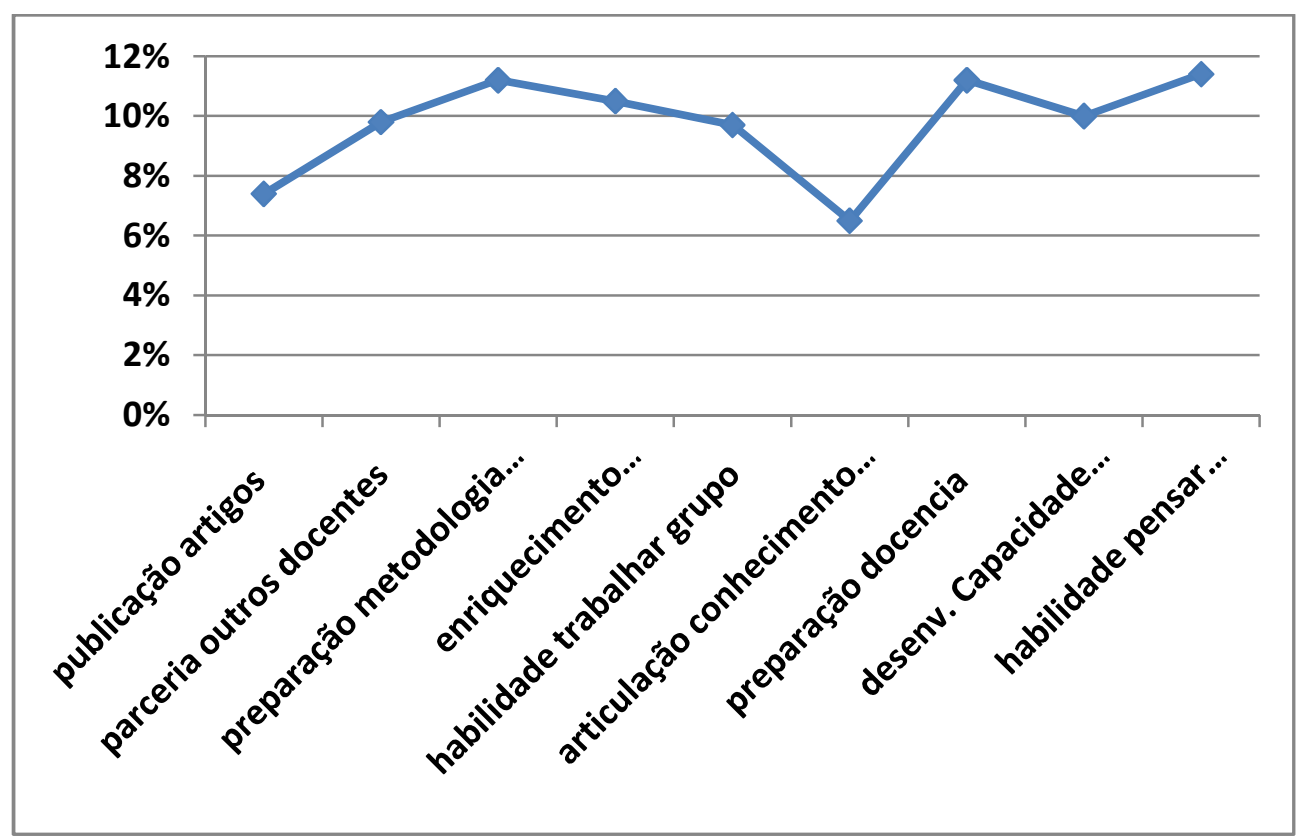

Fonte: Pesquisa com Egressos 2013- PPGIB-EESC-IQSC-FMRP-USP

Em relação à apresentação de trabalho em encontros durante a permanência do egresso no programa, $44 \%$ afirmam ter realizado esta tarefa, enquanto $36 \%$ afirmam não ter apresentado trabalhos. O que chama a atenção neste ponto do questionário é o grande número de egressos que deixou de responder a pergunta, $20 \%$, o que possivelmente poderia ter melhorado a porcentagem de apresentações feitas (Gráfico 29). 
Gráfico 29: Porcentagem dos egressos segundo os artigos apresentados durante sua permanência no PPGIB

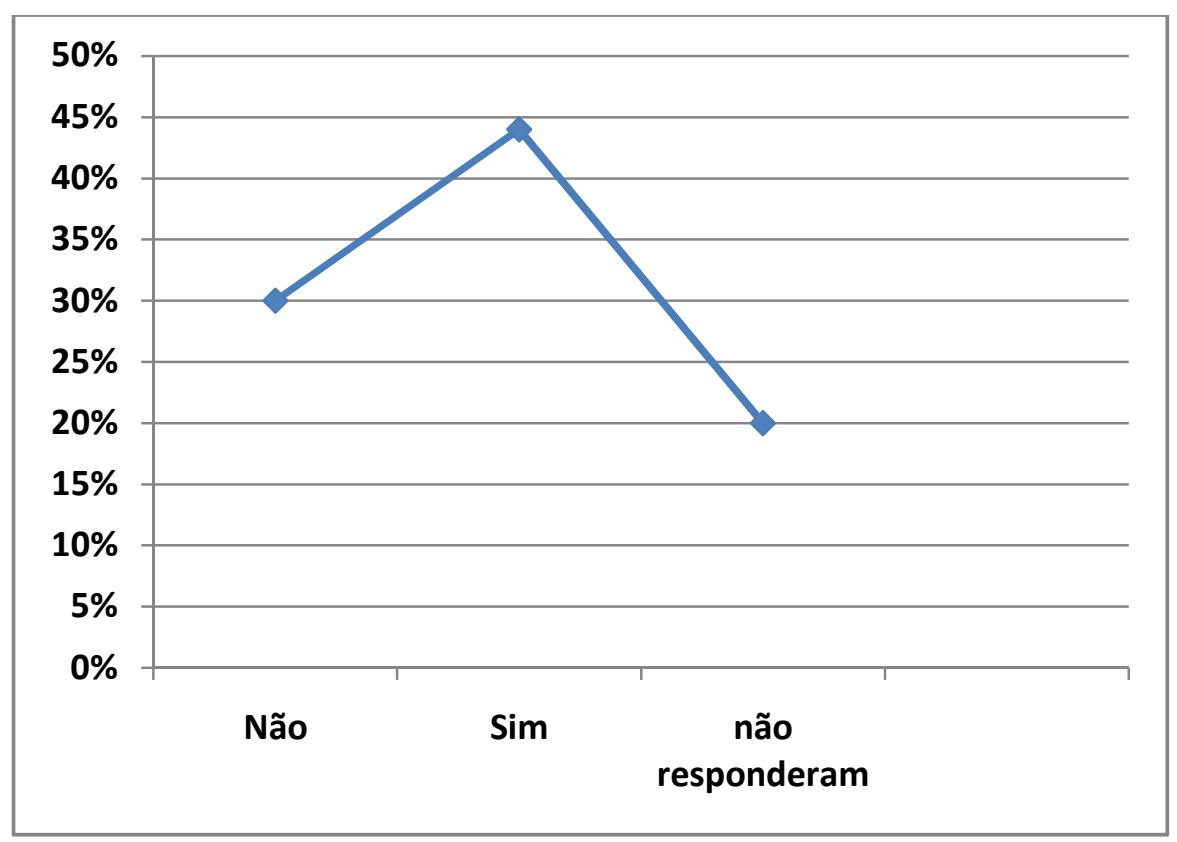

Fonte: Pesquisa com Egressos 2013- PPGIB-EESC-IQSC-FMRP-USP

O tipo de encontro, no qual os egressos apresentaram o maior número de trabalhos, foram congressos regionais/nacionais, com $36 \%$, sendo em congressos internacionais 10\%; em seminários em outras instituições que não a do programa 18\%; praticamente empatados com $17 \%$ que apresentaram trabalhos em seminários realizados na instituição do programa (Gráfico 30). 
Gráfico 30: Porcentagem dos egressos segundo o tipo de encontro e o número de artigos apresentados.

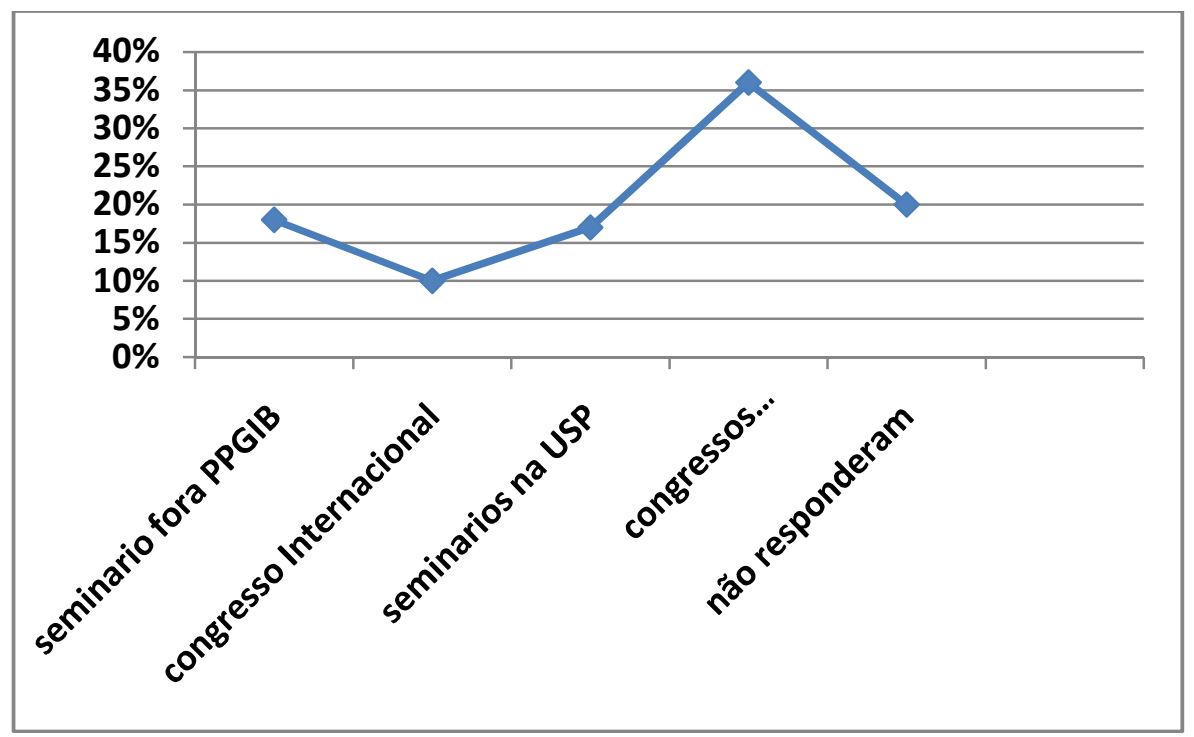

Fonte: Pesquisa com Egressos 2013- PPGIB-EESC-IQSC-FMRP-USP

Em relação às publicações feitas durante a permanência do egresso no programa, $46 \%$ afirmam ter publicado, enquanto $36 \%$ responderam não ter publicado. Novamente, o número de egressos que não respondeu ao questionamento é alto, 18\% (Gráfico 31). 
Gráfico 31: Porcentagem dos egressos segundo publicação incluindo as já aceitas para serem publicadas.

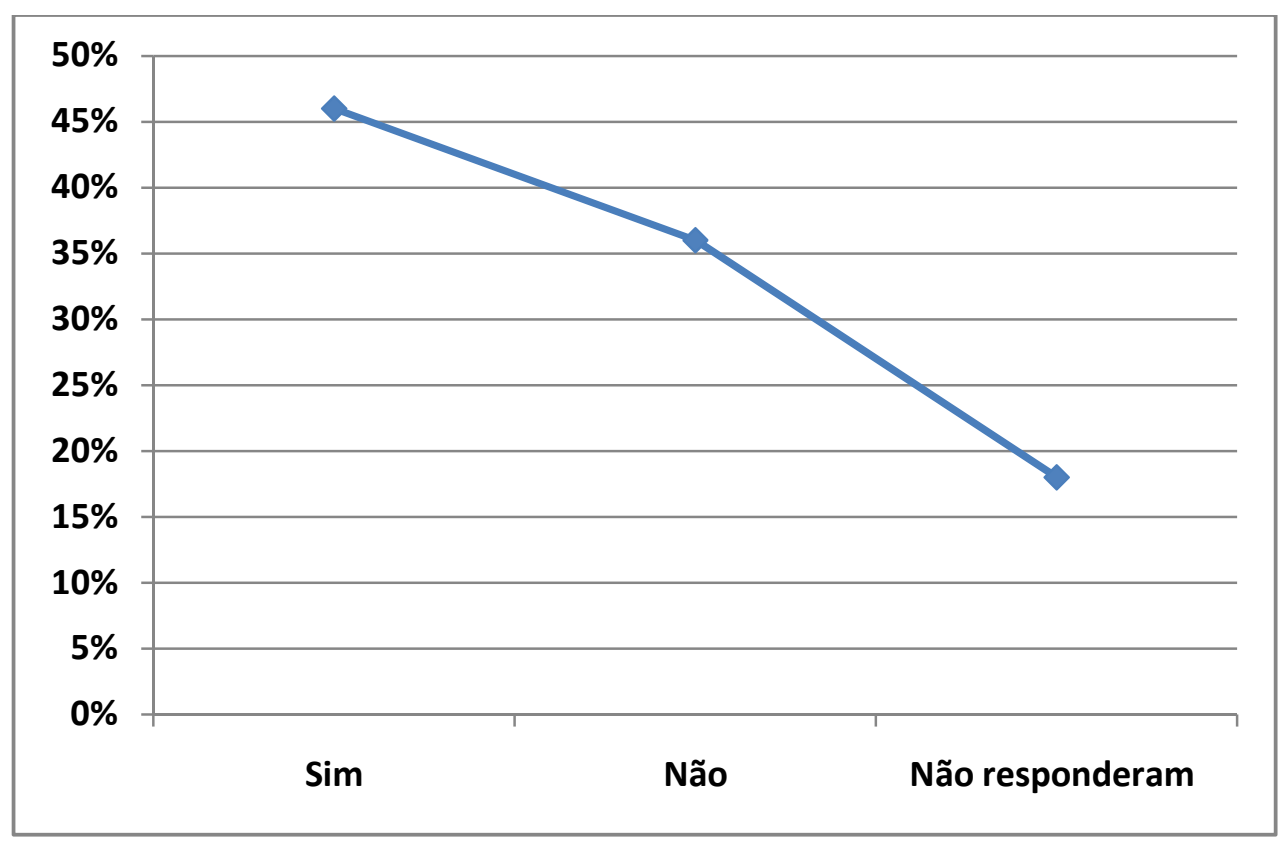

Fonte: Pesquisa com Egressos 2013- PPGIB-EESC-IQSC-FMRP-USP

Quanto ao número e tipo de encontro, no qual houve divulgação de sua pesquisa, $14 \%$ dos egressos afirmam ter ganho prêmios durante sua permanência nesta etapa acadêmica. Apenas $1 \%$ afirma ter patente em seu nome, enquanto $2 \%$ afirmam ter divulgado seus trabalhos em exposições e mostras. Mais uma vez, grande número de egressos, $83 \%$ não respondeu a pergunta. 
Gráfico 32: Porcentagem dos egressos segundo o número de:

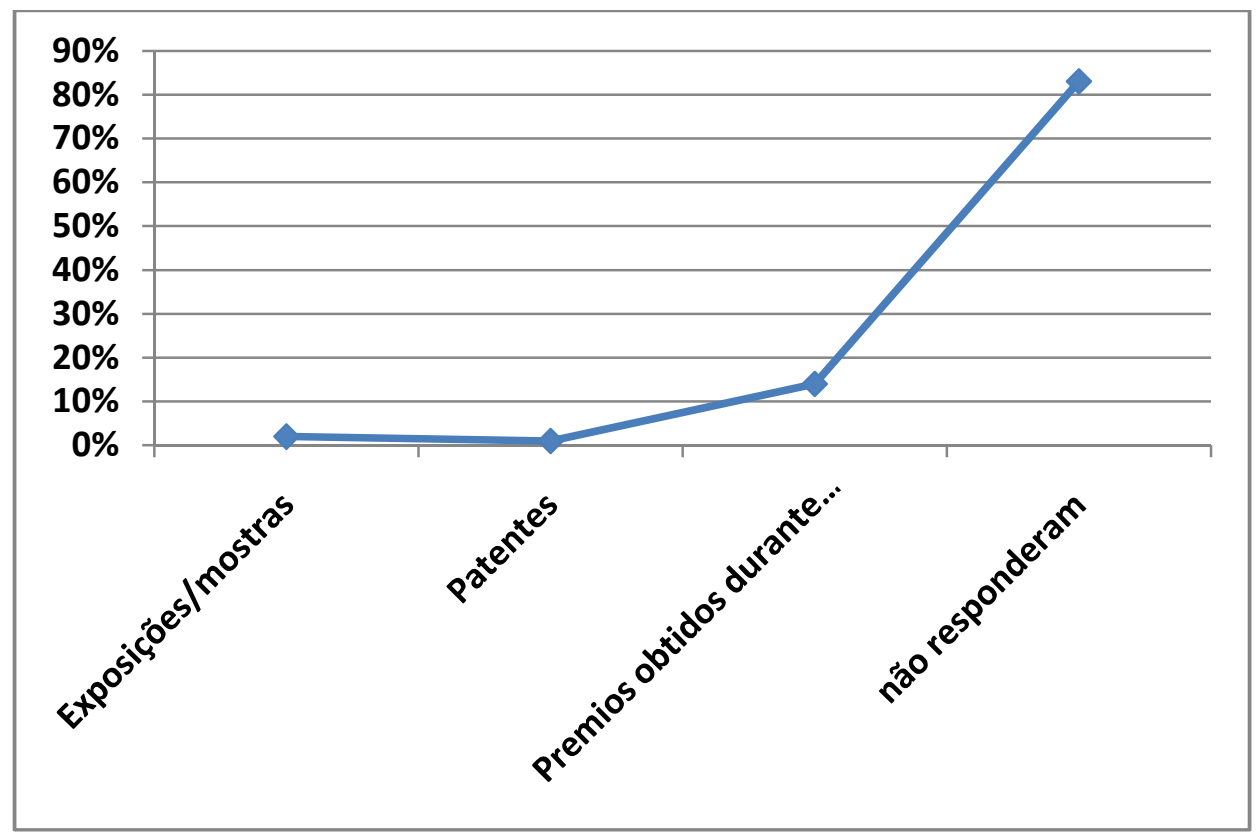

Fonte: Pesquisa com Egressos 2013- PPGIB-EESC-IQSC-FMRP-USP

Ao contrário do que se observou na pergunta anterior, apenas $1 \%$ não respondeu quanto ao número de publicações produzidas no mestrado. As publicações em que o egresso aparece como autor principal é maioria, totalizando $43 \%$, seguidos de $30 \%$ que afirmam ter publicações em anais de congressos/simpósio/encontros, como co-autores são 16\% dos egressos que afirmam ter publicações sob esta condição, enquanto que, o que chama a atenção é que apenas $9 \%$ afirmam ter publicações em periódicos com política seletiva editorial (Gráfico 33). 
Gráfico 33: Porcentagem dos egressos segundo suas publicações no PPGIB, incluindo também as serem publicadas

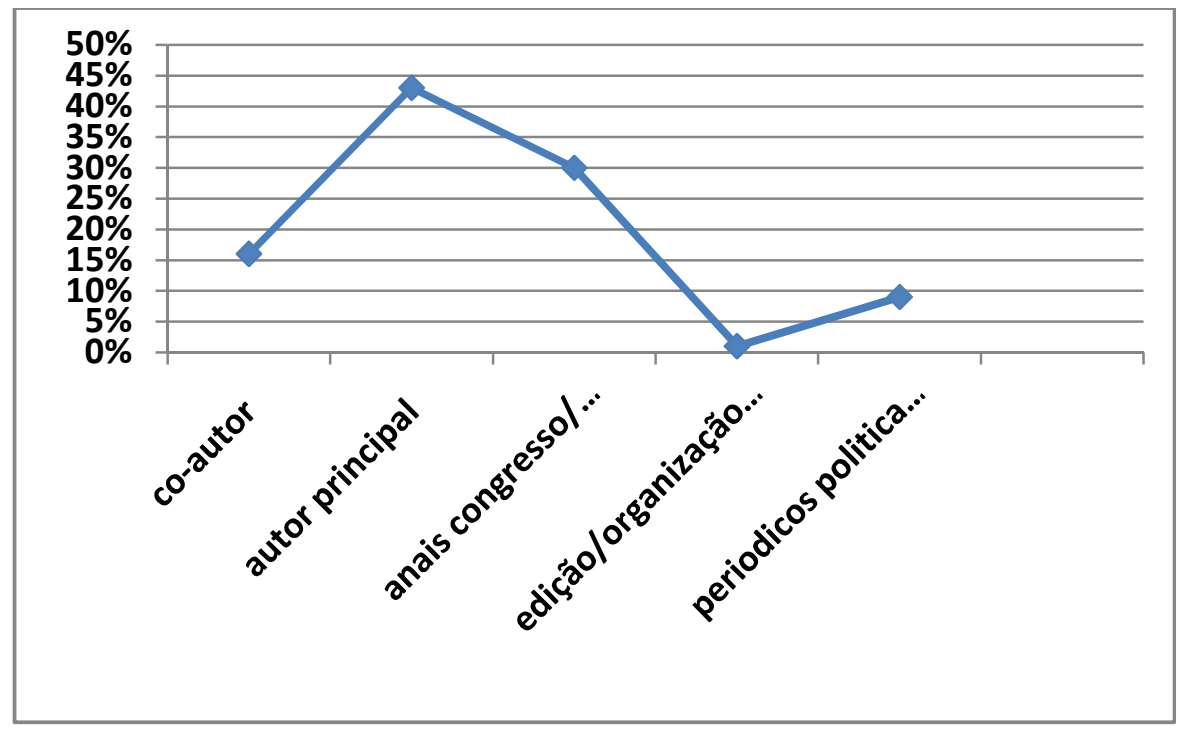

Fonte: Pesquisa com Egressos 2013- PPGIB-EESC-IQSC-FMRP-USP

As questões apresentadas nesta categoria têm por objetivo colher informações sobre o programa de Pós-Graduação. As questões constituem-se de assertivas, com as quais você pode ou não concordar. Foi solicitada avaliação em cada uma delas, cabendo ao egresso optar dentre as alternativas disponíveis.

Podemos observar pelo Gráfico 34 , que a maioria dos egressos, $56 \%$ concorda plenamente, que participar deste programa de pós-graduação foi uma decisão acertada e aconteceu no momento apropriado. Por outro lado, $28 \%$ concordam parcialmente com esta afirmação. Aqueles que discordam total ou parcialmente desta afirmação, totalizam completar 
Gráfico 34: Porcentagem dos egressos segundo a decisão de participar PPGIB ocorreu no momento apropriado.

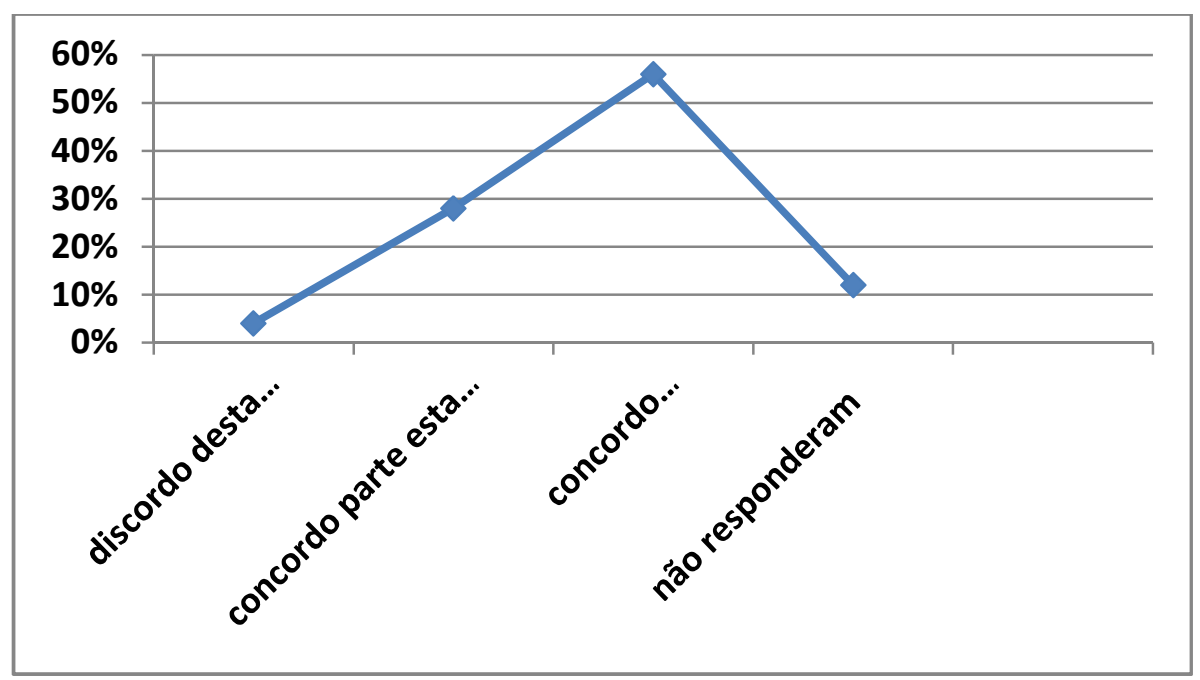

Fonte: Pesquisa com Egressos 2013- PPGIB-EESC-IQSC-FMRP-USP

Ao serem questionados se o programa de Pós-Graduação desta etapa acadêmica atendeu totalmente as expectativas, a maioria dos egressos, $42 \%$ concordam plenamente com esta declaração, $37 \%$ concordam em parte, $9 \%$ dos egressos não souberam avaliar, e empatados com $5 \%$ estão os egressos que não souberam avaliar ou discordam inteiramente desta declaração (Gráfico 35). 
Gráfico 35: Porcentagem dos egressos segundo o PPGIB atender totalmente as expectativas

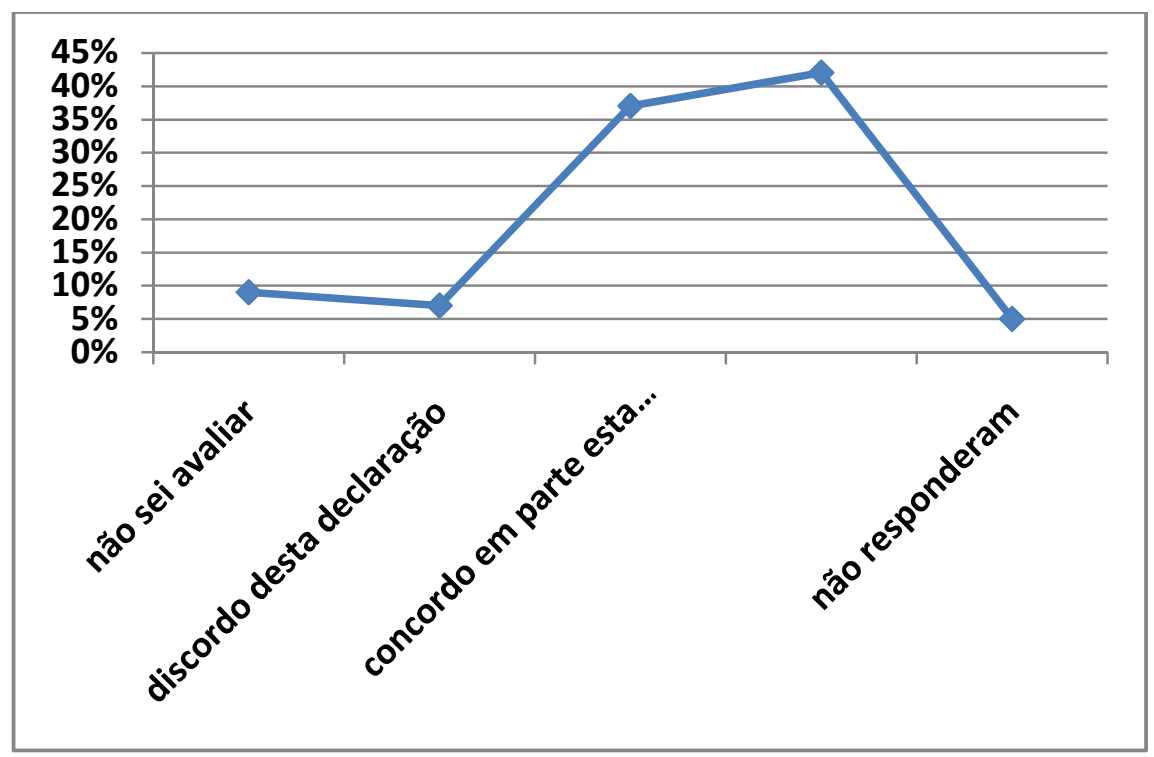

Fonte: Pesquisa com Egressos 2013- PPGIB-EESC-IQSC-FMRP-USP

Quanto ás instalações físicas, foi perguntado aos egressos se as mesmas, em termos de salas de aula, laboratórios e ambientes de estudo/trabalho estavam em conformidade com as necessidades do programa de pós-graduação. A maioria dos egressos, $47 \%$ concordam em parte com esta declaração, ou seja, para eles, ainda que pouco, algumas das instalações oferecidas não são totalmente adequadas. Para $36 \%$ dos egressos, a concordância é plena, com relação às instalações, enquanto que para $12 \%$ dos egressos, as instalações não estão de acordo com as necessidades. Assim sendo, acredita-se que caso hajam adequações a serem feitas na estrutura física, estas serão de pequeno porte (Gráfico 36). 
Gráfico 36: Porcentagem dos egressos segundo as instalações físicas do PPGIB serem perfeitamente adequadas às necessidades.

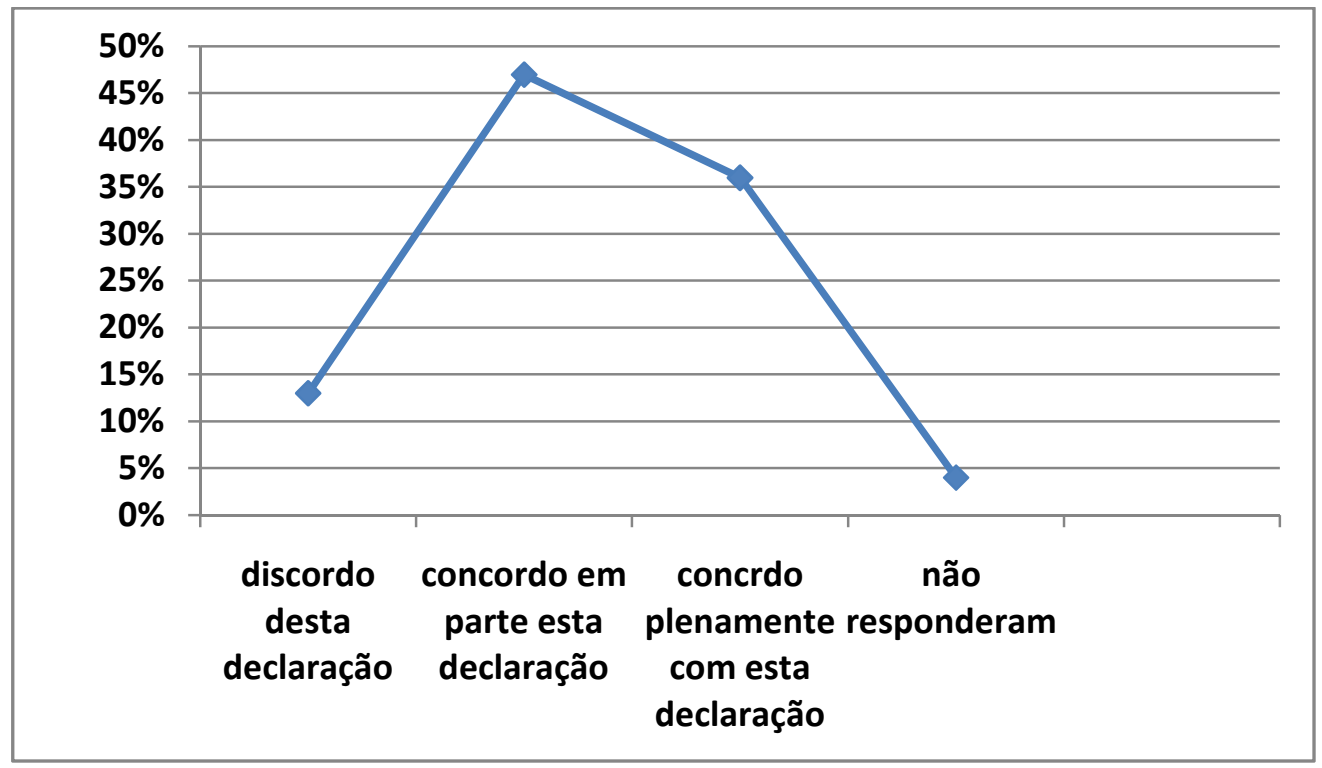

Fonte: Pesquisa com Egressos 2013- PPGIB-EESC-IQSC-FMRP-USP

Também foi perguntada aos egressos, sua opinião quanto a compatibilidade do sistema informatizado, oferecido pela biblioteca que atende ao programa, com as necessidades do mesmo. A maioria dos egressos, $53 \%$ concordam plenamente que o sistema oferecido pela biblioteca supre as necessidades do programa, enquanto que $33 \%$ concordam que as necessidades são supridas em parte pelo sistema. Apenas 4\% não concordam com a eficiência do sistema em suprir as necessidades do programa e 5\% não souberam avaliar (Gráfico 37). Desta forma, entende-se que o sistema informatizado, oferecido pela biblioteca está em conformidade com as necessidades do programa e não necessita de ajustes. 
Gráfico 37: Porcentagem dos egressos segundo a disposição do sistema informatizado das bibliotecas disponíveis para o PPGIB serem compatíveis com as necessidades.

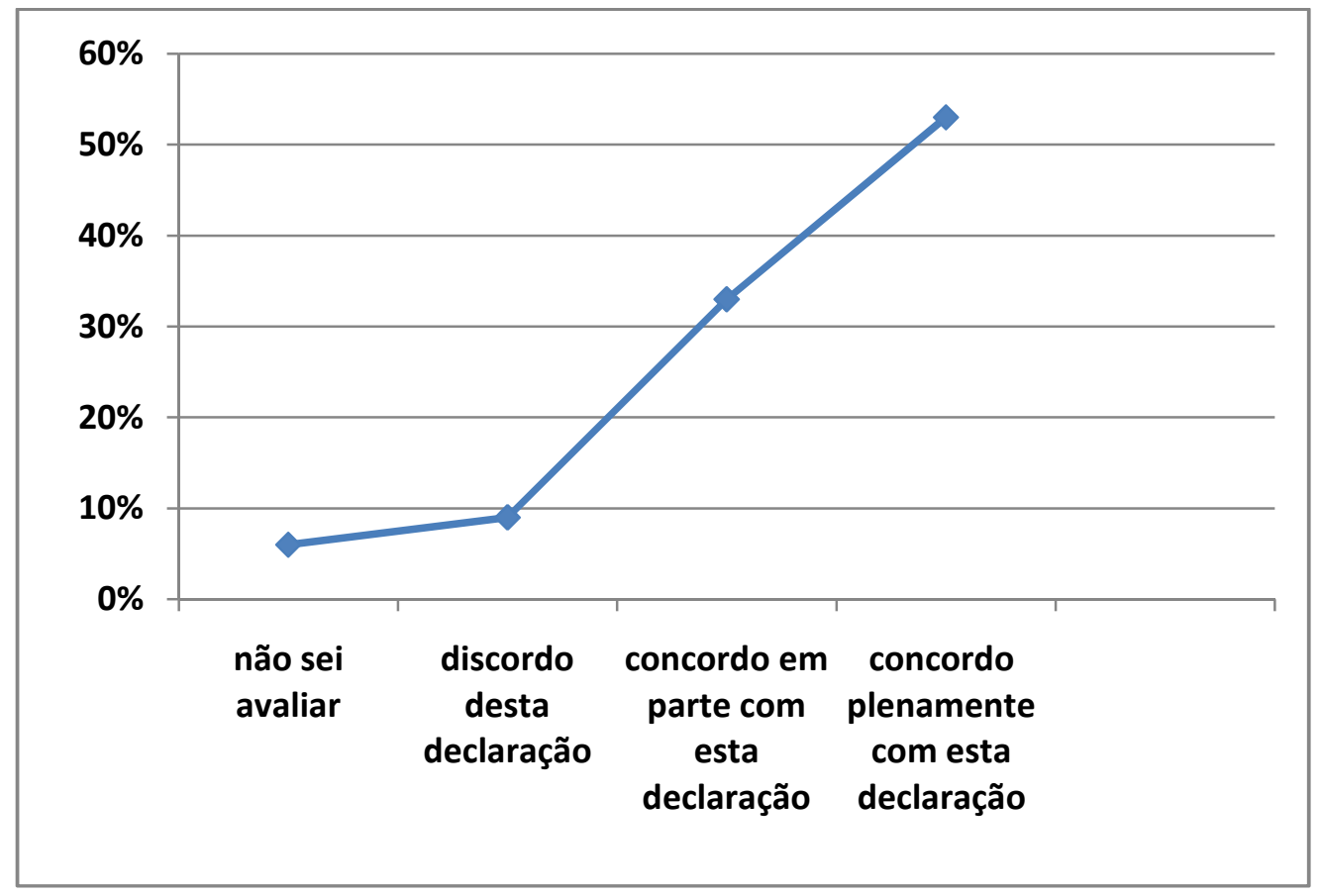

Fonte: Pesquisa com Egressos 2013- PPGIB-EESC-IQSC-FMRP-USP 
Gráfico 38: Porcentagem dos egressos segundo o acervo livros das bibliotecas serem adequados em face das necessidades da pesquisa

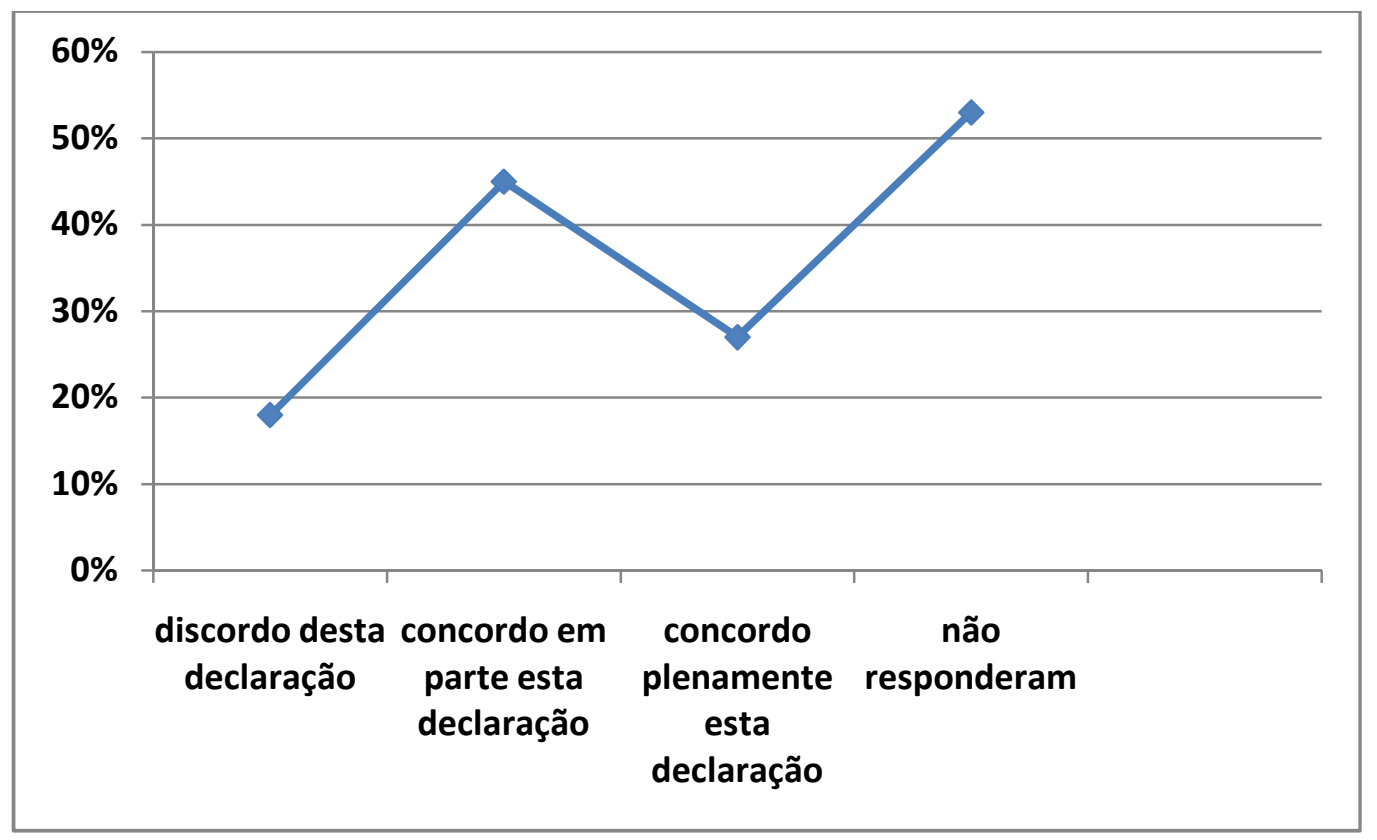

Fonte: Pesquisa com Egressos 2013- PPGIB-EESC-IQSC-FMRP-USP

Ainda em relação à biblioteca que atende ao programa, mas agora com referência aos livros, foi perguntado aos egressos, se o acervo de livros era adequado, em face das necessidades de sua pesquisa. A maioria dos egressos concordou em partes com essa declaração, totalizando $45 \%$. Já $27 \%$ dos egressos concordam plenamente com esta declaração; 18\% discordam desta declaração; $8 \%$ dos egressos não responderam, e 2\% não souberam avaliar (Gráfico 38). 
Gráfico 39: Porcentagem dos egressos segundo a participação no PPGIB ser decisiva na definição da vida profissional.

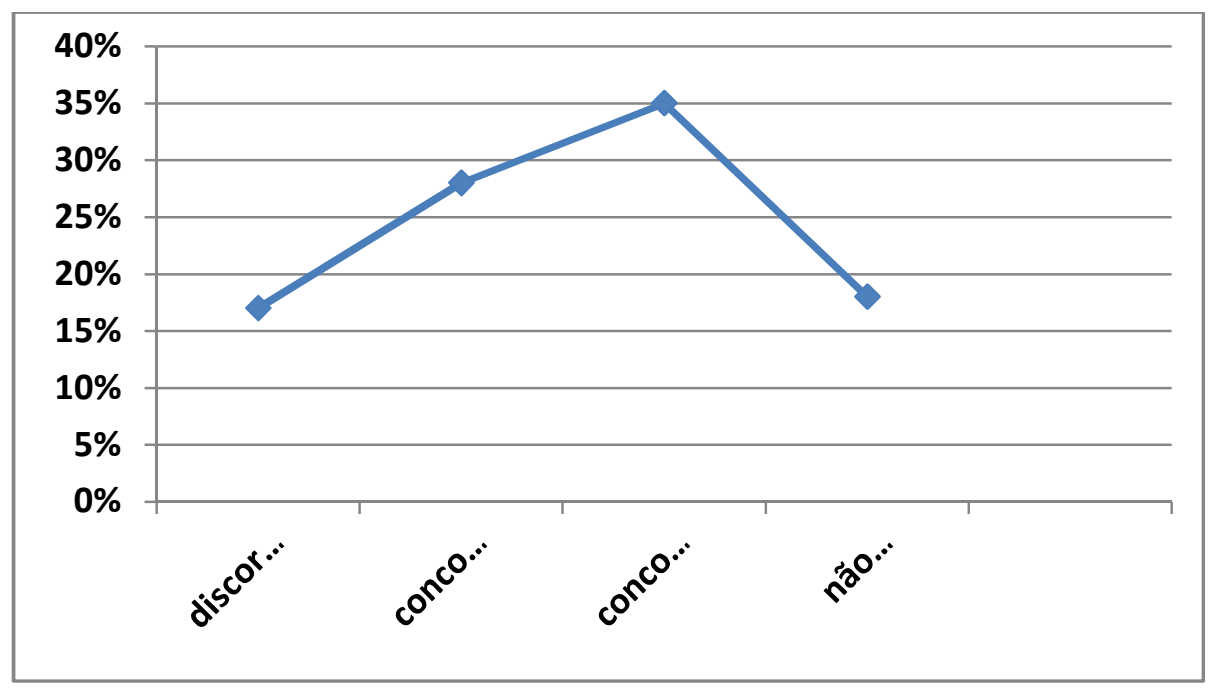

\section{Fonte: Pesquisa com Egressos 2013- PPGIB-EESC-IQSC-FMRP-USP}

Quando questionados sobre a participação neste programa de PósGraduação ter sido decisiva, na definição da sua vida profissional, $35 \%$ dos egressos concordam plenamente com esta declaração; $28 \%$ concordam em parte; $18 \%$ dos egressos não responderam; $14 \%$ discordam desta declaração e $2 \%$ dos egressos não souberam avaliar (Gráfico 39). Podemos observar que se somando todos os que concordam, total ou parcialmente com esta afirmação, teremos $63 \%$ dos egressos concordando que participar do programa foi decisivo em suas vidas profissionais, índice muito superior aos que discordam, 17\%, total ou parcialmente com a afirmação. Ainda que, os $18 \%$ dos egressos que não votaram, discordassem da afirmação, a maioria, ainda seria favorável, levando a concluir que os egressos estão satisfeitos com a relação entre sua participação no programa e a definição de sua vida profissional. 
Os egressos foram perguntados se sua participação no programa de pósgraduação contribuiu para sua formação profissional. Assim como observado no gráfico acima, a maioria dos egressos, $78 \%$ concordam plena ou parcialmente com esta afirmação; enquanto que $11 \%$ discordam parcial ou inteiramente com esta afirmação e percentual parecido $9 \%$ não responderam, sendo que apenas $2 \%$ não souberam avaliar (Gráfico 40).

Gráfico 40: Porcentagem dos egressos segundo a participação no PPGIB ter contribuído para a formação

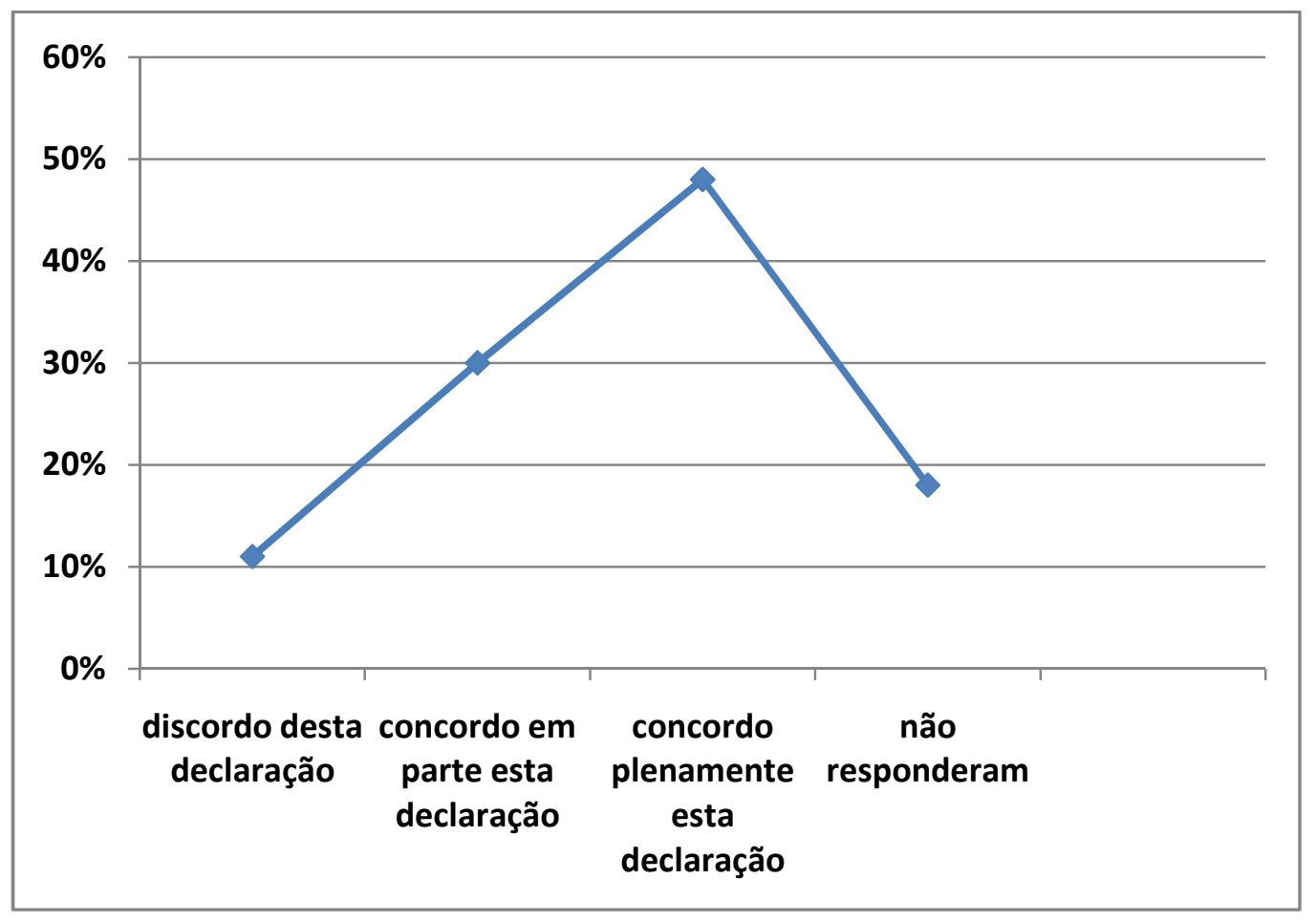

Fonte: Pesquisa com Egressos 2013- PPGIB-EESC-IQSC-FMRP-USP 
Gráfico 41: Porcentagem dos egressos segundo os aspectos mais positivos do PPGIB.

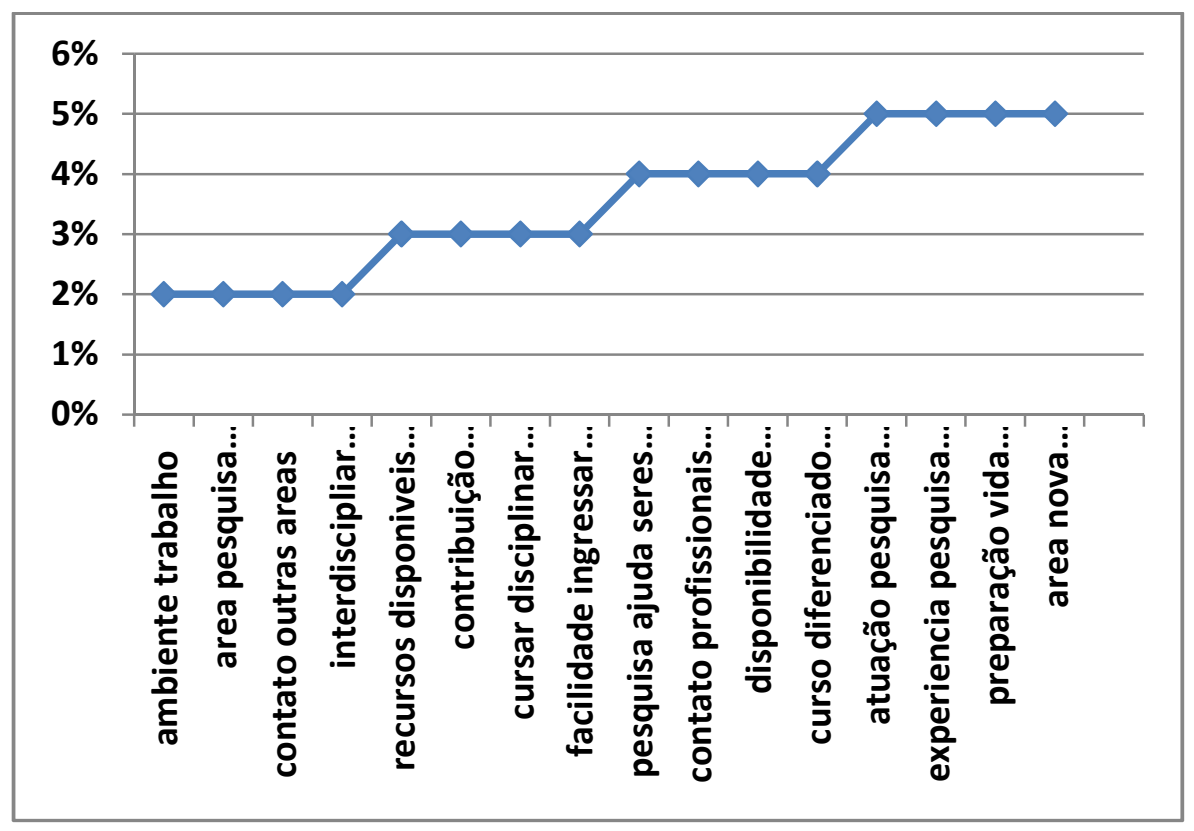

Fonte: Pesquisa com Egressos 2013- PPGIB-EESC-IQSC-FMRP-USP

Perguntas abertas geram múltiplas opiniões e dividem muito os percentuais relativos a cada resposta, não sendo possível então, observar uma maioria significativa em apenas uma alternativa (Gráfico 41). Os maiores percentuais, $5 \%$ foram registrados em alternativas como atuação em pesquisa inovadora; experiência com pesquisa multidisciplinar; preparação para a vida acadêmica; área nova do conhecimento e crescimento da bioengenharia. Em seguida, com 4\% estão descritas como aspectos positivos, pesquisa desenvolvida para ajudar seres humanos; possibilidade de contato com profissionais da formação; assiduidade e disponibilidade dos professores; curso diferenciado de pós-graduação; interação com outras universidades; preparação com a carreira de docente, entre outros. Na seqüência, com 3\% estão a contribuição para a formação profissional; a possibilidade de cursar disciplinas de interesse fora da unidade; facilidade de 
ingresso no programa, entre outros. Assim, podemos concluir que os resultados obtidos neste quesito, estão de acordo com várias respostas obtidas anteriormente.

Gráfico 42: Porcentagem dos egressos sobre os aspectos mais negativos do PPGIB

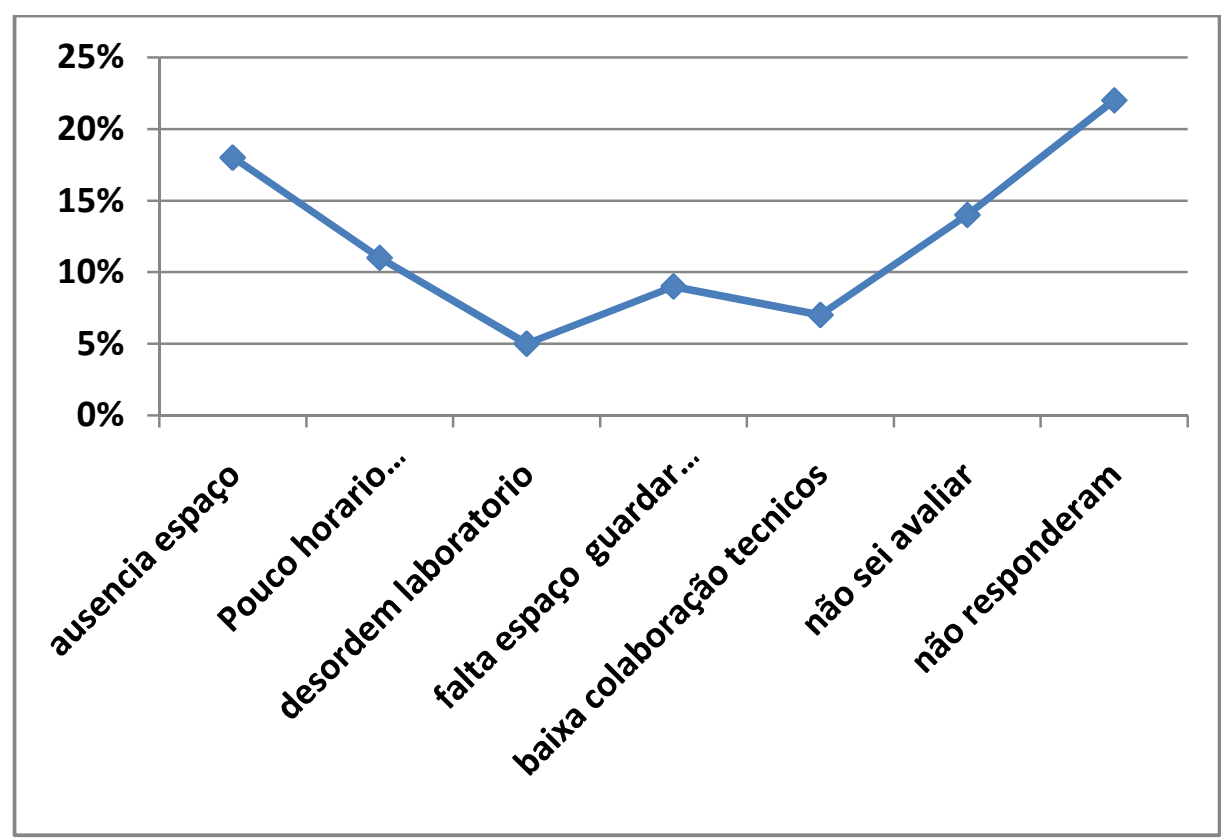

Fonte: Pesquisa com Egressos 2013- PPGIB-EESC-IQSC-FMRP-USP

Quando questionados em relação aos pontos negativos, observa-se na ausência de espaço, com $18 \%$ da escolha dos egressos, seguido da dificuldade em estudar no local de convivência, com 14\%, mesmo índice observado para aqueles egressos que não souberam avaliar. Com $11 \%$ sobre o pequeno horário de atendimento da secretaria. Aspectos relativos ao laboratório como a desordem, estão com $5 \%$, e quanto à sala de estudo, $9 \%$ reclamam da falta de lugar para se deixar o material pessoal. As respostas obtidas nesta questão são de grande importância para o programa, e geram um fio condutor sobre as mudanças necessárias, grande parte em termos de organização de espaço físico, para 
proporcionar melhor conforto aos alunos e com isso, aumentar seus rendimentos (Gráfico 42).

Gráfico 43: Porcentagem dos egressos segundo sua dissertação ter sido publicada.

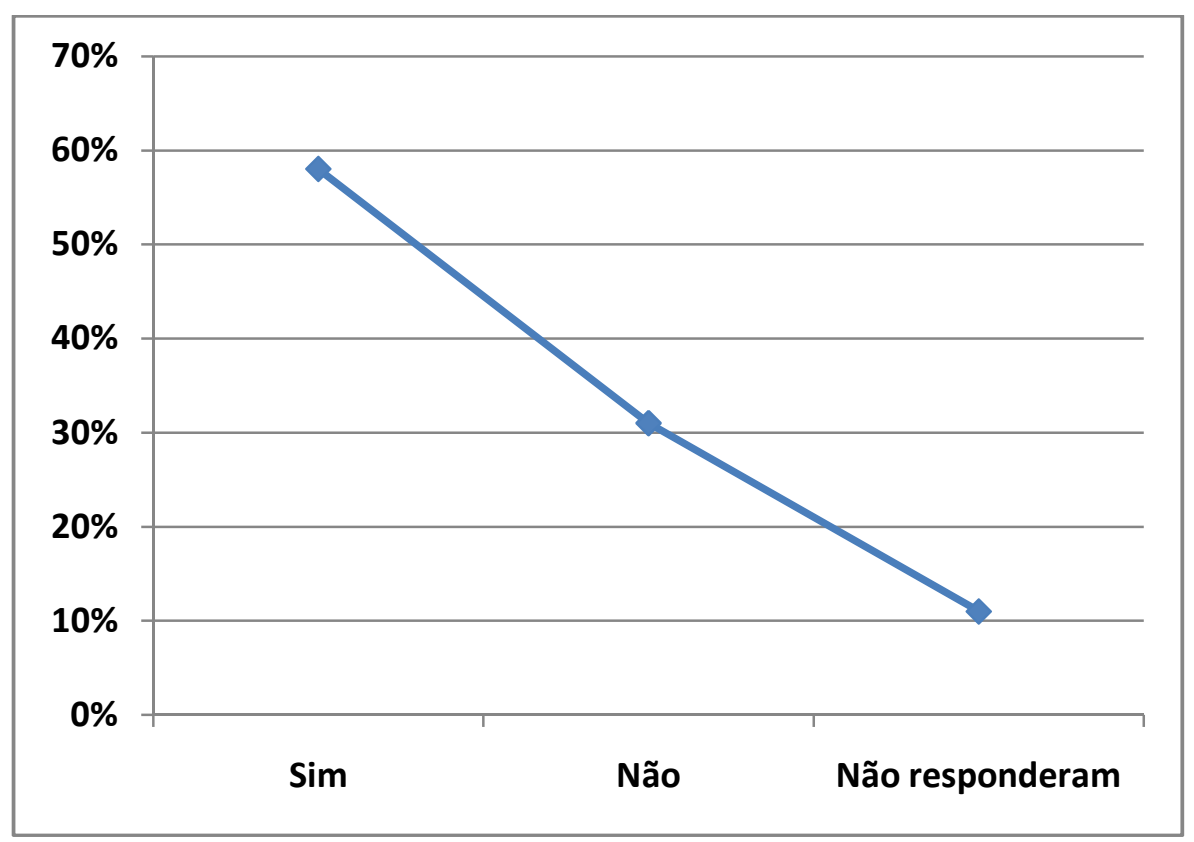

Fonte: Pesquisa com Egressos 2013- PPGIB-EESC-IQSC-FMRP-USP

Quando perguntados se sua dissertação de mestrado foi publicada, 58\% dos egressos afirmam a publicação, enquanto $31 \%$ afirmam não ter publicado a dissertação. Esse número de publicações poderia aumentar, se fossem checadas ao final das defesas, as dissertações que apresentassem conteúdo de qualidade, a partir do qual, pudessem ser extraídos artigos publicáveis em revistas nacionais ou internacionais. Além disso, é possível que o número de egressos que não respondeu essa pergunta, $11 \%$ tenha publicado sua dissertação, o que elevaria o nível de publicações (Gráfico 43). 
Gráfico 44: Porcentagem dos egressos segundo nota atribuída de zero a dez, referente ao grau de satisfação com o PPGIB

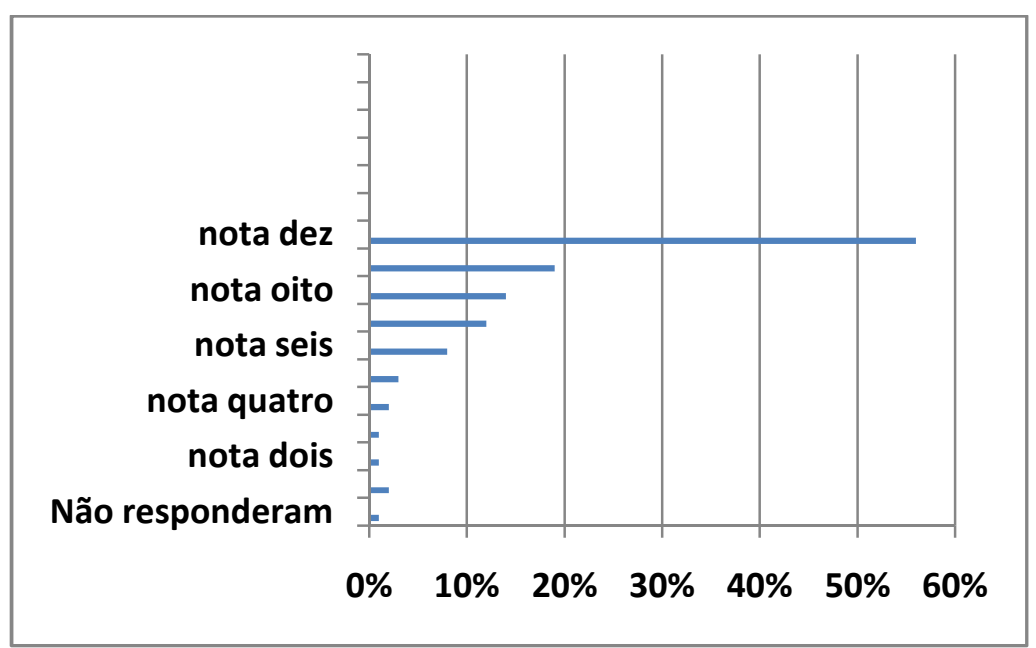

Fonte: Pesquisa com Egressos 2013- PPGIB-EESC-IQSC-FMRP-USP

Atribuindo-se uma escala que vai de 01 a 10, para o grau de satisfação dos egressos com o programa de pós- graduação observa-se pelos dados do Gráfico 44, que a grande maioria, $36 \%$ atribuíram nota 10 ao seu grau de satisfação; seguidos de $19 \%$ que atribuíram nota $09 ; 14 \%$ dos egressos atribuíram nota $08 ; 12 \%$ atribuíram nota 07 . Conforme a escala diminui, é também diminuída a porcentagem de egressos que atribui às notas. Assim, é possível concluir que a maioria dos egressos está satisfeita com o programa. 


\subsection{O Mercado de Trabalho}

Este tópico abrange a questões relativas aos aspectos do mercado de trabalho, tais como: objetivos posteriores ao término do curso de mestrado, atual ocupação no mercado de trabalho, como se deu o ingresso no emprego, quantas vezes houve mudança de emprego, salário, condições de trabalho, prestígio, atividades desempenhadas, estabilidade, aptidão para o mercado de trabalho.

Os egressos foram perguntados sobre quais seus objetivos imediatos, após o término do programa. Dentre as várias opções de resposta, 30\% identificaram como sendo seu objetivo imediato, seguir carreira acadêmica em instituição de ensino superior. Logo atrás, com $22 \%$, estão os egressos, cujo objetivo imediato era ingressar em outro programa de pós-graduação na mesma área, uma vez que no período compreendido pela pesquisa, não havia a possibilidade de continuar no mesmo programa, pois este ainda não oferecia curso de doutorado. Com 12\%, empatados, estão os egressos, cujos objetivos imediatos eram procurar emprego fora da área acadêmica e ingressar em outro programa de pós- graduação em área diferente. Essa parcela dos egressos, provavelmente não se identificou completamente com o programa escolhido para cursar o mestrado. Trabalhar como pesquisador era o objetivo imediato de $9 \%$ dos egressos, sendo que $7 \%$ tinham como objetivo a abertura de seu próprio negócio. Entre 3\% e 1\%, dividem-se outros objetivos, como começar a trabalhar em outra área, ser professor de ensino médio, começar a trabalhar na área de formação, entre outros (Gráfico 45). 


\section{Gráfico 45: Porcentagem dos egressos segundo o objetivo imediato após o PPGIB}

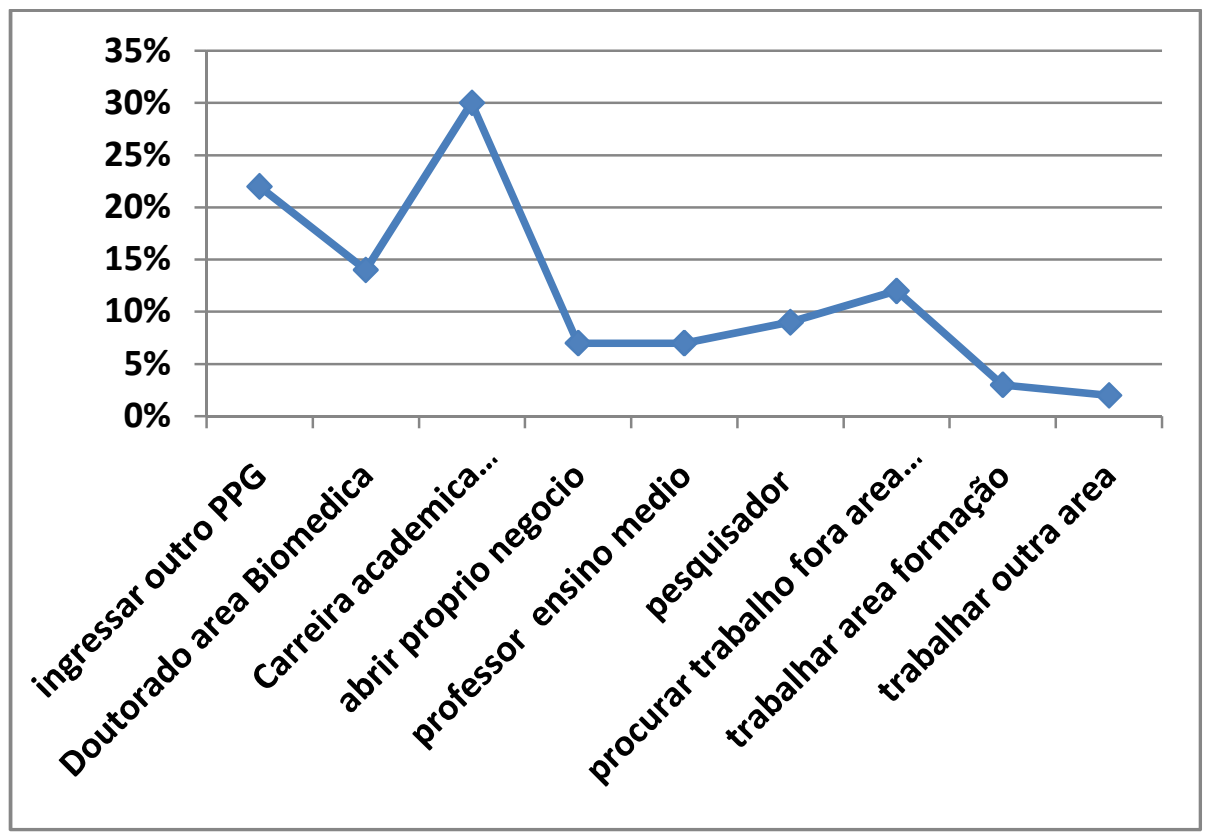

Fonte: Pesquisa com Egressos 2013- PPGIB-EESC-IQSC-FMRP-USP

Além de identificar o objetivo imediato dos egressos ao término do programa, essa pesquisa também quis apurar a inserção dos mesmos no mercado de trabalho, nos dias atuais e verificar com isto, se os objetivos pensados por eles ao término do programa haviam se concretizado. Observa-se pelos dados referentes ao Gráfico 46, que a maioria dos egressos exerce função de docente em instituições de ensino superior pública (federais ou estaduais), 29\%; são estudantes de pós-graduação $16 \%$ dos egressos; empatados com 10\% estão aqueles que exercem trabalhos em área hospitalar e os que são docentes de ensino superior em instituições privadas. São responsáveis pela família, exercendo atividades da casa, $7 \%$ dos egressos e $9 \%$ são pesquisadores. Além disso, $5 \%$ são empregados em empresas particulares, 3\% empregados em empresas multinacionais e outros 3\% proprietários de empresas 
do ramo médico. De maneira geral, os objetivos que os egressos possuíam ao término do curso, se concretizaram.

Gráfico 46: Porcentagem dos egressos segundo a atual ocupação no mercado de trabalho.

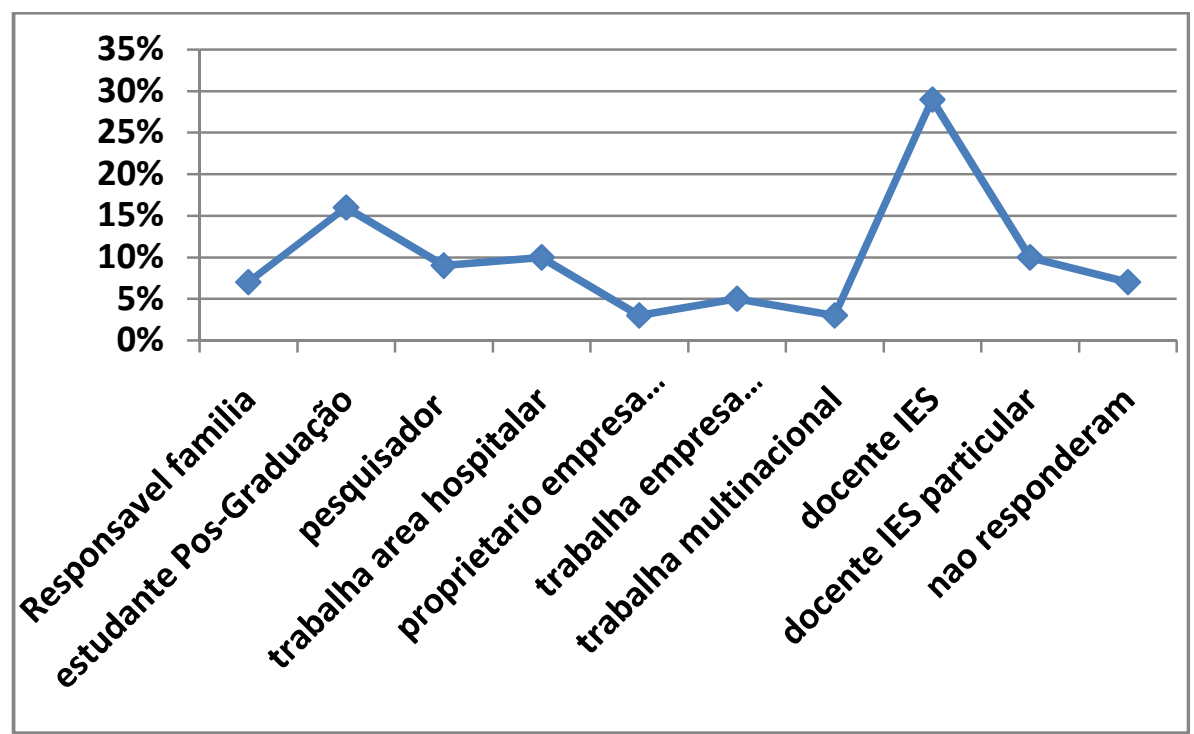

Fonte: Pesquisa com Egressos 2013- PPGIB-EESC-IQSC-FMRP-USP

A maneira pela qual os egressos entraram no mercado de trabalho, também foi tema de analise. Utilizou-se de concurso ou seleção, $38 \%$ dos egressos, para sua inserção no mercado de trabalho. Praticamente empatados, estão aqueles que tiveram indicação profissional por profissionais da área, com 15\% e aqueles, cuja indicação partiu de parente e amigos, com 14\%. Ingressaram no mercado de trabalho através de agências ou associações profissionais, 4\%, mesma porcentagem encontrada para os que ingressaram por meio de anúncios nos meios de comunicação (Gráfico 47). 
Gráfico 47: Porcentagem dos egressos segundo o ingresso em seu emprego atual

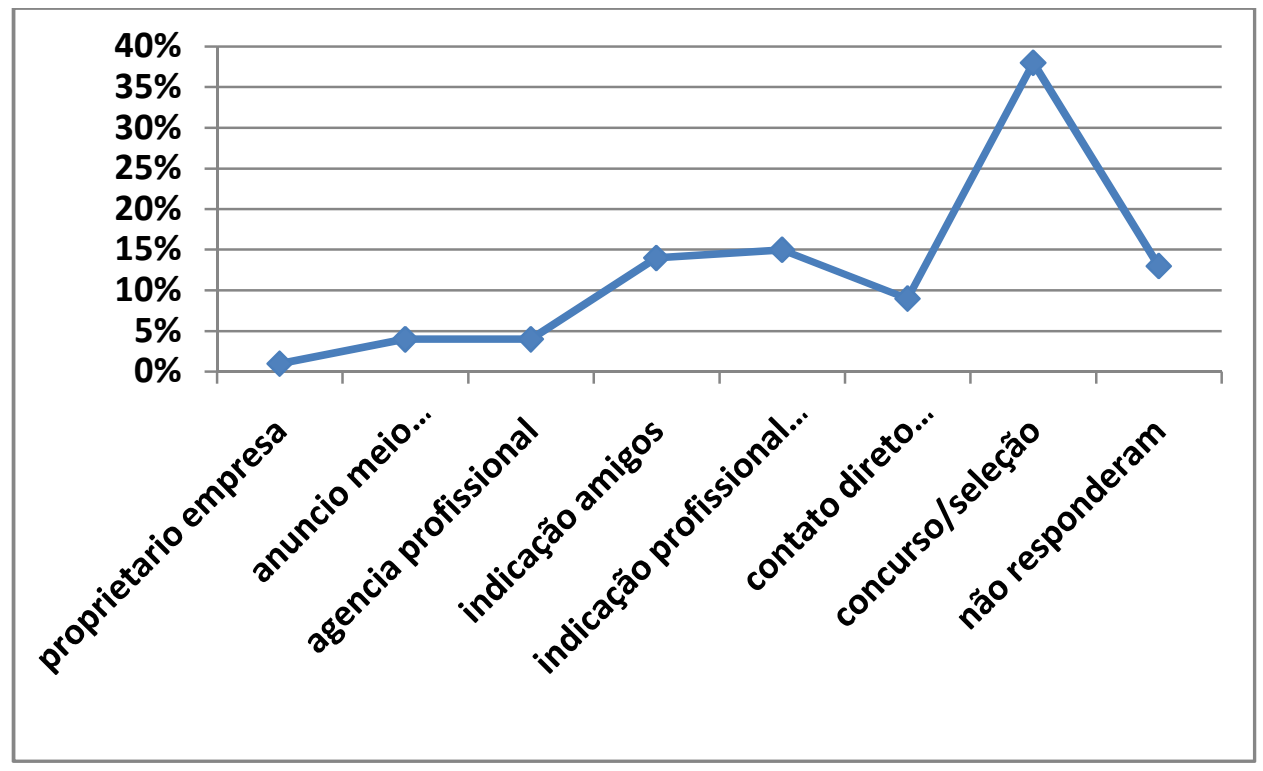

Fonte: Pesquisa com Egressos 2013- PPGIB-EESC-IQSC-FMRP-USP

Após concluírem o curso de mestrado e se colocarem no mercado de trabalho, $37 \%$ dos egressos afirma que não mudou nenhuma vez de emprego, enquanto que $22 \%$ afirmam ter mudado de emprego de duas a três vezes. Já $25 \%$ afirmam ter mudado uma vez e $3 \%$ afirmam ter mudado quatro ou mais vezes de emprego (Gráfico 48). Assim, pode se concluir que a permanência no emprego, entre os egressos, é alta. 
Gráfico 48: Porcentagem dos egressos segundo após a conclusão do mestrado ter mudado diversas vezes de emprego.

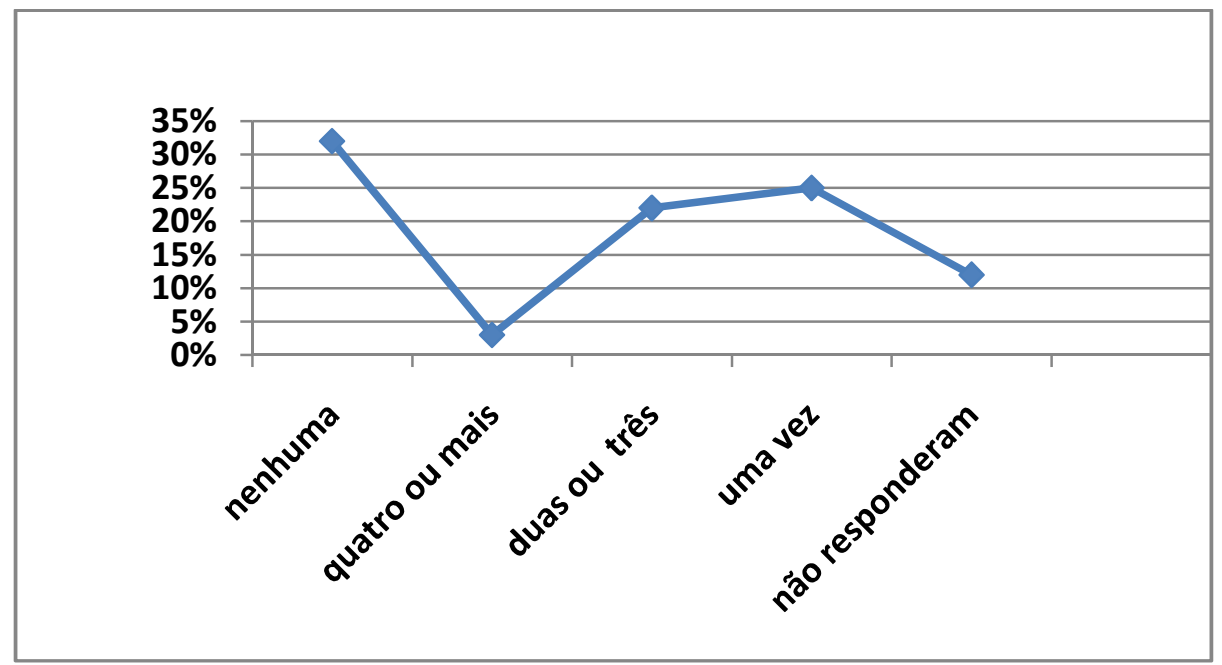

Fonte: Pesquisa com Egressos 2013- PPGIB-EESC-IQSC-FMRP-USP

Mostram-se satisfeitos com o salário, $71 \%$ dos egressos, constituindo maioria, seguidos de $14 \%$ que se dizem não estar satisfeitos com o salário, (Gráfico 49). 
Gráfico 49: Porcentagem dos egressos segundo salário.

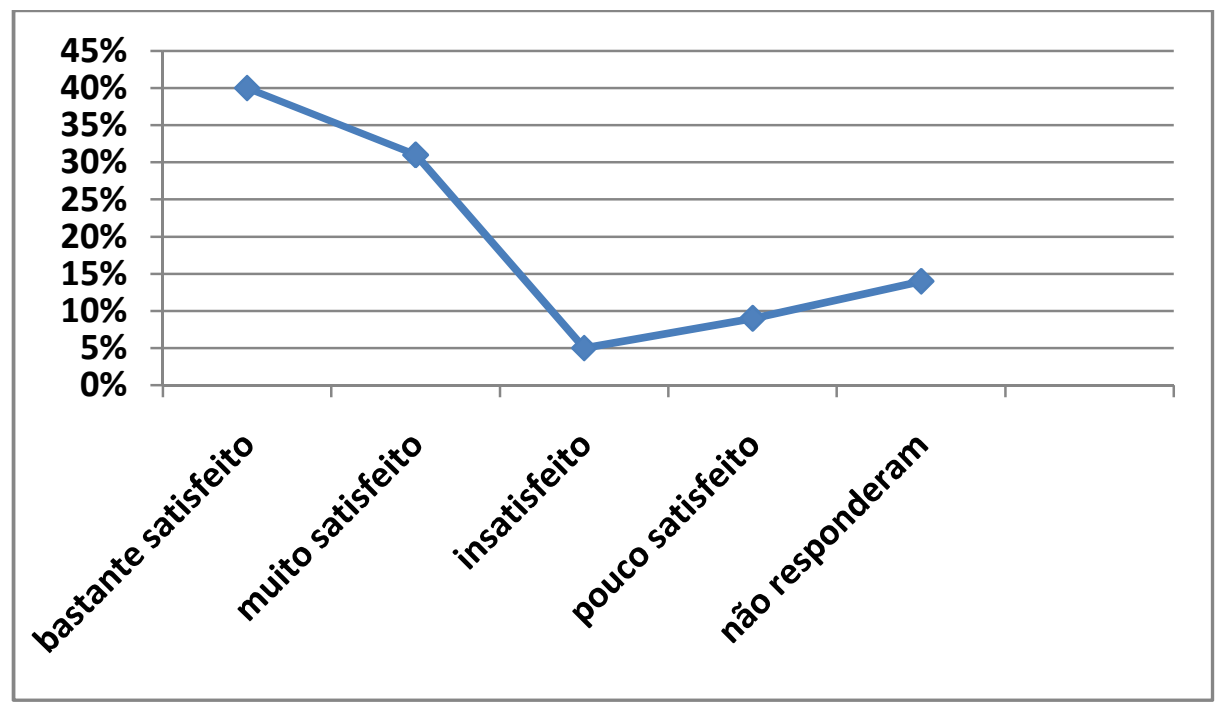

Fonte: Pesquisa com Egressos 2013- PPGIB-EESC-IQSC-FMRP-USP

Além do salário, várias profissões contam com abono e outros incentivos monetários, incorporados ou não ao salário principal. Isso também acontece com os egressos, e a pesquisa quis saber qual o grau de satisfação em relação a essas vantagens. A maioria dos egressos, $38 \%$, se diz bastante satisfeita com abonos; $8 \%$ muito satisfeitos; $16 \%$ insatisfeitos; $17 \%$ pouco satisfeitos e $21 \%$ não opinaram. Através desse panorama, é possível afirmar, que a satisfação com o salário, não é a mesma para com abonos e incentivos (Gráfico 50). 
Gráfico 50: Porcentagem dos egressos segundo abono/incentivos outras vantagens

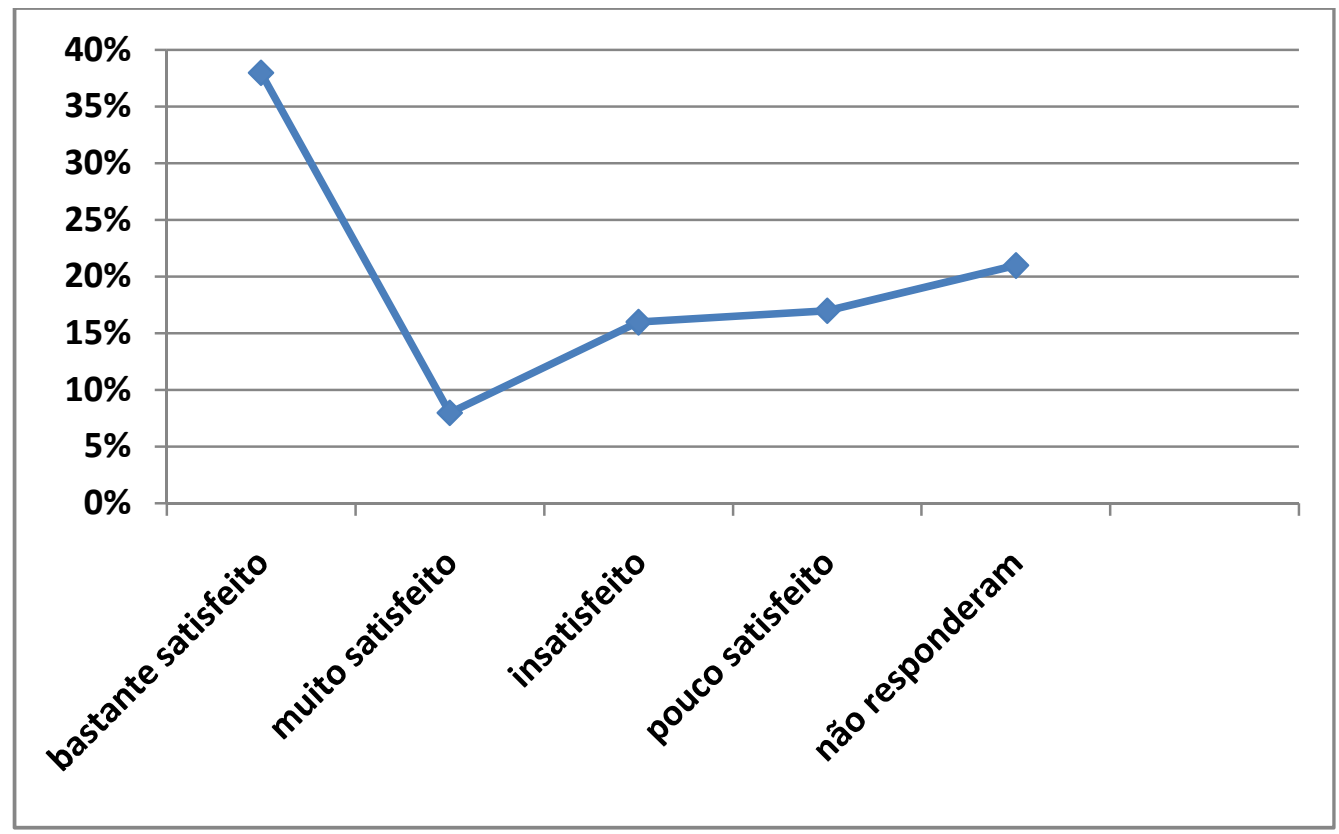

Fonte: Pesquisa com Egressos 2013- PPGIB-EESC-IQSC-FMRP-USP

Gráfico 51: Porcentagem dos egressos segundo condições de trabalho

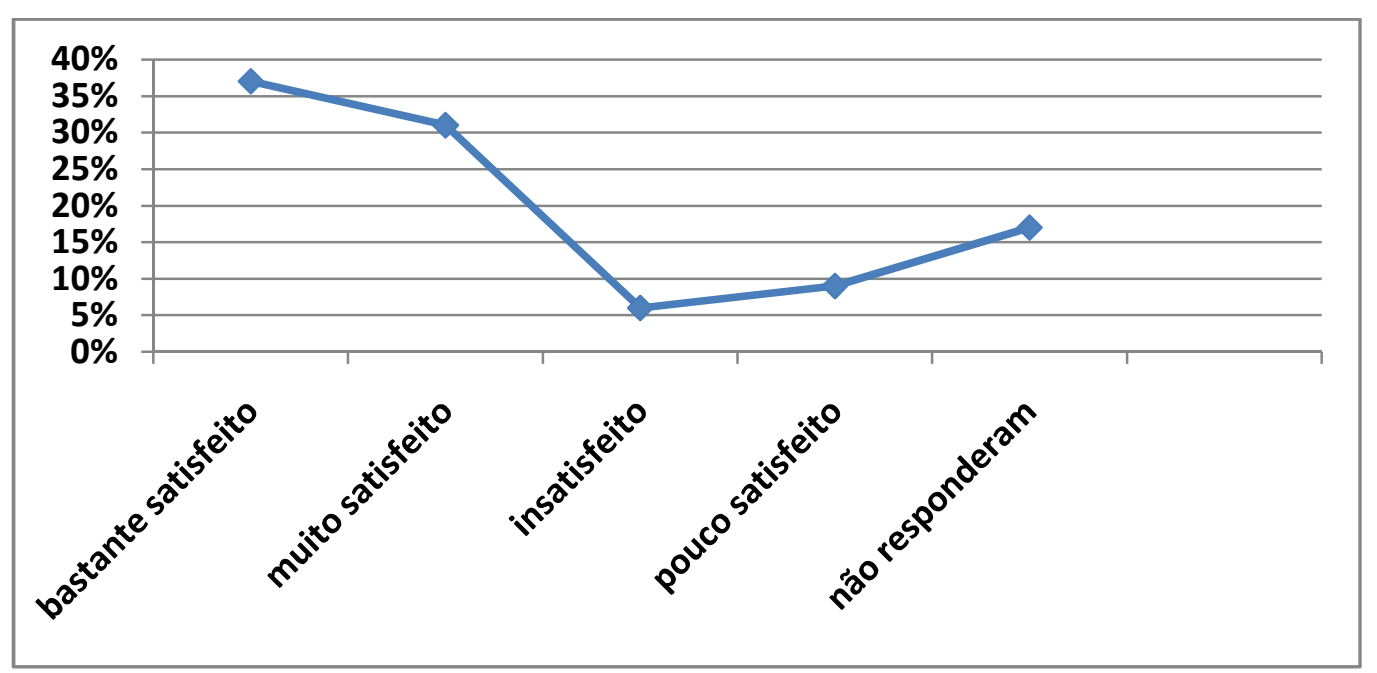

Fonte: Pesquisa com Egressos 2013- PPGIB-EESC-IQSC-FMRP-USP

Aliadas ao salário e abonos estão às condições de trabalho. Para a maioria dos egressos, $35 \%$, as condições de trabalho são bastante satisfatórias; estão muito 
satisfeitos $24 \%$ dos egressos, enquanto que $14 \%$ estão insatisfeitos e $9 \%$ pouco satisfeitos. Neste ponto do questionamento, 18\% não responderam (Gráfico 51).

Gráfico 52: Porcentagem dos egressos segundo prestigio onde trabalha.

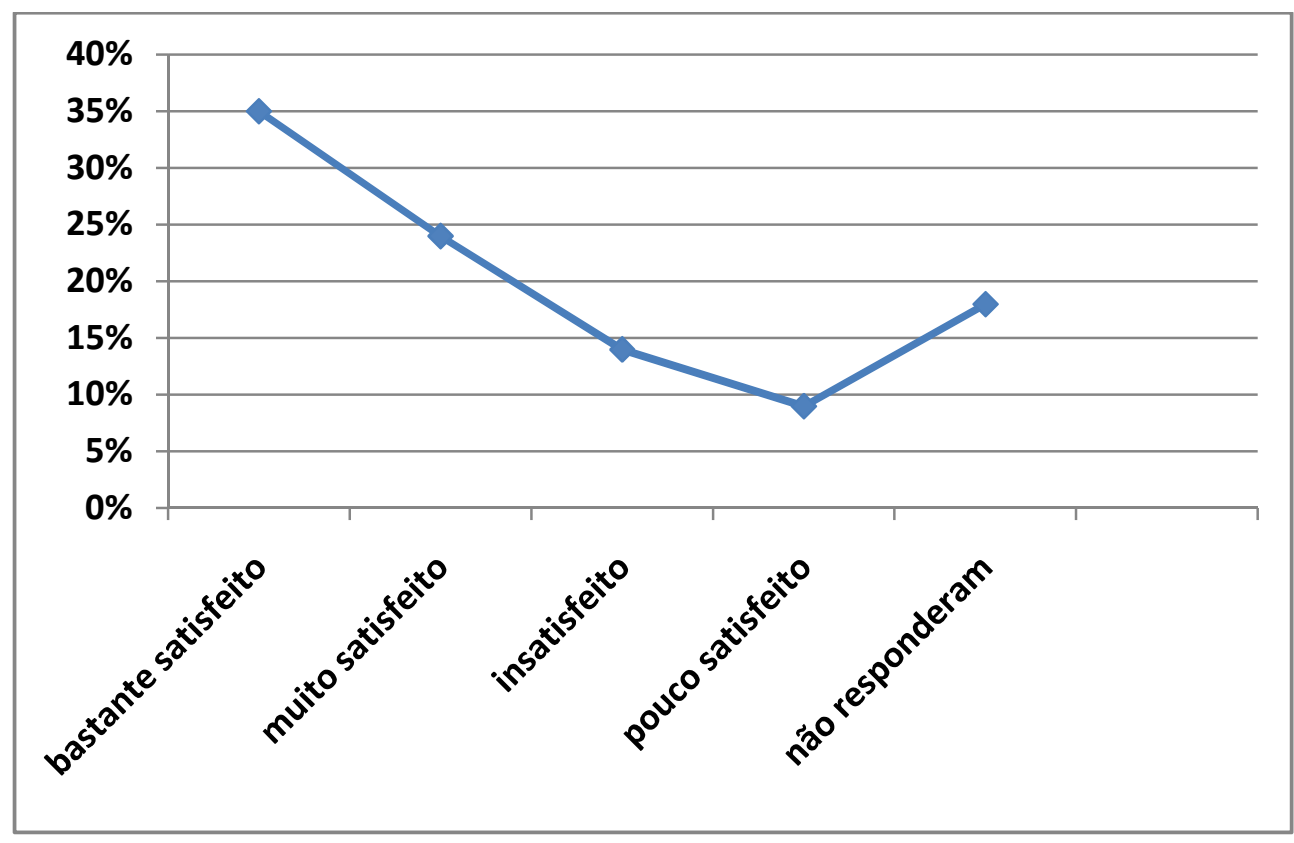

Fonte: Pesquisa com Egressos 2013- PPGIB-EESC-IQSC-FMRP-USP

Quando perguntados sobre o prestígio que possuem em seu local de trabalho, ou seja, sobre o reconhecimento de sua função como bioengenheiro, os egressos se mostraram em sua maioria, $37 \%$, bastante satisfeitos, seguidos de $31 \%$ de egressos muito satisfeitos. Encontram insatisfeitos $6 \%$ e $9 \%$ pouco satisfeitos (Gráfico 52). 
Gráfico 53: Porcentagem dos egressos segundo a variedade de atividade que desempenha.

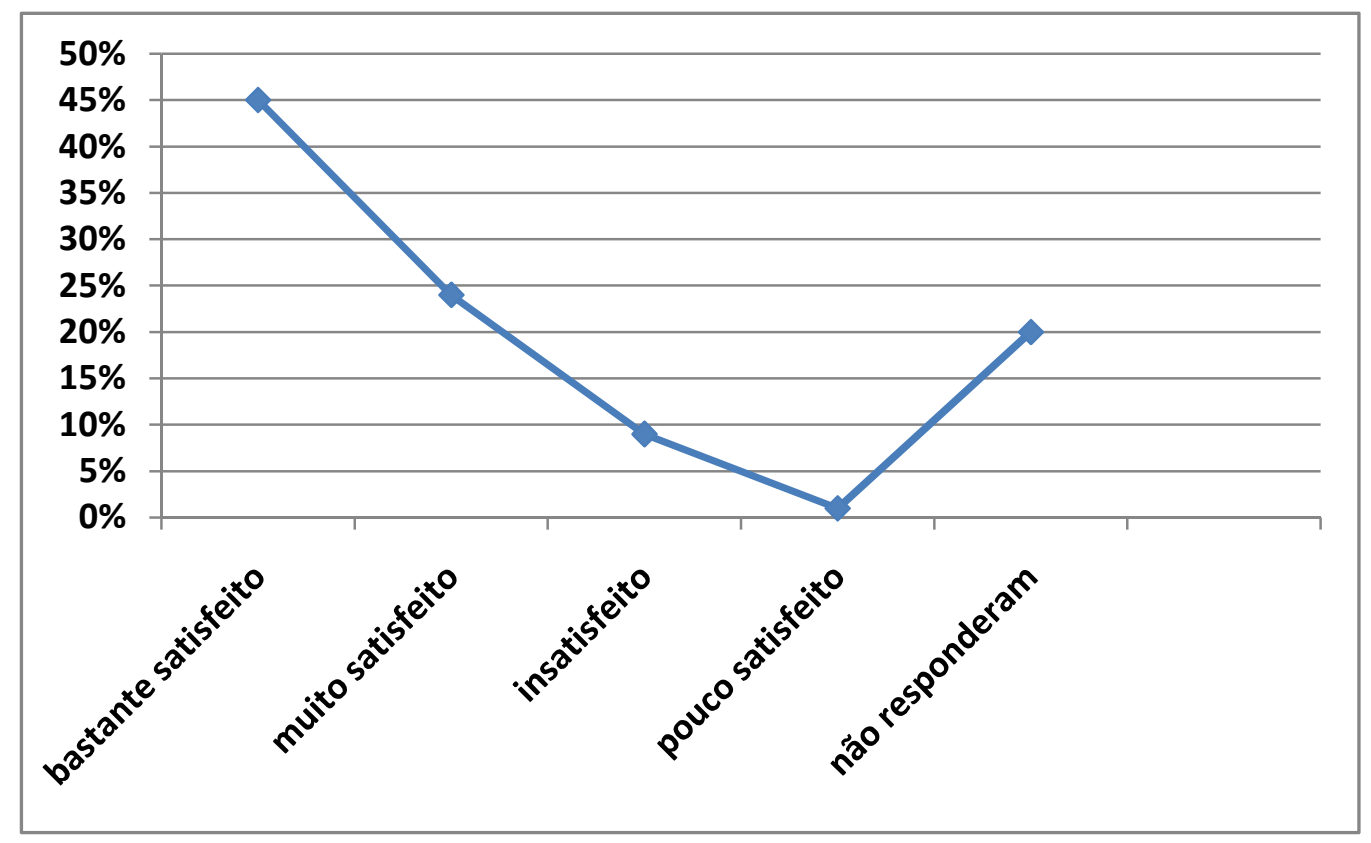

Fonte: Pesquisa com Egressos 2013- PPGIB-EESC-IQSC-FMRP-USP

Sabe-se que vários profissionais desempenham uma variedade de funções e com os egressos não poderia ser diferente. Quando perguntados sobre sua satisfação em relação a essa variedade de atividades desempenhadas, $45 \%$ se mostraram bastante satisfeitos; $24 \%$ estão muito satisfeitos; $9 \%$ estão insatisfeitos e apenas $1 \%$ pouco satisfeitos. Isso leva a concluir que de fato, os egressos se sentem satisfeitos com seus empregos atuais (Gráfico 53). 
Gráfico 54: Porcentagem dos egressos segundo estabilidade no emprego.

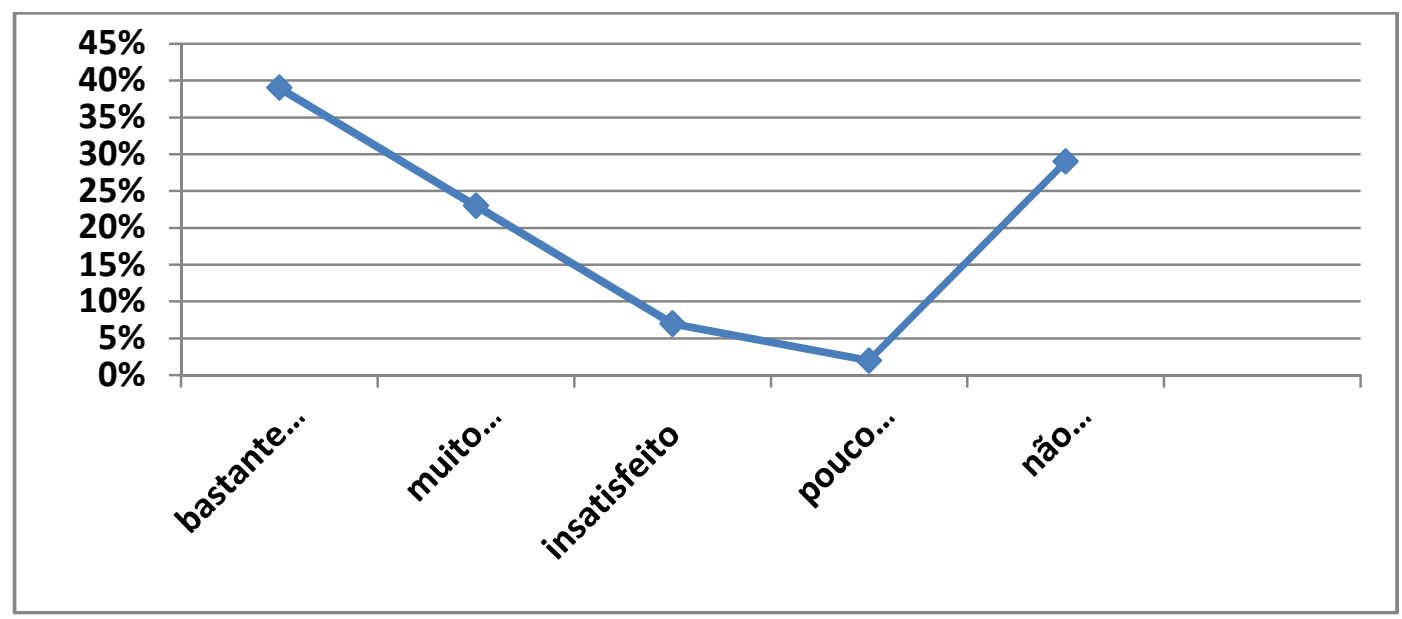

Fonte: Pesquisa com Egressos 2013- PPGIB-EESC-IQSC-FMRP-USP

Quanto à estabilidade do emprego, os egressos se mostraram bastante satisfeitos, com $39 \%$, enquanto que $23 \%$ estão muito satisfeitos; $7 \%$ estão insatisfeitos e $2 \%$ pouco satisfeitos. Neste quesito, uma boa porcentagem de egressos, 29\% não responderam (Gráfico 54).

Para terminar o questionário, perguntou-se ao egresso, se ao final do curso ,ele se achou apto a concorrer com outros profissionais da área formados em outras instituições, seja para o mercado de trabalho ou para ingressar em curso de doutorado. A maioria, $54 \%$ se sentiam aptos após a conclusão do curso, seguidos por $45 \%$ que não se julgavam aptos (Gráfico 55). 
Gráfico 55: Percentual dos egressos, segundo após conclusão do PPGIB estar aptos a concorrer com outros profissionais na área, formados por outras instituições; para ingressoar em curso de PG nível doutorado ou mercado de trabalho.

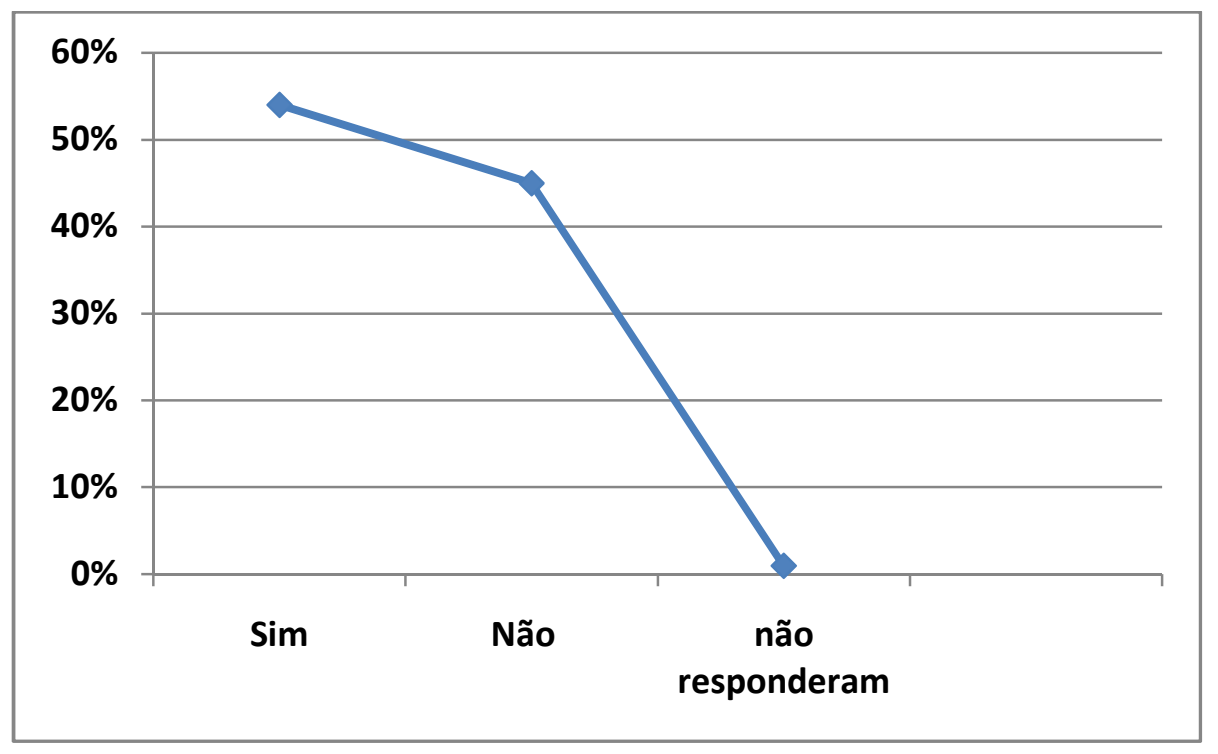

Fonte: Pesquisa com Egressos 2013- PPGIB-EESC-IQSC-FMRP-USP 


\section{CONCLUSÃO}

Este trabalho teve o propósito de apresentar contribuições da comunidade acadêmica, em relação ao sistema de avaliação da Universidade de São Paulo da Pós-Graduação. Podemos concluir pontualmente que:

$44 \%$ dos egressos cursaram o ensino médio em escola publica.

$83,5 \%$ dos egressos concluíram o ensino médio em tempo regular.

$76 \%$ dos egressos freqüentaram o ensino médio em período diurno.

$68 \%$ dos egressos freqüentaram a Universidade na graduação.

$78 \%$ dos egressos cursaram a graduação em escola publica.

$76 \%$ dos egressos freqüentaram em período integral a graduação.

$35 \%$ dos egressos participaram de atividades culturais no país (palestras ou conferencias, etc.) durante a graduação.

$48 \%$ dos egressos com conhecimento de língua inglesa no inicio da pósgraduação (lia, escrevia e falava mediamente).

$76 \%$ dos egressos afirmam que o curso graduação preparou adequadamente para realizar pós-graduação em Bioengenharia,

$73 \%$ dos egressos afirmam que o tipo de organização acadêmica concluída por ele contribuiu positivamente para o meu desempenho na pós-graduação.

$70 \%$ dos egressos afirmam que a escolha da USP foi um fator positivo no desempenho na pós-graduação.

94\% dos egressos afirmam que o período em que freqüentou a graduação foi um fator de contribuição positiva para seu desempenho na pós-graduação.

94\% dos egressos pontuaram com satisfação o seu próprio desempenho na pós-graduação. 
Os egressos afirmam que foram influenciados em sua decisão ao ingressarem no PPGIB sendo agrupadas em três conjuntos de razões: 54\% razões ligadas ao PPGIB + $27 \%$ razões externas $+18 \%$ fatores pessoais.

24\% dos egressos afirmam terem ingressado do PPGIB imediatamente após conclusão da graduação e $34 \%$ até dois anos após a conclusão graduação e $36 \%$ demorou mais de dois anos após concluir a graduação.

$54,3 \%$ dos egressos afirmam ter participado de projeto cientifico antes de ingressar no PPGIB.

$30 \%$ egressos afirmam que fizeram interação com profissionais fora da área acadêmica, sendo essa a melhor característica que descreve o PPGIB.

$15 \%$ dos egressos cursaram disciplinas de interesse fora do PPGIB sendo este o principal aspecto plenamente satisfatório do PPGIB. E 13\% optaram pela disponibilidade do corpo docente e o contato com outros profissionais.

$50 \%$ dos egressos afirmam que foi o melhor preparo para sua formação profissional a principal contribuição do PPGIB para sua vida profissional.

$60 \%$ dos egressos procuraram seu orientador e $24 \%$ dos egressos afirmam terem sido convidados pelo orientador.

$67 \%$ dos egressos afirmam terem continuidade de parceria com seus orientadores após o termino do PPGIB.

$31 \%$ dos egressos afirmam que a parceria entre ele e seu orientador se deu por pesquisa conjunta no PPGIB e também 25\% afirmam que as publicações conjuntas no PPGIB.

$42 \%$ dos egressos apontam a disponibilidade para atendimento de seu orientador como sendo o aspecto mais satisfatório de relacionamento no PPGIB. 
$80 \%$ dos egressos consideram que o PPGIB trouxe contribuições para a vida profissional.

$11,4 \%$ dos egressos consideram desenvolvimento de habilidade de pensar criticamente como contribuição do PPGIB para sua formação e com 11,2\% dos egressos considera a autonomia em pesquisas seguida de preparação em metodologia de pesquisa.

44\% dos egressos afirmam ter realizado apresentação de trabalhos em encontros durante sua permanência no PPGIB.

$36 \%$ dos egressos afirmam que os congressos regionais/nacionais apresentaram seus trabalhos e $10 \%$ em encontros internacionais.

$46 \%$ dos egressos afirmam ter publicações feitas no PPGIB e $36 \%$ dos egressos afirmam não terem publicado.

$43 \%$ dos egressos é o autor principal de suas publicações e $30 \%$ dos egressos são co-autores de suas publicações em congressos e anais.

$56 \%$ dos egressos afirmam que sua participação no PPGIB foi uma decisão acertada e aconteceu no momento apropriado.

$42 \%$ dos egressos afirmam que o PPGIB atendeu totalmente suas expectativas.

47\% dos egressos afirmam que as instalações físicas do PPGIB estavam em conformidade com suas necessidades.

$53 \%$ dos egressos afirmam que a compatibilidade do sistema informatizado de bibliotecas que atende ao PPGIB.

$72 \%$ dos egressos afirmam que o acervo de livros é adequado em face de necessidade de sua pesquisa. 
$63 \%$ dos egressos afirmam que sua participação no PPGIB foi decisiva na sua vida profissional.

Quanto aos aspectos mais positivos do PPGIB. Os percentuais são respostas abertas e geram múltiplas opiniões; atuação em pesquisas inovadoras, experiência com pesquisas multidisciplinares, preparação para a vida acadêmica, área nova de conhecimento e crescimento da bioengenharia $5 \%$, pesquisas para ajudarem seres humanos, possibilidade de contato com profissionais de formação. Assiduidade e disponibilidade dos professores, curso diferenciado de pós-graduação, interação com outras universidades, preparação para a carreira de docente $4 \%$ entre outras.

Quanto aos aspectos negativos do PPGIB. 18\% dos egressos afirmam ter dificuldades de estudarem na sala de convivência, entre outras.

$58 \%$ dos egressos afirmam que sua dissertação foi publicada enquanto que $31 \%$ dos egressos afirmam não terem sido publicadas.

$69 \%$ dos egressos atribuíram uma nota (zero a dez) referente ao grau de satisfação com o PPGIB (notas entre 7 e dez).

$30 \%$ dos egressos afirmam que seu objetivo imediato após o termino do PPGIB era seguir carreira acadêmica em IES.

$29 \%$ dos egressos afirmam exercer a função de docente em IES publica (federal ou estadual) e 10\% são docentes em IE particular.

$38 \%$ dos egressos afirmam ter utilizado o concurso ou seleção para entrarem no mercado de trabalho.

$37 \%$ dos egressos afirmam que ao se colocarem no mercado de trabalho não mudaram seu emprego nenhuma vez.

$40 \%$ dos egressos afirmam estarem satisfeitos com seus salários. 
$38 \%$ dos egressos afirmam estarem satisfeitos com o abono/incentivo monetário incorporado ou não ao salário principal.

$24 \%$ dos egressos afirmam estarem satisfeitos com suas condições de trabalho.

$37 \%$ dos egressos afirmam que o prestigio que possuem em seu local de trabalho.

$45 \%$ dos egressos afirmam que sua satisfação em relação à variedade de funções que desempenha.

$23 \%$ dos egressos afirmam estarem satisfeitos com sua estabilidade de seu emprego.

$54 \%$ dos egressos dos egressos se julgam apto para concorrer com outros profissionais da área, formados por outros PPG para ingressar em cursos de PG ou mercado de trabalho. 


\section{REFERÊNCIAS ${ }^{1}$}

ALTAFIM, R. A. C.; SILVA, M. A. A. 50 anos da EESC: um olhar no passado visando o futuro. 2. ed. São Carlos: Escola de Engenharia de São Carlos, 2004. 134 p.

ANDRADE, A. J. P. Bioengenharia no Instituto Dante Pazzanese de Cardiologia. Disponível em:<http://wikipedia.org.wiki/bioengenharia>. Acesso em: 18 ago. 2013.

ANTONIO, A. M.; ROLLO, J. M. D. A. Bioengineering twentieth century in Brazil: state of the art. Saarbrücken: LAP LAMBERT, 2013. 188 p.

BALBAVEVSCY, E. A. Pós-graduação no Brasil: novos desafios para uma política bem sucedida. In: BROCK, C.; SCHWARTZMAN, S. (Org.) Os Desafios da educação no Brasil. Rio de Janeiro: Nova Fronteira, 2005. p. 275-304.

BRASIL. Lei $\mathrm{n}^{\circ}$ 9.394, de 20 de dezembro de 1996. Diário Oficial [da] República Federativa do Brasil, Poder Executivo, Brasília, DF, 23 dez.1996. Seção 1, p. 2783327841. Disponível em: <http://www.jusbrasil.com.br/topicos/11688234/artigo52-dalei-n-9394-de-2-de-dezembro-de-1996>. Acesso em: 28 ago. 2013.

CADASTRO NACIONAL DE ESTABELECIMENTOS DE SAÚDE. Pesquisa sobre estabelecimento de saúde. Disponível em: <http://cnes.datasus.gov.br/Exibe_Ficha_Estabelecimento.asp?VCo_Unidade $=4115$ 202587335>. Acesso em: out. $20 \overline{13}$.

DEPARTAMENTO INTERSINDICAL DE ESTATÍSTICA E ESTUDOS ECONÔMICOS. A Situação do trabalho no Brasil na primeira década de 2000. São Paulo: DIEESE, 2012.

Diário Oficial da União. Ano 1977. Disponível em:< http://www.jusbrasil.com.br/diarios/DOU/1977/12/27>. Acessado em 26 out. 2013.

ENCONTRO ACADÊMICO DE GESTÃO DA PÓS-GRADUAÇÃO USP, 2., São Paulo, 2012.

FÁVERO, L. L. Oralidade e escrita: perspectivas para o ensino da língua materna. São Paulo: Cortez, 1999.

FACULDADE DE MEDICINA DA BAHIA. Histórico. Disponível em:< http://www.fameb.ufba.br/index.php?option=com_content\&view=article\&id=54\&ltemid =73>. Acesso em: out. 2013.

${ }^{1}$ De acordo com a Associação Brasileira Normas Técnicas NBR 6023 
FORESTI, E. 50 anos da EESC. Jornal da USP, São Paulo, 19/25 de maio 2003. p.2.

HORTALE, V. A.; KOIFMAN, L. Programas de pós-graduação em saúde pública na Argentina e no Brasil: origens históricas e tendências recentes de processos de avaliação de qualidade. Interface - comunicação, saúde, educação, v. 11, n. 21, p. 119-130, 2007.

INFANTOSI, Criação bioengenharia no Brasil: entrevista [jun. 2001]. Entrevistadora: Ana Maria Antonio. 02 fitas cassetes.

JIMENEZ, V. A. Contenidos y esquemas sobre diagnósticos em educación. Málaga: Grupo Editorial Universitário, 2005.

LOPES, M. I. V. Mercado de trabalho dos egressos dos cursos de comunicação social no Brasil: resultados de uma pesquisa nacional de diagnósticos e avaliação. 1998. 150 f. Tese (Livre Docência)-Departamento de Comunicações e Artes, Escola de Comunicação e Artes, Universidade de São Paulo, São Paulo, 1998.

LOPES, M. I. V. Pesquisa em comunicação. 8. ed. São Paulo: Loyola, 2005.

MENDES, R. F. et al. Percepção sobre o curso e perfil dos egressos do programa de mestrado em ciência e saúde da UFPI. Revista Brasileira da Pós-Graduação, v. 7, n. 12, p. 82-101, 2010.

MENEZES-FILHO, N. A.; FERNANDES, R.; PICCHETTI, P. A Evolução da distribuição de salários no Brasil: fatos estilizados para as décadas de 80 e 90 . In: HENRIQUES, R. (Org.). Desigualdade e pobreza no Brasil. Rio de Janeiro: IPEA, 2000.

MENEZES-FILHO, N.; MENDES, M.; ALMEIDA, E. O diferencial de salários formalinformal no Brasil: segmentação ou viés de seleção? Revista Brasileira de Economia, v. 58, n. 2, p. 235-248, 2004.

MODESTO, M. S. A. et al. Avaliação de curso técnico de agente comunitário de saúde sob a ótica dos egressos. Revista Trabalho, Educação e Saúde, v. 10, n. 3, p. 387-406, 2012.

NOSELLA, P.; BUFFA, E. Universidade de São Paulo, Escola de Engenharia de São Carlos: os primeiros tempos: 1948 - 1971. São Carlos: EDUFSCar, 2000. 
OLIVEIRA, S. M. Início da Bioengenharia na USP e no Brasil: entrevista [maio 2003]. Entrevistadora: Ana Maria Antonio. 2 fitas cassete.

ORTIGOZA, S. A. G.; POLTRONIERI, L. C.; MACHADO, L. M. C. P. A Atuação profissional dos egressos como importante dimensão no processo de avaliação de programas de Pós-Graduação. Revista Sociedade e Natureza, v. 24, n. 2, p. 243254, 2012.

PESQUISA SOBRE ESTABELECIMENTO DE SAÚDE. Disponível em: $<$ http://cnes.datasus.gov.br/Mod_Hospitalar.asp?VCo_Unidade=3550302078015>. Acesso em: nov. 2013.

PESQUISA SOBRE UNIDADES DE ESCOLAS MÉDICAS DO BRASIL. Disponível em:<http://www.escolasmedicas.com.br/news_det.php?cod=1208>. Acesso em: 10 jul. 2013.

PIMENTA, S. G.; ANASTASIOU, L. G. C. Docência no ensino superior. São Paulo: Cortez, 2002.

PIRES, R. C. M. A Formação inicial do professor pesquisador universitário no Programa Institucional de Bolsas de Iniciação Científica - PIBIC/CNPq e a prática profissional de seus egressos: um estudo de caso na Universidade do Estado da Bahia. 2008. 356 f. Tese (Doutorado em Educação) - Faculdade de Educação, Universidade Federal do Rio Grande do Sul, Porto Alegre, 2008.

PORTAL UNIVERSIA. História do ensino superior. Disponível em: $<$ http://universidades.universia.com.br/universidades-brasil/historia-ensinosuperior/>. Acesso em: 8 ago. 2013.

PRIES, L. Teoria sociológica Del mercado de trabalho. In: TOLEDO, E. L.G. Tratado latino americano de sociología del trabajo. México: FCE/Flacso, 2000.

AS PROFISSÕES em alta: o que está mudando nas profissões. Veja, São Paulo, ano 26, n. 37, edição 1305, set. 1993.

40 ANOS de engenharia dedicados à saúde. Rio de Janeiro: COPPE/UFRJ, 2011. Disponível em:<http://peb.ufrj/br>. Acesso em: 15 set. 2013.

SÃO LUíS. Relatório da pesquisa de perfil do aluno egresso. Revista PubCom, v. 2, n. 2, nov. 2012. Disponível em:< http://www.saoluis.br/revistacientifica/publicidadepropaganda/revist. php>. Acesso em: jan. 2014.

SHIRE, N. Engenharia na área biomédica e alguns recentes avanços no Canadá. Revista AEASC, ano 2, n. 5, Edição especial, 2012. 
SOCIEDADE BRASILEIRA DE ENGENHARIA BIOMÉDICA. Endereço para correspondências. Disponível em: <http://www.sbeb.org.br/fale. php>. Acesso em: 11 out. 2013.

SPAGNOLO, F.; CALHAU, M. G. Observadores internacionais avaliam a avaliação da CAPES. INFOCAPES, v. 10, n. 1, jan./mar. 2002, p. 5-33. Disponível em:<http://www.capes.gov.br/images/stories/download/bolsas/Infocapes10_1_2002. pdf>. Acesso em: 30 jun. 2014.

TOLEDO, F.; MILIONE, B. Dicionário RH de Administração de Recursos Humanos. São Paulo: Associação Brasileira de Recursos Humanos, 1983. v. 2.

TRINDADE, A.; MAZZARI JÚNIOR, E. Autonomia universitária e direito educacional. In: TRINDADE, A. (Org.) Direito universitário e educação contemporânea. Porto Alegre: Livraria do Advogado, 2009.

WIKIPÉDIA. Universidade do Vale do Paraíba. Disponível em:< http://pt.wikipedia.org/wiki/Universidade_do_Vale_do_Para\%C3\%ADba>. Acesso em: 5 ago. 2013.

WORLD HEALTH ORGANIZATION. Traditional medicine. Disponível em:< http://www.who.int/mediacentre/factsheets/2003/fs134/en/>. Acesso em: 3 mar. 2013.

WORLD HEALTH ORGANIZATION. Men, ageing and health. Disponível em: <http://whqlibdoc.who.int/hq/2001/who_nmh_nph_01. 2. pdf>. Acesso em: 10 mar. 2013. 


\section{ANEXO A}

\section{CARTA CONVITE}

Prezado senhor (a),

Venho convidá-lo (a) a participar da pesquisa "Avaliação da Inserção no Mercado de trabalho dos Egressos do Curso Mestrado Interunidades em Bioengenharia", realizada pela Pesquisadora do Curso de Doutorado em Bioengenharia da Universidade de São Paulo- EESC - IQSC - FMRP, e que servirá de base para meu doutorado.

O objetivo da pesquisa é identificar os egressos do Programa de PósGraduação Interunidades em Bioengenharia (conhecimentos, habilidades e atitudes) que têm maior impacto na atuação do profissional Mestre em Bioengenharia. Conhecer esses atributos contribui para a melhor gestão de pessoas e o aumento da eficiência e eficácia da unidade de Pós-Graduação em Bioengenharia - EESC IQSC - FMRP.

A sua participação é imprescindível na construção do perfil de competências dos profissionais mestres em Bioengenharia. Para contribuir com a pesquisa, basta responder ao questionário disponível na web.

É possível responder ao questionário no seu ritmo. Ele pode ser respondido todo de uma vez. Conforme sua disponibilidade, ao longo de 15 dias.

A partir das percepções de todos os participantes será consolidado o perfil de competências dos egressos em mestrado do Programa de Pós-Graduação Interunidades em Bioengenharia. O perfil de competências será amplamente divulgado por meio, da tese e de periódicos científicos. 
Além de contribuir para a construção do perfil de competências em Bioengenharia no Brasil, o participante poderá fazer uma auto-avaliação sobre a abrangência e atualização de suas competências em Bioengenharia.

Para participar, acesse o endereço elrônico www.eesc.usp.br/bioeng/questionario_egressos/ Agradeço em nome de todos os envolvidos e conto com sua colaboração.

Atenciosamente,
Ana Maria Antonio
Pesquisadora do PPGIB --USP São Carlos
Doutoranda do PPGIB - USP São Carlos
amar@sc.usp.br 
ANEXO B

\section{Comitê de ética}

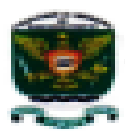

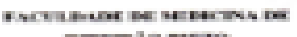

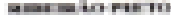

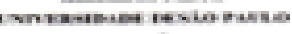

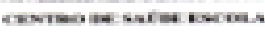

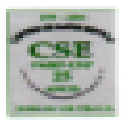

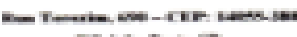

menterats

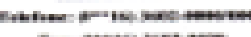

how

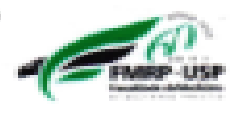

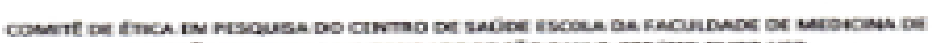

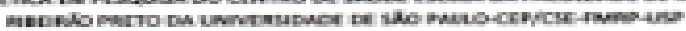

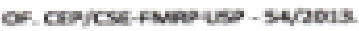

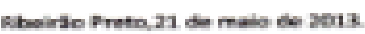

Dreate couthor

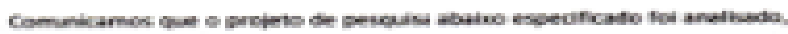

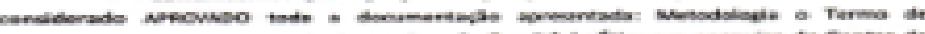

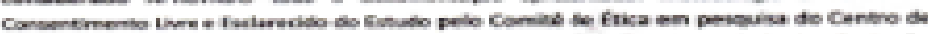

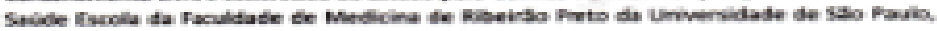

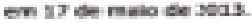

cent: Bew

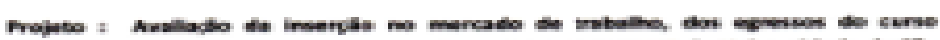

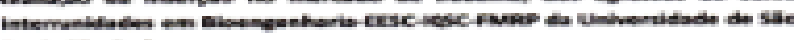
Pathens callon

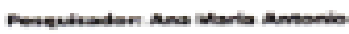

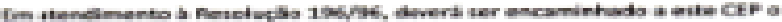

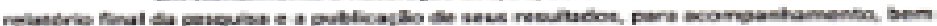

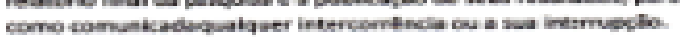

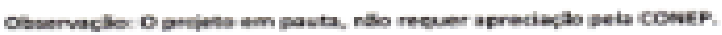

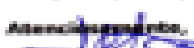

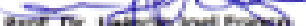

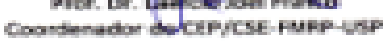

ind sa

An Burto Antoge

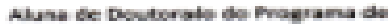

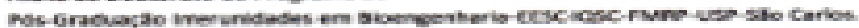


ANEXO C

\section{Bioengenharia}

Informações Gerais

1.1 - Características do Ensino Médio

1.1.1 - Em que tipo de escola você cursou o ensino médio?

C Todo

em

escola

publica;

C Todo

em

escola

privada;

C A maior parte do tempo em escola publica;

C A maior parte do tempo em escola privada;

C Metade em escola publica e metade em escola privada;

1.1.2 - Que tipo de ensino médio você concluiu?

C Comum ou de educação geral (colegial, cientifico etc.), no ensino regular C Técnico (eletrônica, contabilidade, agrícola etc.), no ensino regular C Magistério de primeira a quarta série (curso normal), no ensino regular C Supletivo

C Outro

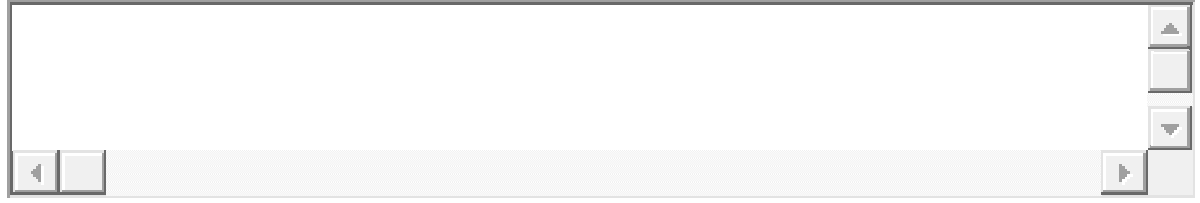

especifique

1.1.3 - Em qual período você freqüentou o ensino médio?

C Todo

0

período

diurno

C Todo

0

período

noturno

C A maior

parte

do

tempo

no

período

diurno

C A maior

parte

do tempo

no

período

noturno

C Metade no período diurno e metade no período noturno

1.2 - Características do curso de graduação (se você fez mais de um curso de graduação, responda sobre aquele que você considere o mais relevante para a sua área de atuação) 
1.2.1 - Qual o tipo de organização acadêmica da instituição em que você freqüentou

0 curso de graduação?

C Universidade

C Centro universitário

C Faculdades integradas

C Faculdade

C Centro

de educação tecnológica

1.2.2 - Qual tipo de categoria administrativa da instituição em que você freqüentou o curso de graduação?

C Federal

C Estadual

C Municipal

C Integral

1.2.3 - Qual o período de estudo do curso de graduação que você freqüentou?

C Matutino

C Vespertino

C Noturno

C Integral

Dimensão: DADOS PESSOAIS

\section{1 - Categoria: FORMAÇÃO GERAL}

2.1.1 - Informe as atividades das qual você participou durante o período da realização desta etapa acadêmica. Assinale tantas alternativas quantas sejam necessárias

\begin{tabular}{rlcccrr}
$\Gamma$ Viagens & ao & \multicolumn{3}{c}{ exterior } & para & estudo \\
$\ulcorner$ Atividades & culturais & no & país & (palestra & conferencia & etc.)) \\
$\ulcorner$ Atividades & culturais & no & exterior & (palestra & conferencia & etc.))
\end{tabular}




\begin{tabular}{|c|c|c|c|c|}
\hline$\ulcorner$ Estudo & de & língua(s) & & estrangeira(s) \\
\hline Г Movimento & & & & estudantil \\
\hline$\ulcorner$ Movimento & & & & sindical \\
\hline$\Gamma$ Atividades & & & & tico-partidárias \\
\hline$\Gamma$ Atividades & relacionadas & ao & programa, & apenas \\
\hline Г Outra- & & & & especifique \\
\hline & & & $\frac{A}{\nabla}$ & \\
\hline \begin{tabular}{|l|l|}
1 \\
\end{tabular} & & & $\cdot \square$ & \\
\hline
\end{tabular}
2.1.2 - Como era seu conhecimento de linha inglesa quando você iniciou esta
etapa
C Lia,
escrevia
e
falava
bem
C Lia, escrevia
e falava
medianamente
C Lia
e
escrevia, mas não falava
C Lia, mas não escrevia falava

C Praticamente nulo

2.2 - Categoria: AVALIAÇÃO PELO EGRESSO

2.2.1 - O curso de graduação me preparou adequadamente para a realização desta etapa acadêmica
C Concordo
plenamente
com
esta
declaração
C Concordo
em
parte
com
esta
declaração
C Discordo desta declaração
E Discordo inteiramente desta declaração
C Não sei
avaliar/
Não se
aplica

2.2.2.-O tipo de organização acadêmica (universidade, faculdade, centro) da instituição em que freqüentei o curso de graduação foi um fator que contribuiu positivamente para 0 meu desempenho nesta etapa acadêmica C Concordo plenamente com esta declaração 


\begin{tabular}{|c|c|c|c|c|c|}
\hline Concordo & em & parte & com & esta & declaração \\
\hline Discordo & \multicolumn{4}{|c|}{ desta } & declaração \\
\hline Discordo & & inteiramente & & & declaração \\
\hline
\end{tabular}

2.2.3 - O tipo de categoria administrativa (publica ou privada) da instituição em que freqüentei o curso de graduação foi um fator que contribuiu positivamente para o meu desempenho neta etapa acadêmica

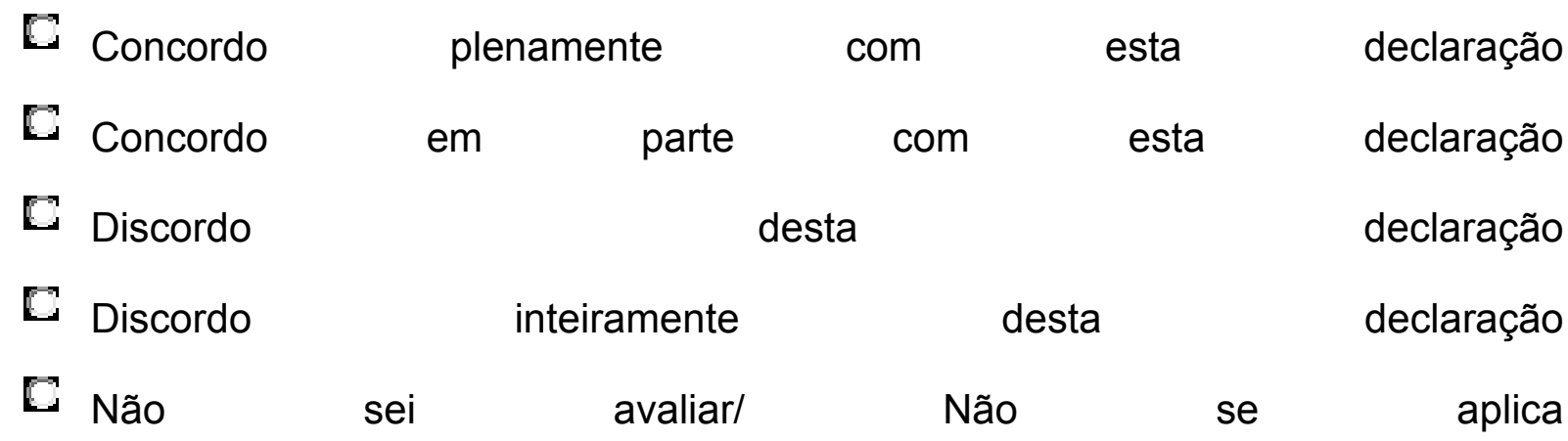

2.2.4 - O período (matutino, vespertino ou integral) em que freqüentei o curso de graduação foi um fator que contribuiu positivamente para o meu desempenho nesta etapa

acadêmica.

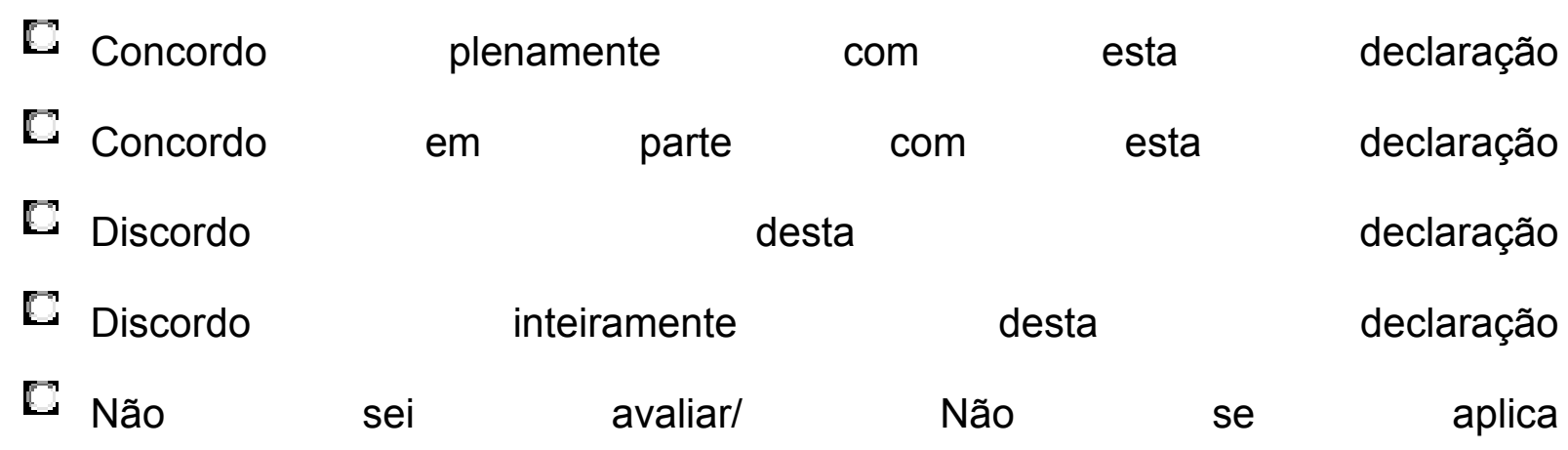

2.2.5 - Numa escala de 01 (um) a 10 (dez) o meu grau de satisfação com o meu próprio desempenho nesta etapa acadêmica são:

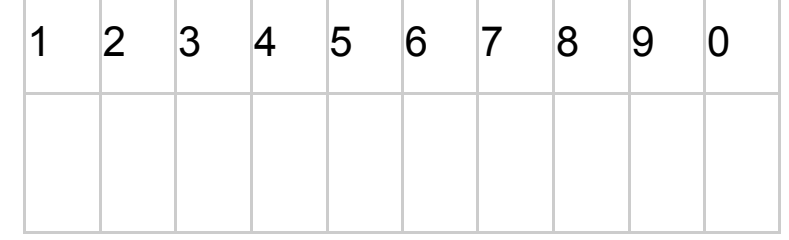


Dimensão: FORMAÇÃO ACADÊMICA

\section{1 - Categoria: MOTIVAÇÃO}

3.1.1 - Identifique as três razoes que influenciaram sua decisão de ingressar neste programa de pós-graduação.

$\ulcorner$ Interesse

na

área

de

pesquisa

Possibilidade

de

ingresso

na

carreira

docente

$\ulcorner$ Recomendação

de professores

no

curso de

graduação

Recomendação

de

amigos

Reputação

do programa

nos

meios

acadêmicos

Falta de opções de programa de pós-graduação na minha área de escolha Alta qualidade da pesquisa desenvolvida neste programa;

$\ulcorner$ Qualificação dos docentes vinculados ao programa

$\ulcorner$ Reputação da instituição que oferece 0 programa

Convite do

orientador

Fonte

de

renda

Prestigio

social

na

área

$\ulcorner$ Possibilidade

de

realização

profissional

$\ulcorner$ Contribuição positiva para exercer profissão no meio acadêmico - cientifica

$\ulcorner$ Contribuição positiva para exercer a profissão fora do meio acadêmico - cientifica

Exigência da instituição à qual estava vinculado

$\ulcorner$ Outra especifique

3.1.2 - Em que momento da sua vida acadêmico você ingressou neste programa de pós-graduação? 
C Imediatamente após a conclusão do curso de graduação C Um ano após a conclusão do curso de graduação C Dois anos após a conclusão do curso de graduação C Mais de dois anos após a conclusão do curso de graduação

3.1.3 - Você participou de algum projeto de iniciação cientifica antes de ingressar neste programa de pós-graduação?
C $\operatorname{sim}$
C Não

Categoria: ADEQUAÇÃO DA PESQUISA

\section{1 - Categoria: ADEQUAÇÃO DA PESQUISA}

4.1 - Identifique a característica que melhor descreve o programa de pósgraduação de que você participou nesta etapa acadêmica. Assinale tantas alternativas quantas sejam

necessárias.

$\ulcorner$ O programa foi direcionado, principalmente, para a carreira acadêmica

$\ulcorner$ O programa foi direcionado, principalmente, para atividades fora da carreira acadêmica

Г O programa envolveu atividades de trabalho em equipe alem do orientador $\Gamma$ O programa envolveu atividades de colaboração com outro(s) pesquisador (es) Г $\mathrm{O}$ programa envolveu atividades de pesquisa interdisciplinar Г O programa possibilitou a interação com profissionais fora da área acadêmica $\Gamma$ Outra especifique

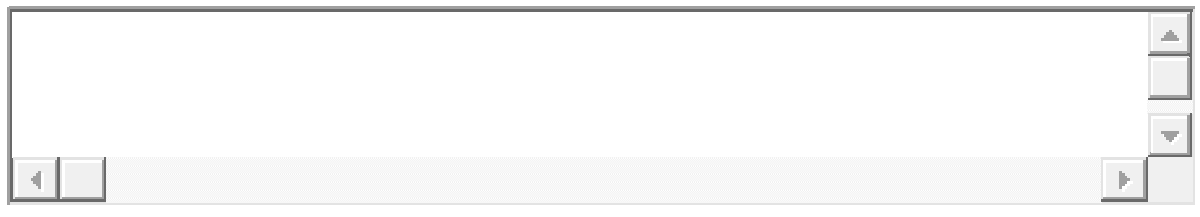

4.1.2 - Quais os aspectos relativos a este programa de pós-graduação que você considera plenamente satisfatórios? Assinale tantas alternativas quantas sejam necessárias.

Г Disciplinas

oferecidas

Г Didática

do

corpo docente

$\ulcorner$ Disponibilidade do corpo docente para atendimento aos

$\Gamma$ Interesse do corpo docente no progresso acadêmico dos estudantes 
$\ulcorner$ Possibilidade de cursar disciplinas de interesse fora do programa

$\ulcorner$ Oportunidade de aprender como elaborar um plano de pesquisa $\ulcorner$ Incentivo à divulgação do resultado da minha pesquisa $\ulcorner$ Ajuda financeira para participar de encontros profissionais

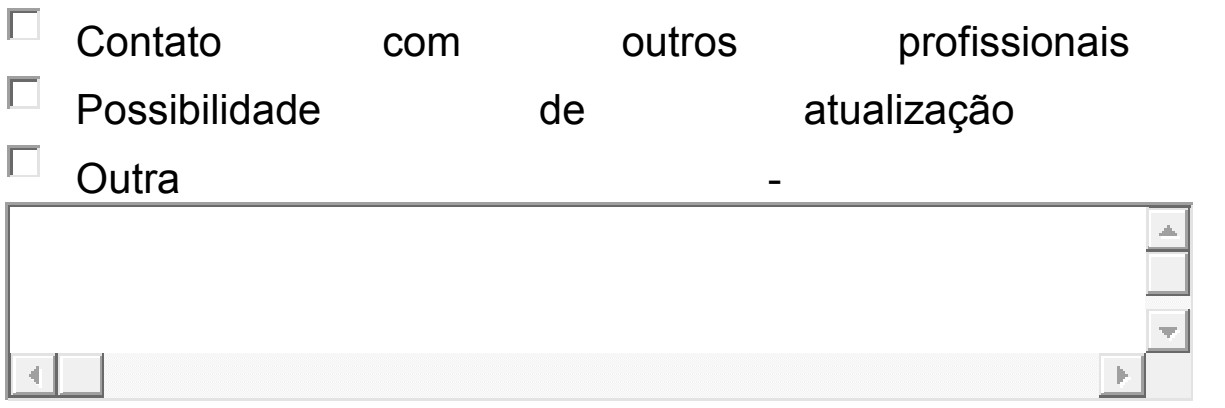

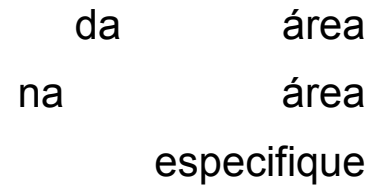

4.1.3 - Qual você considera a PRINCIPAL contribuição deste programa de pósgraduação

C Aquisição de que você participou?

C Melhor preparo de cultura geral

C Melhor preparo para para

a formação profissional

C Facilidade de ingresso a formação técnica

C Ampliação do na carreira docente horizonte profissional

C Outra especifique

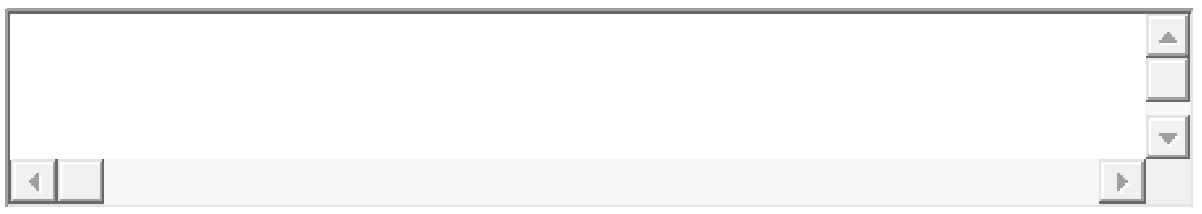

4.2 - Categoria: ADEQUAÇAO DA ORIENTAÇAO

4.2.1 - Como foi definido o seu orientador desta etapa de formação?

C Procurei meu orientador

C Fui convidado

(a)

pelo

meu orientador

C Passei

por

um

processo

de seleção

C Outra especifique

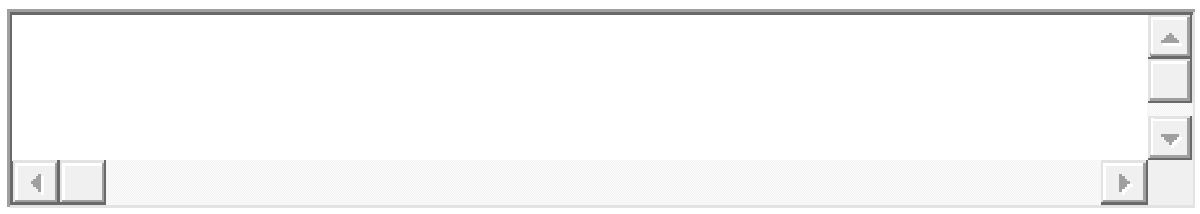

4.2.2 - Houve continuidade da parceria com seu orientador em outros projetos após 
0

termino

deste

programa?

C Sim

C Não

C Outra

especifique

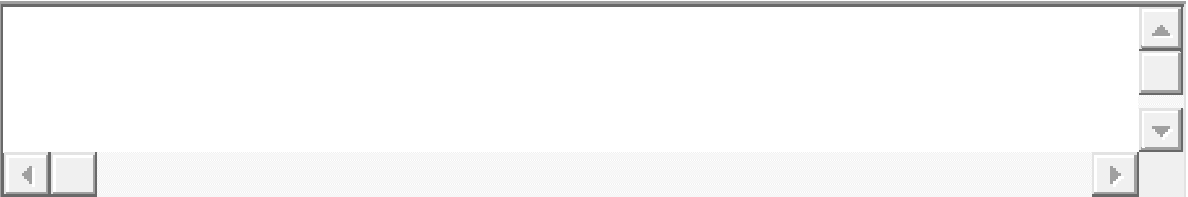

4.2.3 - Como se deu parceria? C Pesquisa conjunta fora de programas regulares de pós-graduação C Pesquisa conjunta no programa de pós-graduação C Publicações conjuntas em periódicos especializados C Trabalho conjunto fora do meio acadêmico C Outra especifique

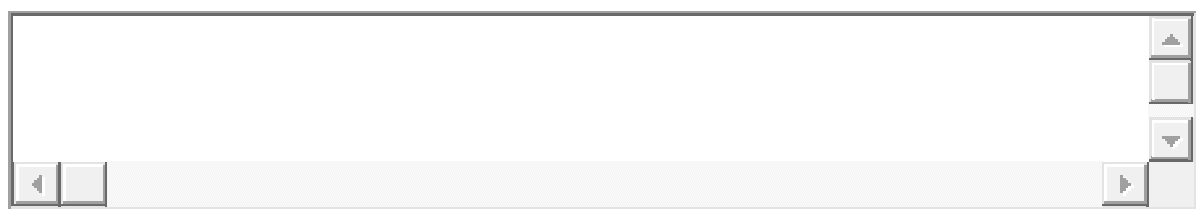

4.2.4 - Quais aspectos relativos ao seu relacionamento com seu orientador durante esta etapa de formação você considera plenamente satisfatórios assinale tantas alternativas

quantas

sejam

necessárias.

$\Gamma$ Disponibilidade

para

atendimento

$\Gamma$ Qualidade

da

orientação

- Assistência /apoio na preparação de apresentações em seminários, congressos

e

simpósios

C Assistências na solicitação / renovação de bolsa

$\Gamma$ Assistência na preparação do(s) relatório(s) exigido(s) pela agencia financiadora

$\Gamma$ Outra

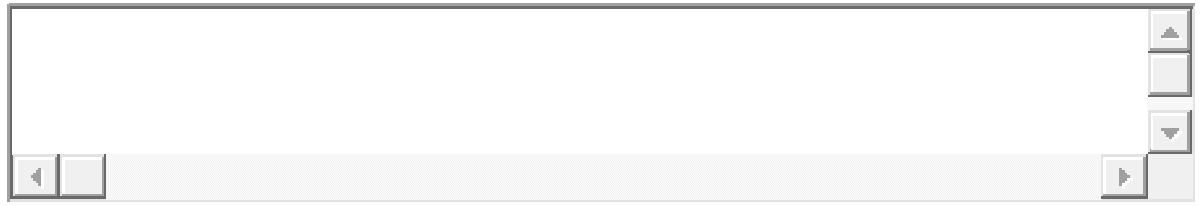

especifique

4.3 - Categoria: CONTRIBUIÇAO PARA FORMAÇAO PROFISSIONAL 
4.3.1 - Você Considera que esse programa de pós-graduação trouxe contribuições positivas para a sua formação profissional?
C $\operatorname{sim}$
C Não

4.3.2 - Qual contribuição para a sua formação que você considera que pode ser atribuída a este programa de pós-graduação do qual você participou? Assinale tantas alternativas

quantas

sejam

necessárias.

\begin{tabular}{|c|c|c|c|c|}
\hline Desenvolvimento & da & habilidade & pensar & \\
\hline Desenvolvimento & de & habilidade & trabalho & em \\
\hline Preparação & & para & & \\
\hline Preparação & em & metodologia & de & \\
\hline Autonomia & & em & & \\
\hline
\end{tabular}

Desenvolvimento da capacidade de organização, expressão e comunicação do pensamento

ᄃ Articulação do conhecimento da área com temas gerais e situações do cotidiano

$\ulcorner$ Enriquecimento

e atualização

profissional

$\ulcorner$ Continuidade da pareceria com outros docentes da instituição em outros projetos

$\ulcorner$ Publicação de artigos

$\ulcorner$ Outra

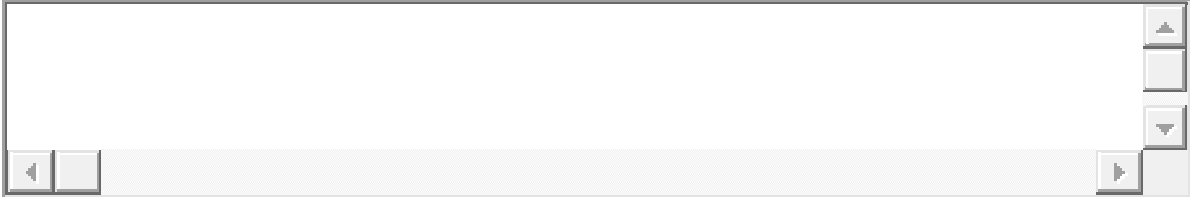

4.3.3 - Você apresentou algum trabalho (artigo) em encontros durante sua permanência neste

especifique
C Sim
C Não

4.3.4 - Informe para cada tipo de encontro, o número de trabalhos (artigos) que você apresentou em encontros durante sua permanência neste programa nesta etapa acadêmica.
C Congressos
regionais/nacionais
C Congressos
internacionais
C Seminários
na
instituição
do programa
C Seminário
em outra
instituição
que não
a do
programa
C Outra 


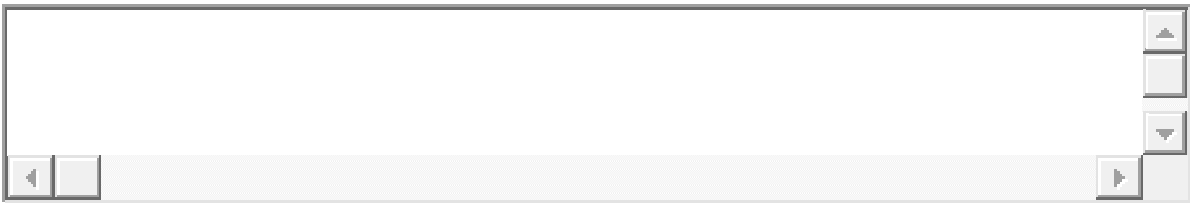

4.3.5 - Você teve alguma publicação durante sua permanência neste programa? Inclua também aquelas já aceitas para serem publicadas.

C $\operatorname{Sim}$

C Não

4.3.6 - Informe o número de publicações que você produziu durante sua permanência neste programa nesta etapa acadêmica. Inclua também aquelas a serem

publicadas.
C Como
autor
principal
C Como
periódicos
autor
co-autor
C Em
anais
com política
seletiva
editorial
C Em
de
congressos/simpósios/encontros
etc.
C Capítulos
de
livros
E Edição
e/ou
organização
de
livros/revistas
C Livros
didáticos

4.3.6 - Informe o número de publicações que você produziu durante sua permanência neste programa nesta etapa acadêmica. Inclua também aquelas a serem publicadas.

Como autor principal \begin{tabular}{ll}
$0 \quad$ \\
\hline
\end{tabular}

Como co-autor $0 \quad$ =

Em periódicos com política seletiva editorial ${ }^{0}$

Em anais de congressos/simpósios/encontros etc. 0

Em periódicos sem política seletiva editorial (jornais, revistas, revisão de livro) $0 \quad-$

Capítulos de livros

Edição e/ou organização de livros/revistas 0

Livros didáticos 0 
4.3.7 - Informe o número de:

Prêmios obtidos durante sua permanência nesta etapa acadêmica $0 \quad-$ Patentes registradas durante sua permanência nesta etapa acadêmica $0 \quad-$

Exposições/mostras

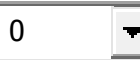

Outra

-especifique:

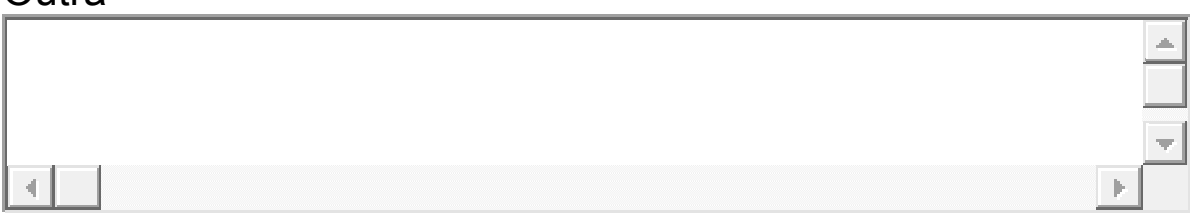

4.4 Categorias: AVALIAÇÃO PELO EGRESSO

As questões apresentadas nesta categoria têm por objetivo colher sua avaliação sobre o programa de pós-graduação. As questões constituem-se de assertivas com as quais você pode ou não concordar, solicitamos sua avaliação em cada uma delas, optando por uma das alternativas disponíveis.

4.4.1 - A minha decisão de participar neste programa de pós-graduação foi acertada

e se deu no momento apropriado.

C Concordo plenamente

com esta declaração

C Concordo em

parte

com esta declaração

C Discordo desta declaração

C Discordo inteiramente desta declaração

C Não sei avaliar/

Não se aplica

4.4.2 - O Programa de pós-graduação desta etapa acadêmica atendeu totalmente às minhas expectativas.
C Concordo
plenamente
com
esta declaração
C Concordo
em
parte
com
esta
declaração
C Discordo
desta
declaração
C Discordo
inteiramente
desta
declaração 
C Não

sei

avaliar/

Não

se

aplica

4.4.3 - As instalações físicas (salas de aula, laboratórios, ambiente de trabalho/estudo) utilizadas na instituição eram perfeitamente adequadas às necessidades deste programa de pós-graduação.

C Concordo plenamente

com

esta declaração

C Concordo em parte com esta declaração

C Discordo desta declaração

C Discordo inteiramente desta declaração

C Não sei avaliar/

Não se aplica

4.4.4 - A(s) biblioteca(s) disponível (eis) para este programa de pós-graduação dispunha $(m)$ de sistema informatizado compatível com as necessidades do programa.

\begin{tabular}{|c|c|c|c|c|}
\hline Concordo & plenamente & com & esta & declaração \\
\hline Concordo & parte & com & esta & declaraç \\
\hline Discordo & \multicolumn{3}{|c|}{ desta } & declaraç \\
\hline Discordo & inteiramente & & desta & declaraç \\
\hline
\end{tabular}

4.4.5 - O acervo de livros disponíveis na(s) biblioteca(s) era adequado em face das necessidades da pesquisa.
C Concordo
plenamente
com
esta
declaração
C Concordo
em
parte
com
esta
declaração
C Discordo
desta
declaração
C Discordo
inteiramente
desta
declaração
C Não
sei
avaliar/
Não
se
aplica 
4.4.6 - minha participação neste programa de pós-graduação foi decisiva na definição da minha vida profissional.

C Concordo plenamente

com esta declaração

C Concordo em parte com esta declaração

C Discordo desta declaração

C Discordo inteiramente desta declaração

C Não sei

avaliar/

Não se aplica

4.4.7 - Minha participação neste programa de pós-graduação contribuiu positivamente para minha formação.

C Concordo plenamente com esta declaração

C Concordo em parte com esta declaração

C Discordo desta declaração

C Discordo inteiramente desta declaração

C Não sei avaliar/

Não se aplica

4.4.8 - Apontem na ordem de importância, os aspectos mais positivos e mais negativos do curso de pós-graduação em bioengenharia.

Positivos

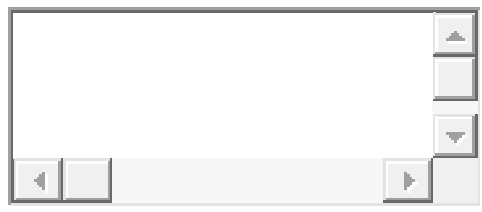

Negativos

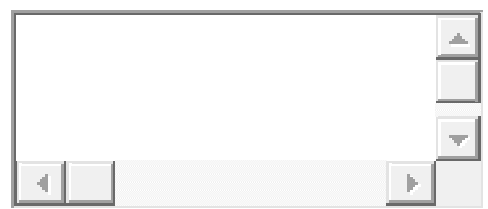

4.4.9 - A sua tese de mestrado em bioengenharia foi publicada. 

C $\operatorname{sim}$
C Não

4.4.10 - Numa escala de 01(um) a 10(dez) o meu grau de satisfação com este programa de pós-graduação é:

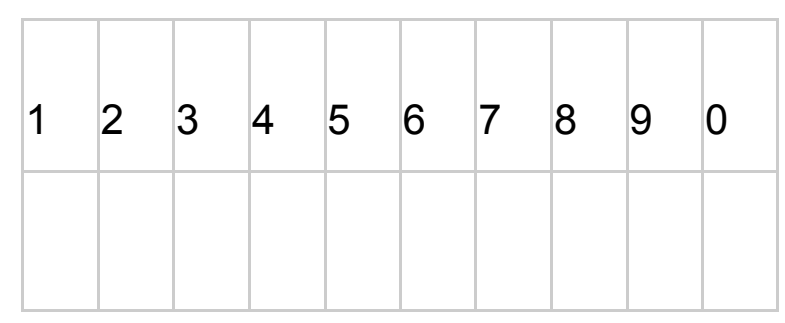

Dimensão: TRAJETÓRIA PROFISSIONAL

5 - Dimensão: TRAJETÓRIA PROFISSIONAL

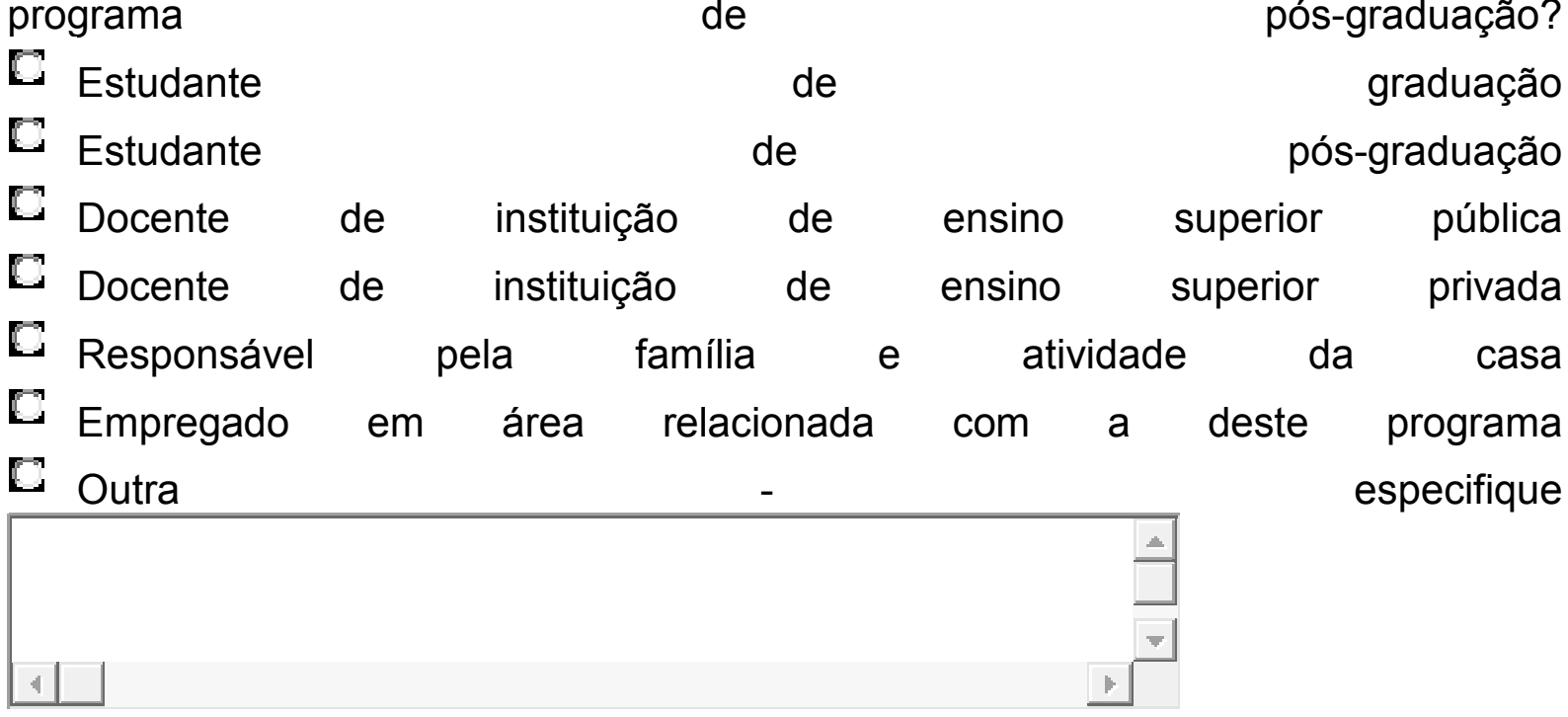

\subsection{Categoria: PERSPECTIVAS FUTURAS}

5.2.1 - Quanto tempo, após o termino desta etapa acadêmica, você esperou para iniciar suas atividades profissionais?
C Até 06 meses
C Acima de 06 06 meses menos de 01 ano
C Acima de 01 e menos 02 anos
C Mais de

5.2.2 - identifique qual era seu objetivo imediatamente após o término deste programa. Assinale tantas alternativas quantas sejam necessárias 
I Ingressar em outro programa de graduação em área diferente Ingressar em outro programa de pós-graduação na mesma área Ingressar em outro programa de pós-graduação em área diferente Seguir carreira acadêmica em instituição de ensino superior federal, estadual ou municipal

$\sqsubset$ Seguir carreira acadêmica em instituição particular de ensino superior

$\ulcorner$ Ser professor no ensino médio

$\ulcorner$ Ser professor no ensino fundamental

ᄃ Ser pesquisador em instituição especializada de pesquisa

$\sqsubset$ Procurar emprego fora da área acadêmica

$\ulcorner$ Começar a trabalhar ou continuar trabalhando em outra área

\begin{tabular}{|c|c|c|}
\hline $\begin{array}{l}\text { Abrir } \\
\text { Outra- }\end{array}$ & meu & próprio \\
\hline
\end{tabular}

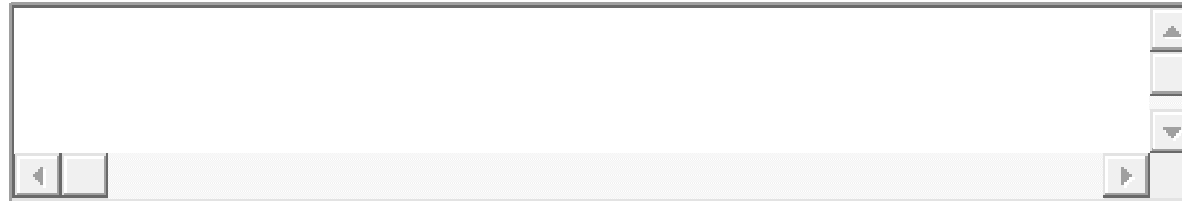
5.2.3 - Atualmente qual sua ocupação no mercado de trabalho C Instituição de
ensino particular
C Instituição de ensino superior federal,
estadual
C Empresa
multinacional
C Empresa particular
C Proprietário de empresa
C Área hospitalar
C Pesquisador

5.2.4 - Indique como conseguiu ingressar no seu emprego atual ou mais recente. Assinale tantas alternativas quantas sejam necessárias.

\begin{tabular}{|c|c|c|c|c|c|c|c|}
\hline Anuncio & & & eios & de & \multirow{2}{*}{\multicolumn{3}{|c|}{$\begin{array}{l}\text { comunicação } \\
\text { profissionais }\end{array}$}} \\
\hline Agência & & & ciação & de & & & \\
\hline Indicação & ou & convite & de & parentes & ou & & amigos \\
\hline Indicação & de & professores & e/ou & profissionais & & $\mathrm{da}$ & área \\
\hline Concurso & & & ou & & & & seleção \\
\hline Contato & & reto & com & 0 & & emp & regador \\
\hline
\end{tabular}


- Na própria empresa ou instituição onde trabalhava, por ascensão ou promoção

$\ulcorner$ Por estabelecer-me por conta própria

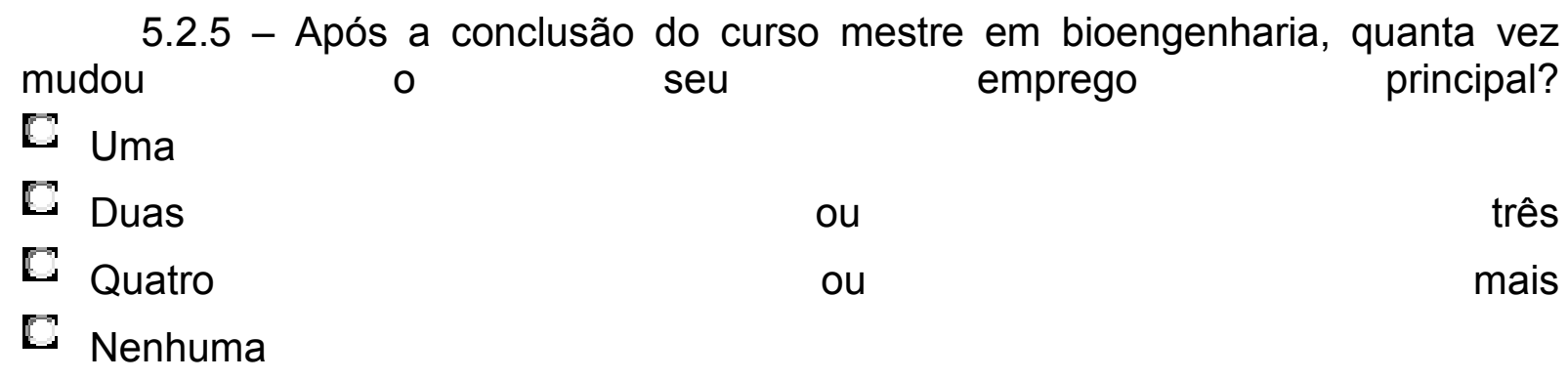

5.2.6 - Assinale o seu grau de satisfação em relação aos seguintes aspectos de seu emprego atual ou mais recente. Responda cada item de acordo com o código.

Salário 0 -Insatisfeito

Abonos, incentivos e outras vantagens $\begin{array}{lll} & 0 \text {-Insatisfeito }\end{array}$

Condições de trabalho (local e horário) 0 -Insatisfeito

Prestigio da instituição onde trabalha 0 -Insatisfeito

Variedade de atividades que desempenha 0 -Insatisfeito $\quad$

Relacionamento pessoal no trabalho $\longdiv { 0 \text { -Insatisfeito } }$

Competência dos colegas 0 -Insatisfeito

Possibilidade de contatos com outros possíveis empregadores 0 - Insatisfeito

Estabilidade no emprego

Oportunidade de atuar com criatividade $\begin{array}{ll}0 \text {-Insatisfeito } \\ -\end{array}$

Oportunidade de utilizar os conhecimentos adquiridos no curso pósgraduação 0 -Insatisfeito

Possibilidade de promoção salarial 0 -Insatisfeito 
Autonomia, independência 0 - Insatisfeito

Outro. Explique

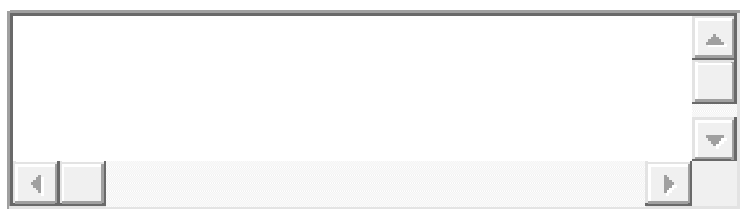

5.2.7 - Após a conclusão do curso você se achou apto a concorrer com outros profissionais da área, formados em outras instituições, para ingressar em um curso de pós-graduação ou no mercado de trabalho? C Sim

C Não 